Aus der Abteilung Medizinische Mikrobiologie

(Prof. Dr. med. U. Groß)

im Zentrum Hygiene und Humangenetik

der Medizinischen Fakultät der Universität Göttingen

\title{
Expression von HLA-Molekülen in humanen Monozyten in Abhängigkeit von Toxoplasma gondii-Infektionen
}

\author{
INAUGURAL - DISSERTATION
}

zur Erlangung des Doktorgrades

der Medizinischen Fakultät der

Georg-August-Universität zu Göttingen

vorgelegt von

Philipp Stalling

aus

Hamburg

Göttingen 2013 
Dekan:

1. Berichterstatter:

2. Berichterstatter:

3. Berichterstatter:

Tag der mündlichen Prüfung:
Prof. Dr. rer. nat. H. Kroemer

Prof. Dr. rer. nat. C. Lüder

Prof. Dr. med. R. Dressel

Prof. Dr. med. M. Oppermann

07. Mai 2013 


\section{Inhaltsverzeichnis}

Verzeichnis der Abbildungen, Tabellen und Formeln .................. IV

Abkürzungsverzeichnis ............................................................ VI

1 Einleitung ..................................................................................... 1

1.1 Toxoplasma gondii............................................................................. 1

1.1.1 Der Parasit .................................................................... 1

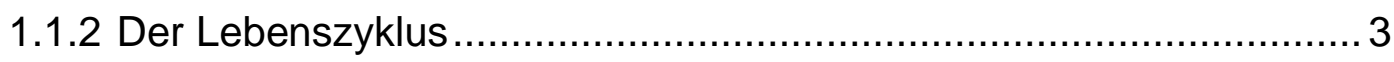

1.2 Die klinische Bedeutung der Toxoplasmose......................................6

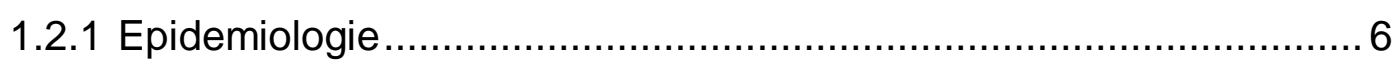

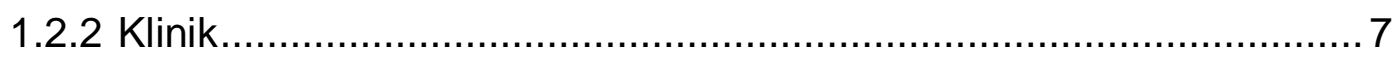

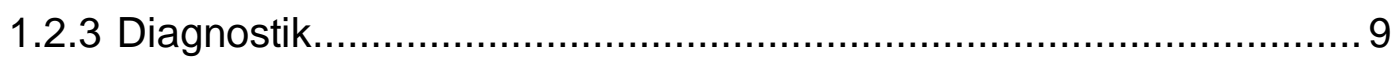

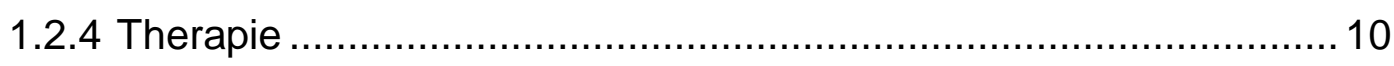

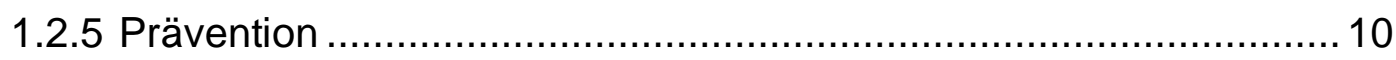

1.3 Die Immunantwort des Wirtes auf eine Infektion mit T. gondii........... 12

1.3.1 Die Immunreaktion auf $T$. gondii....................................... 12

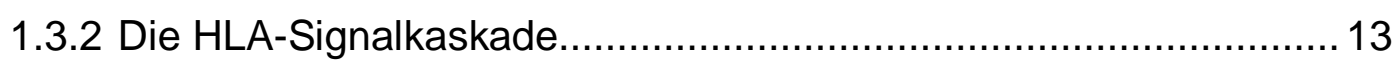

1.4 Ziele dieser Arbeit................................................................................ 16

2 Material und Methoden.............................................................. 18

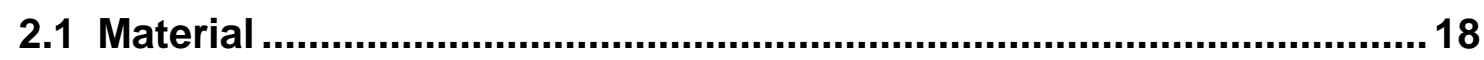

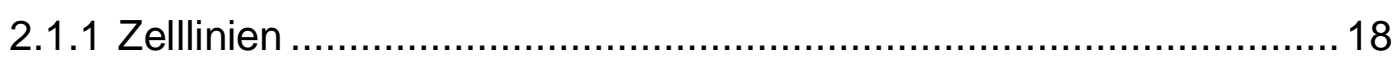

2.1.2 Zellkulturmedien und Zusätze ............................................ 18

2.1.3 Chemikalien und Reagenzien............................................ 19

2.1 .4 Antikörper .................................................................. 20

2.1.5 DNA-Molekulargewichtsmarker ......................................... 21

2.1.6 Oligonukleotide........................................................... 21

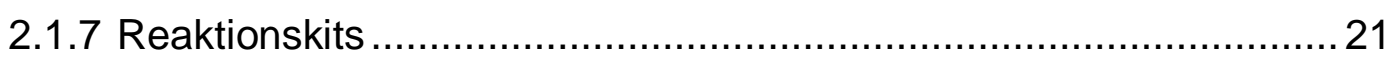

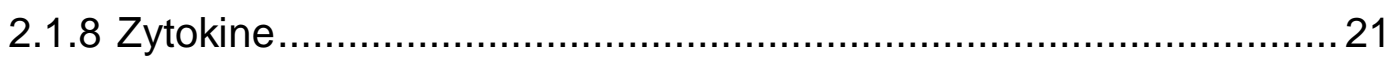

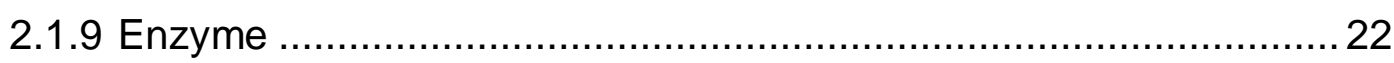

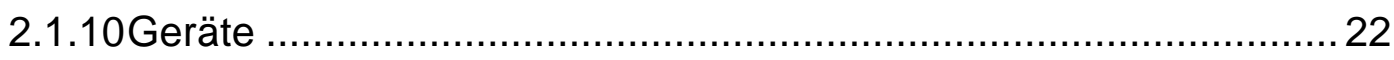

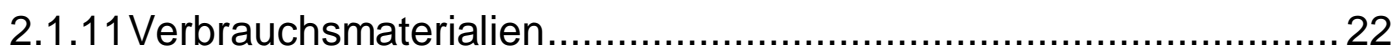




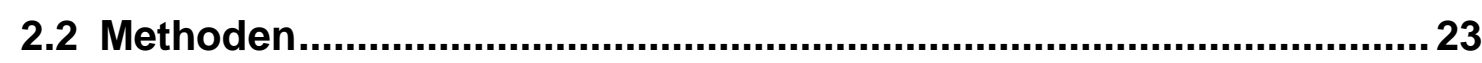

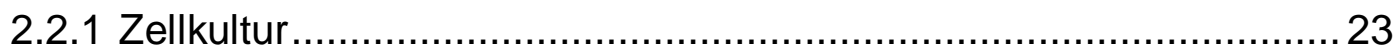

2.2.2 Infektionsversuche mit humanen Monozyten ............................... 26

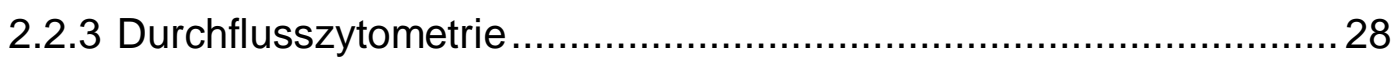

2.2.4 Immunfluoreszenztest (IFT) .................................................. 31

2.2 .5 qRT-PCR

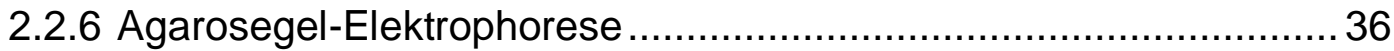

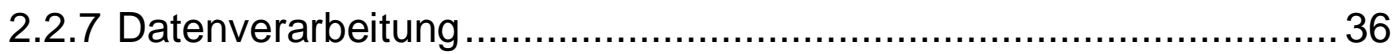

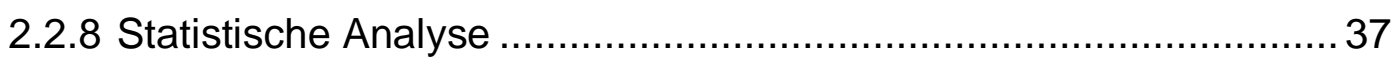

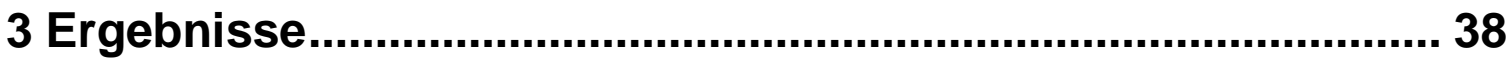

3.1 Toxoplasma gondii inhibiert Dosis-abhängig die HLA-Expression

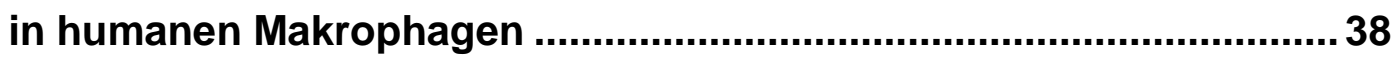

3.1.1 Primäre Monozyten aus PBMC ……………............................ 38

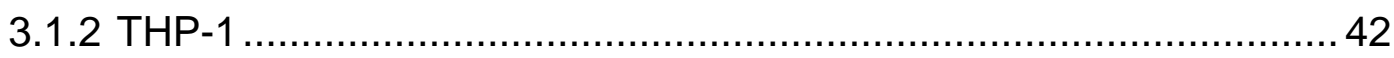

3.1.3 Inhibition der HLA-Expression auf Einzelzellebene ........................ 45

3.2 Die Inhibition der HLA-Expression durch T. gondii findet über einen weiten Konzentrationsbereich von Interferon- $y$ statt.

3.3 Unterschiede in der HLA-Expression in primären Monozyten von

T. gondii-positiven bzw. -negativen Individuen .................................51

3.4 Die Inhibition der HLA-Expression auf mRNA-Ebene .........................55

3.4.1 Transkriptionsfaktoren der HLA-Kaskade werden Erregerdosis-

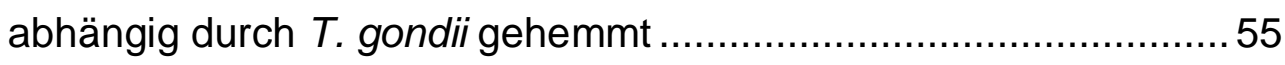

3.4.2 Validierung der qRT-PCR-Ergebnisse durch Agarosegel-

Elektrophorese

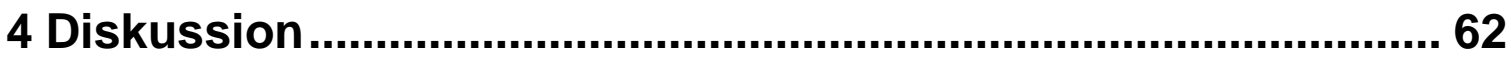

4.1 Unterschiede in der HLA-Expression primärer Monozyten von

T. gondii-infizierten und nicht-infizierten Individuen. 63

4.2 T. gondii inhibiert dosisabhängig die MHC-Expression in primären und permanenten humanen Monozyten . 68 
4.3 Mechanismen der verminderten HLA-Expression nach T. gondii-

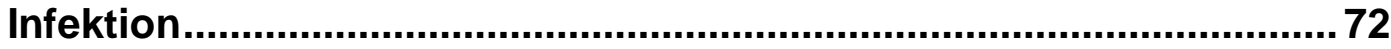

4.3.1 Die Hemmung der HLA-Expression auf Einzelzellebene.................72

4.3.2 Eine Infektion mit $T$. gondii führt zu einer dosisabhängigen Inhibierung von Transkriptionsfaktoren der HLA-Kaskade .............. 74

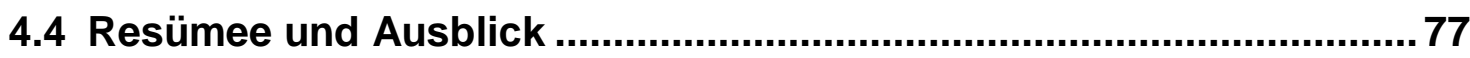

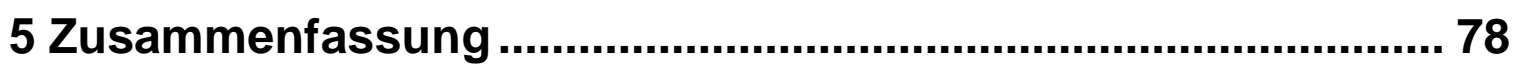

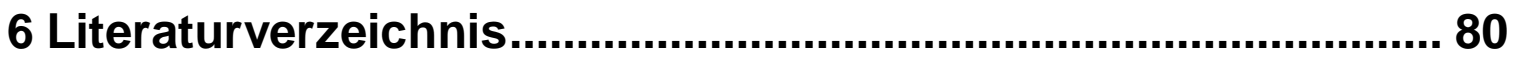

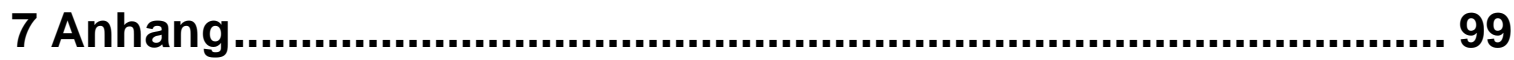

8 Präsentationen ......................................................................... 100 


\section{Verzeichnis der Abbildungen, Tabellen und Formeln}

\section{Abbildungen}

Abb. 1.1 Ultrastruktur eines Toxoplasma gondii-Tachyzoiten ........................... 2

Abb. 1.2 Der Lebenszyklus von Toxoplasma gondii ................................... 5

Abb. 1.3 Die Interferon-y-Signalkaskade .............................................. 15

Abb. 2.1 Dichtegradientenzentrifugation mit Ficoll-Paque® Plus ......................24

Abb. 2.2 Das Prinzip der Durchflusszytometrie ...........................................29

Abb. 3.1 Anteil von Monozyten $\left(\mathrm{CD} 14^{+}\right)$in isolierten mononukleären Zellen des peripheren Blutes........................................................ 39

Abb. 3.2 Hemmung der HLA-A-, -B-, -C- und der HLA-DR-, -DP-, -DQ-

Expression nach Infektion primärer Monozyten mit T. gondii .

Abb. 3.3 Die Expression von HLA-Molekülen in primären Monozyten korreliert mit der T. gondii-Infektionsrate

Abb. 3.4 FACS-Analyse von THP-1-Zellen unter dem Einfluss von T. gondii und IFN-Y

Abb. 3.5 HLA-Inhibierung in THP-1-Monozyten in Abhängigkeit der T. gondiiInfektionsrate

Abb. 3.6 Konfokale Laserscanmikroskopie (CLSM) nach

Immunfluoreszenzfärbung von T. gondii-infizierten und IFN- $\gamma$ stimulierten THP-1-Monozyten

Abb. 3.7 Hemmung der IFN-y-induzierten HLA-Expression in Parasit-positiven Wirtszellen

Abb. 3.8 T. gondii inhibiert deutlich die HLA-Expression in Parasit-positiven permanenten Monozyten, zu einem geringeren Prozentsatz aber auch in Parasit-freien Zellen

Abb. 3.9 Unterschiedliche IFN- $\gamma$-Konzentrationen heben die T. gondiiinduzierte HLA-Inhibition nicht auf.... 50

Abb. 3.10 Verteilung von T. gondii-positiven und -negativen Blutspenden 52

Abb. 3.11 T. gondii-positive Blutspender zeigen im Vergleich zu Parasitnegativen Spendern eine deutlich höhere HLA-Expression.

Abb. 3.12 Signifikante Hemmung der IFN-Y-induzierten Transkripte von IRF-1 durch T. gondii. 
Abb. 3.13 Der inhibitorische Einfluss von $T$. gondii auf die relative mRNAMenge von CIITA ist signifikant.

Abb. 3.14 Die relative mRNA-Expression von HLA-DRa wird durch $T$. gondii deutlich reduziert 58

Abb. 3.15 T. gondii inhibiert dosisabhängig die relative mRNA-Expression von HLA-A 59

Abb. 3.16 Validierung der qRT-PCR-Versuche durch Agarosegel-

Elektrophorese 61

Abb. 4.1 Inhibition der Interferon-y-Signalkaskade durch Toxoplasma gondii ...75

\section{Tabellen}

Tabelle 2.1 Blockier- und Inkubationslösung für FACS-Analysen......................30

Tabelle 2.2 Antikörper für die FACS-Färbung ............................................ 30

Tabelle 2.3 Antikörper für den Immunfluoreszenztest..................................... 32

Tabelle 2.4 Reaktionsmix für reverse Transkription .........................................33

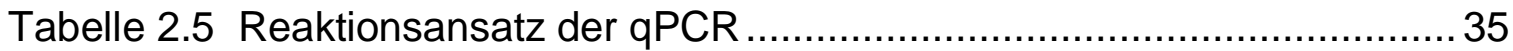

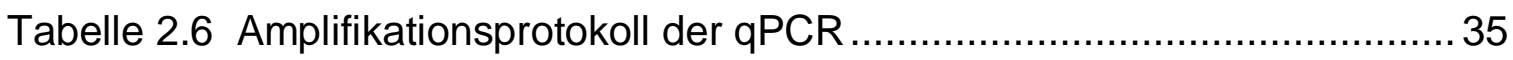

Tabelle 2.7 Puffer für Agarosegel-Elektrophorese ……...................................36

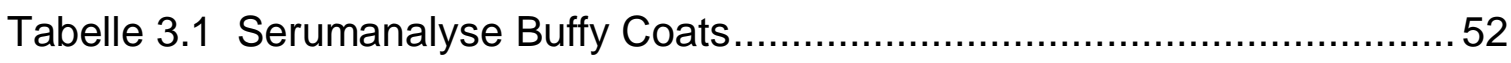

Tabelle 7.1 Anteil CD14-positiver Zellen (Monozyten) in FACS-Analysen mit

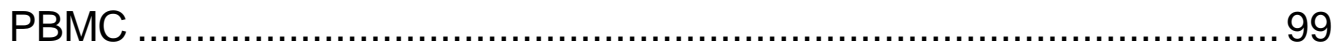

\section{Formeln}

Formel 2.1 Berechnung der RNA-Konzentration .......................................... 33

Formel 2.2 Effizienz-korrigierte relative Quantifizierung von mRNA .................34 


\section{Abkürzungsverzeichnis}

\begin{tabular}{|c|c|}
\hline Abb. & Abbildung \\
\hline ADP & Adenosindiphosphat \\
\hline \multirow[t]{2}{*}{ AIDS } & Erworbenes Immunschwächesyndrom \\
\hline & (Acquired Immune Deficiency Syndrome) \\
\hline ANOVA & Varianzanalyse (Analysis of Variance) \\
\hline APC & Antigenpräsentierende Zellen (antigenpresenting cells) \\
\hline $\mathrm{AU}$ & Arbitrary Units (Fluorescence Intensity) \\
\hline BMM & $\begin{array}{l}\text { Knochenmarks-Makrophagen der Maus } \\
\text { (murine bone marrow derived macrophages) }\end{array}$ \\
\hline $\mathrm{Bp}$ & Basenpaare \\
\hline BRG1 & Chromatin Remodeling Komplexe (brahma-related gene 1) \\
\hline BSA & Rinderserum-Albumin (bovine serum albumin) \\
\hline bzw. & beziehungsweise \\
\hline${ }^{\circ} \mathrm{C}$ & Grad Celsius \\
\hline $\mathrm{C}-18$ & Cyclophilin-18 \\
\hline ca. & circa \\
\hline CCR & CC-Chemokin-Rezeptoren \\
\hline $\mathrm{CD}$ & Cluster of differentiation \\
\hline cDNA & komplementäre DNA (complementary DNA) \\
\hline CIITA & Class II transactivator \\
\hline CLIP & Class-II-associated invariant chain peptide \\
\hline CLSM & Konfokale Laserscanmikroskopie \\
\hline $\mathrm{CO}_{2}$ & Kohlendioxid \\
\hline $\mathrm{CP}$ & Crossing Point \\
\hline $\mathrm{Cy} 2$ & Carbocyanin \\
\hline Cy5 & Indodicarbocyanin \\
\hline DC & Dendritische Zellen (Dendritic cells) \\
\hline DEPC & Diethylpyrocarbonat \\
\hline d.h. & das heißt \\
\hline DMEM & Dulbecco's Modified Eagle Medium \\
\hline DMSO & Dimethylsulfoxid \\
\hline DNA & Desoxyribonukleinsäure \\
\hline dNTP & desoxy-Nukleotidtriphosphat \\
\hline EDTA & Ethylendiamintetraacetat \\
\hline ELISA & Enzyme-linked immuno-sorbent assay \\
\hline ER & Endoplasmatisches Retikulum \\
\hline ESA & excreted / secreted antigens \\
\hline et al. & und andere (et alii) \\
\hline
\end{tabular}




\begin{tabular}{|c|c|}
\hline FACS & Durchflusszytometrie (Fluorescence Acitvated Cell Sorting) \\
\hline FCS & Fötales Kälberserum (fetal calf serum) \\
\hline FITC & Fluorescein-Isothiocyanat \\
\hline FL & Fluoreszenz \\
\hline FSC & Durchflusszytometrie-Vorwärtsstreulicht (Forward scatter) \\
\hline $\mathrm{g}$ & Gramm \\
\hline g & Gravitationsbeschleunigung $\left(\approx 9,81 \mathrm{~m} / \mathrm{s}^{2}\right)$ \\
\hline GAS & (Interferon-) Gamma Activated Sequence \\
\hline GPI & Glycosylphosphatidylinositol \\
\hline GRA & dense granule proteine (T. gondii) \\
\hline $\mathrm{h}$ & Stunde (hora) \\
\hline HAART & Hochaktive antiretrovirale Therapie \\
\hline HAT & Histon-Acetyltransferase \\
\hline $\mathrm{HCl}$ & Salzsäure \\
\hline HEPES & 2-(4-(2-Hydroxyethyl)-1-piperazinyl)-Ethansulfonsäure \\
\hline $\mathrm{HFF}$ & Humane Vorhaut-Fibroblasten (human foreskin fibroblasts) \\
\hline HIV & Humanes Immundefizienz-Virus \\
\hline HLA & Humane Leukozyten-Antigene \\
\hline $\mathrm{H}_{2} \mathrm{O}$ & Wasser \\
\hline i.d.R. & in der Regel \\
\hline IFAT & Immunfluoreszenz-Antikörper-Test \\
\hline IFN- $\gamma$ & Interferon-gamma \\
\hline IFNGR & Interferon-gamma-Rezeptor \\
\hline IfSG & Infektionsschutzgesetz \\
\hline IIFT / IFT & (indirekter) Immunfluoreszenztest \\
\hline $\operatorname{Ig}$ & Immunglobulin \\
\hline $\mathrm{IL}$ & Interleukin \\
\hline inf. & infiziert \\
\hline iNOS & induzierbare NO-Synthase \\
\hline IRF-1 & Interferon-regulatory factor- 1 \\
\hline IU & Internationale Einheiten (International Units) \\
\hline JAK & Januskinase (Tyrosinkinase) \\
\hline $\mathrm{Kb}$ & Kilobasen \\
\hline 1 & Liter \\
\hline LPS & Lipopolysaccharide \\
\hline M & Molar \\
\hline $\mathrm{mg}$ & Milligramm \\
\hline $\mathrm{MHC}$ & $\begin{array}{l}\text { Haupthistokompatibilitätskomplex } \\
\text { (Major Histocompatibility Complex) }\end{array}$ \\
\hline
\end{tabular}




\begin{tabular}{|c|c|}
\hline MIIG & $\begin{array}{l}\text { IFN- } \gamma \text {-Rezeptor-defiziente Makrophagen } \\
\text { (macrophages insensitive to IFN-gamma) }\end{array}$ \\
\hline $\min$ & Minute \\
\hline mind. & mindestens \\
\hline $\mathrm{ml}$ & Milliliter \\
\hline $\mathrm{mM}$ & millimolar \\
\hline MOI & Vielfachheit der Infektion (multiplicity of infection) \\
\hline mRNA & messenger RNA \\
\hline MyD88 & myeloid differentiation primary-response protein 88 \\
\hline$\mu 1$ & Mikroliter \\
\hline$\mu \mathrm{M}$ & Mikromol \\
\hline $\mathrm{Na}$ & Natrium \\
\hline $\mathrm{NaCl}$ & Natriumchlorid \\
\hline $\mathrm{NaHCO}_{3}$ & Natriumhydrogencarbonat \\
\hline $\mathrm{NaN} 3$ & Natriumazid \\
\hline Na-Pyruvat & Natrium-Pyruvat \\
\hline NEAA & Nicht-essentielle Aminosäuren (nonessential amino acids) \\
\hline $\mathrm{NF} \kappa \mathrm{B}$ & Nukleärer Faktor kappa B \\
\hline ng & Nanogramm \\
\hline $\mathrm{NH} 4 \mathrm{Cl}$ & Ammoniumchlorid \\
\hline n.i. & nicht-infiziert \\
\hline NK & Natürliche Killerzellen \\
\hline $\mathrm{nm}$ & Nanometer \\
\hline $\mathrm{NO}$ & Stickstoffmonoxid \\
\hline OD & optische Dichte \\
\hline P. falciparum & Plasmodium falciparum \\
\hline PBMC & $\begin{array}{l}\text { mononukleäre Zellen des peripheren Blutes } \\
\text { (peripheral blood mononuclear cells) }\end{array}$ \\
\hline PBS & $\begin{array}{l}\text { Phosphat-gepufferte Kochsalzlösung } \\
\text { (phosphate buffered saline) }\end{array}$ \\
\hline PCR & Polymerase-Kettenreaktion (polymerase chain reaction) \\
\hline PE & Phycoerythrin \\
\hline PFA & Paraformaldehyd \\
\hline $\mathrm{pH}$ & pondus Hydrogenii \\
\hline PLC & peptide loading complex \\
\hline PMA & Phorbol 12-Myristat 13-Acetat \\
\hline PMT & photomultiplier tube \\
\hline PV & Parasitophore Vakuole \\
\hline $\mathrm{q}(\mathrm{RT}-) \mathrm{PCR}$ & quantitative (Reverse Transkriptase) \\
\hline & Polymerasekettenreaktion \\
\hline RNA & Ribonukleinsäure (ribonucleic acid) \\
\hline
\end{tabular}




\begin{tabular}{|c|c|}
\hline RPMI & Roswell Park Memorial Institute \\
\hline RT & reverse Transkription \\
\hline RT & Raumtemperatur \\
\hline SDS & Natrium-Dodecylsulfat (sodium-dodecylsulfate) \\
\hline $\mathrm{SE}$ & Standardfehler (Standard error) \\
\hline sec & Sekunde \\
\hline SEM & $\begin{array}{l}\text { Standardfehler des Mittelwertes } \\
\text { (Standard error of the mean) }\end{array}$ \\
\hline SOCS 1 & Suppressor of cytokine signaling-1 \\
\hline Spp. & Spezies (P1.) \\
\hline SSC & Durchflusszytometrie-Seitwärtsstreulicht (Side scatter) \\
\hline SSW & Schwangerschaftswoche \\
\hline STAg & lösliches Tachyzoiten-Antigen (soluble tachyzoite antigen) \\
\hline STAT $1 \alpha$ & Signal Transducer and Activator of Transcription 1 alpha \\
\hline T. gondii & Toxoplasma gondii \\
\hline TAE-Puffer & Tris-Acetat-EDTA-Puffer \\
\hline TAP & Transporter associated with antigen processing \\
\hline $\mathrm{Taq}$ & Thermus aquaticus \\
\hline $\mathrm{TE}$ & Toxoplasma-Enzephalitis \\
\hline TES & 2-(Tris(hydroxymethyl)methylamino)-Ethansulfonsäure \\
\hline TGF- $\beta$ & Transforming Growth Factor beta \\
\hline $\mathrm{TL}$ & T. gondii-Lysat \\
\hline TLR & Toll-like receptor \\
\hline TNF- $\alpha$ & Tumornekrosefaktor alpha \\
\hline Tris & Tris(Hydroxymethyl)-Aminomethan \\
\hline $\mathrm{U}$ & Einheiten (Units) \\
\hline u.a. & unter anderem \\
\hline uninf. & uninfiziert \\
\hline USF-1 & Upstream stimulatory factor 1 \\
\hline UV & Ultraviolett \\
\hline $\mathrm{V}$ & Volt \\
\hline v.a. & vor allem \\
\hline ver. & Version \\
\hline vgl. & vergleiche \\
\hline wo & ohne (without) \\
\hline z.B. & zum Beispiel \\
\hline z. T. & zum Teil \\
\hline ZNS & zentrales Nervensystem \\
\hline
\end{tabular}




\section{Einleitung}

\subsection{Toxoplasma gondii}

\subsubsection{Der Parasit}

Das obligat intrazellulär lebende Protozoon Toxoplasma gondii wurde 1908 von den französischen Ärzten Charles Nicolle und Louis Herbert Manceaux in Tunis sowie unabhängig davon etwa zur selben Zeit von Alfonso Splendore in Brasilien entdeckt und beschrieben. Die sichelförmige gebogene Form (griech.: toxon = Bogen, plasma $=$ Form) und das nordafrikanische Nagetier Ctenodactylus gundi, aus dem der Parasit erstmals isoliert wurde, gaben dem Erreger den Gattungs- bzw. Speziesnamen Toxoplasma gondii (Nicolle \& Manceaux 1908; Kim \& Weiss 2008a).

T. gondii gehört zum Stamm der Apicomplexa, zu dem auch andere humanpathogene Parasiten wie Plasmodium spp., Sarcocystis spp., Cryptosporidium spp. u.a. gezählt werden. Diese phylogenetische Gruppe zeichnet sich durch einen differenzierten, komplexen Lebenszyklus mit verschiedenen Stadien- und Wirtswechseln aus. Apicomplexa sind in ihrer Ultrastruktur an eine intrazelluläre Lebensweise angepasst und haben für eine aktive Wirtszellinvasion am apikalen Pol invasiver Stadien einen speziellen Komplex ausgebildet (Abb. 1.1). Dieser Apikalkomplex besteht in der Regel aus dem vorderen Polring, einem Conoid, Mikronemen, Rhoptrien und dichter Granula (Dubey et al. 1998). Ein komplexes Zytoskelett durchzieht $T$. gondii und spielt neben den sekretorischen Organellen des Apikalkomplexes bei der Zelladhäsion und -invasion eine bedeutende Rolle (Nam 2009). Der für Toxoplasmen spezifische komplizierte Mechanismus der Wirtszell-Identifikation, anschließender Adhäsion und Invasion ist nach wie vor Gegenstand intensiver Forschung (Dobrowolski \& Sibley 1996; Carruthers 2002). 


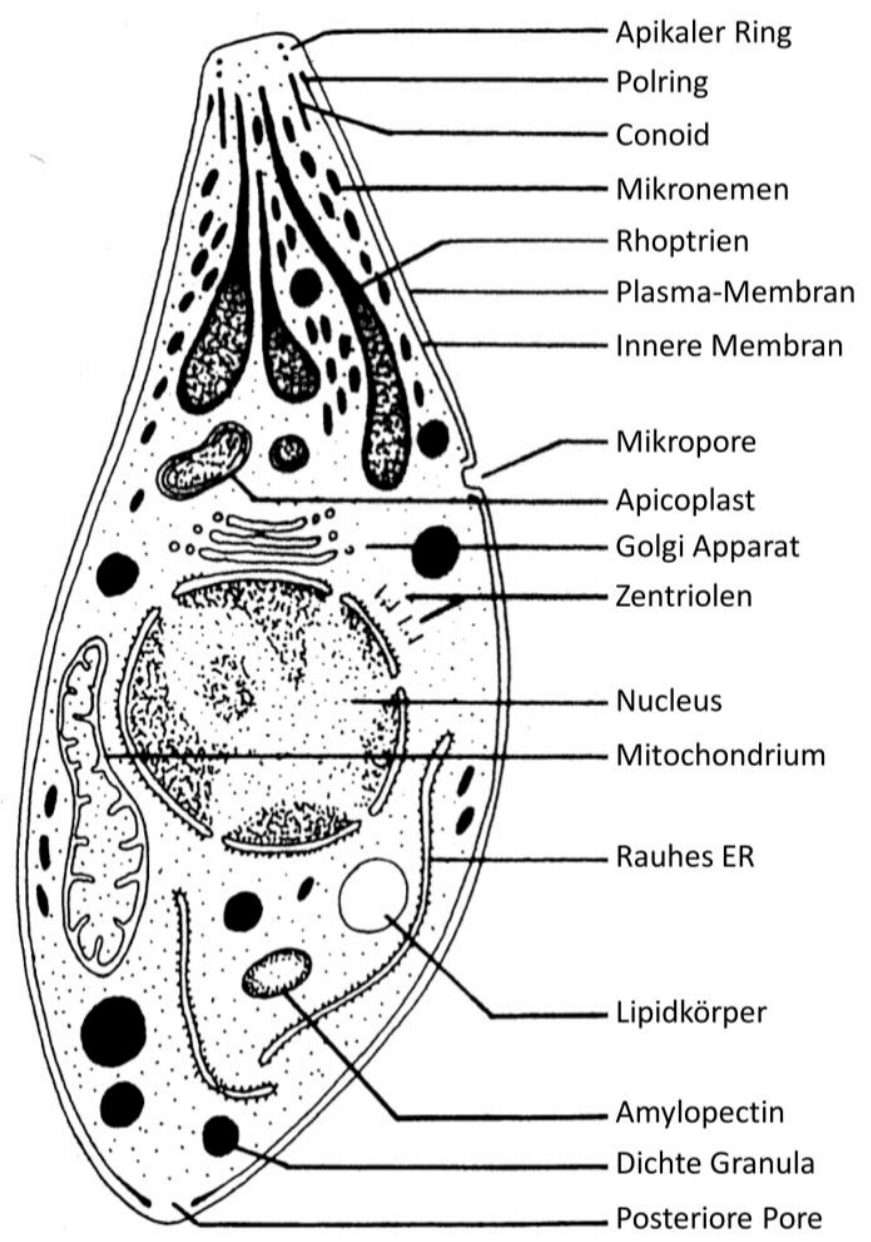

Abb. 1.1 Ultrastruktur eines Toxoplasma gondii-Tachyzoiten

Dargestellt ist eine schematische Abbildung eines Toxoplasma gondii-Tachyzoiten. Abbildung modifiziert nach Dubey et al. (1998), S. 269.

Durch den Befall aller eukaryoten, kernhaltigen Zellen von warmblütigen Tieren (Säugetiere und Vögel) und Menschen (Hill et al. 2005) weist T. gondii eine ungewöhnlich geringe Wirts- und Zellspezifität auf und ist daher Erreger einer der häufigsten parasitären Zoonosen. Durch die ubiquitäre Verbreitung (1.2.1) und Pathogenität des Erregers (1.2.2) ist die Toxoplasmose von deutlicher humanmedizinischer, veterinärmedizinischer und ökonomischer Bedeutung (Murrell 1991; Freyre et al. 1999). 


\subsubsection{Der Lebenszyklus}

Der Lebenszyklus von $T$. gondii ist von einem kontinuierlichen Wechsel zwischen den komplexen Entwicklungsstadien Sporozoiten, Tachyzoiten und Bradyzoiten geprägt (Abb. 1.2). In Katzen und anderen Feliden, den Endwirten von T. gondii, findet die geschlechtliche Vermehrung zu Sporozoiten statt; zu einer ungeschlechtlichen Teilungsphase von Tachyzoiten und Bradyzoiten kommt es in den Zwischenwirten, die alle warmblütigen Tiere und den Menschen umfassen. Hervorzuheben ist hierbei, dass Toxoplasmen von einem Endwirt auf einen Zwischenwirt und vice versa, aber auch auf horizontaler Ebene innerhalb von Endwirten bzw. von Zwischenwirten übertragen werden können (Dubey \& Beattie 1988; Tenter 2009).

Eine Infektion des Zwischenwirts kann über verschiedene Wege erfolgen: Die Aufnahme von Bradyzoiten-haltigen Gewebszysten in infiziertem (Beute-) Fleisch, eine Ingestion von umweltresistenten Sporozoiten-haltigen Oozysten durch kontaminierte Lebensmittel, Erde oder Wasser, sowie eine diaplazentare Übertragung auf den Fetus durch die akutinfizierte Mutter sind die häufigsten Infektionswege. Ebenfalls sind Toxoplasmenverseuchte Organtransplantate, Blutspenden und unpasteurisierte Milch als Ursachen zu nennen (Frenkel et al. 1975; Tenter et al. 2000). Im Gastrointestinaltrakt des Zwischenwirts wird die Zellwand der Gewebezysten oder Oozysten durch proteolytische Enzyme und Salzsäure lysiert, die freigesetzten magensaftresistenten ${ }^{1}$ Parasiten dringen aktiv in Dünndarm-Epithelzellen des Wirtes ein und bilden intrazellulär sog. parasitophore Vakuolen (PV), die eine Elimination durch lysosomalen Verdau der Wirtszelle verhindern (Dubey et al. 1970; Joiner et al. 1994; Schwab et al. 1994). In der PV erfolgt durch wiederholte Endodyogenie ${ }^{2}$, eine schnelle Teilung des Erregers, bis es zur Ruptur der Wirtszelle kommt. Die freigesetzten Tachyzoiten disseminieren hämato-/lymphogen im gesamten Körper und können zur weiteren Replikation innerhalb von wenigen Tagen in nahezu alle kernhaltigen Zellen der Viszeralorgane, v.a. Leber, Lunge und Lymphknoten eindringen (Frenkel 1988; Dubey 1997; Dubey et al. 1998). Dieses Stadium der schnellen, proliferativen Vermehrung wird als akute Toxoplasmose definiert und ist nicht selten symptomatisch. In Folge der daraufhin einsetzenden Immunantwort des Wirtes kommt es

\footnotetext{
${ }^{1}$ Die Literatur beschreibt bei Bradyzoiten - im Gegensatz zu oral aufgenommenen Tachyzoiten - eine Magensaftresistenz. Gegenüber Trypsin und Pepsin ist die Widerstandsfähigkeit der einzelnen Erreger-Stadien jedoch nicht eindeutig geklärt (Dubey 1998).

${ }^{2}$ Endodyogenie: Bezeichnet die wiederholte ungeschlechtliche Längsteilung in einer Mutterzelle, die bei Tachyzoiten meist synchron verläuft.
} 
zu einer Stadienkonversion der sich schnell teilenden Tachyzoiten zu Bradyzoiten, die durch eine stark verminderte Replikationsrate, einem verlangsamten Metabolismus und ein spezifisches Antigen-Profil charakterisiert sind (Kasper 1989; Bohne et al. 1999). Mit der Stadienkonversion erfolgt ein Umbau der PV zu einer Gewebszyste mit rigider Zystenwand, in der sich die Bradyzoiten durch unterschiedliche Evasionsmechanismen dem Immunsystem entziehen und so die latente, inaktive Phase der Toxoplasmose lebenslang aufrechterhalten können. Zwar ist dies prinzipiell in einer Vielzahl von Geweben möglich, T. gondii weist jedoch eine Affinität für neuro-muskuläre Gewebe wie Gehirn, Auge, Herz- und anderer Muskulatur auf (Gross et al. 1992; Dubey et al. 1998). Der beschriebene Zyklus der Infektion eines Zwischenwirtes kann sich unbegrenzt wiederholen und so die ungeschlechtliche Vermehrung von Toxoplasmagondii garantieren.

Infiziert sich hingegen eine Katze über ein Parasit-positives Beutetier, ist der Entwicklungszyklus zu Beginn ähnlich wie im Zwischenwirt: Nach der gastrointestinalen Lyse der Gewebszystenwand konvertieren freigesetzte Bradyzoiten zu Tachyzoiten und penetrieren die Epithelzellen des Dünndarms zur sexuellen Vermehrung (Dubey et al. 1998; Hill et al. 2005). Hier spalten die Toxoplasmen im Rahmen des sog. enteroepithelialen Kreislaufs als Schizonten kleine Merozoiten (Tochterzellen) ab, welche männliche und weibliche Gameten bilden. Nach der Befruchtung werden die Gameten von einer resistenten Oozystenwand umhüllt, die Parasit-gefüllten Epithelzellen rupturieren und mehrere Millionen Oozysten gelangen nach einer Präpatenzzeit ${ }^{3}$ von 3 bis 18 Tagen mit den Faeces in die Umwelt. Die eingeschlossenen Sporozysten sporulieren innerhalb von 1-5 Tagen und bilden Sporozoiten. Sie sind danach infektiös und beginnen den Lebenszyklus von $T$. gondii nach Aufnahme durch einen Wirt von Neuem (Dubey et al. 1998; Dubey 2005).

\footnotetext{
3 Die Präpatenzzeit beschreibt den Zeitraum der initialen Infektion bis zum Ausscheiden der entwickelten Oozysten mit den Faeces des Endwirts. Dies ist vom inokulierten Parasitenstadium abhängig und dauert bei Gewebszysten 3-10 Tage, bei Oozysten >18 Tage und bei Tachyzoiten $>13$ Tage (Dubey et al. 1998).
} 

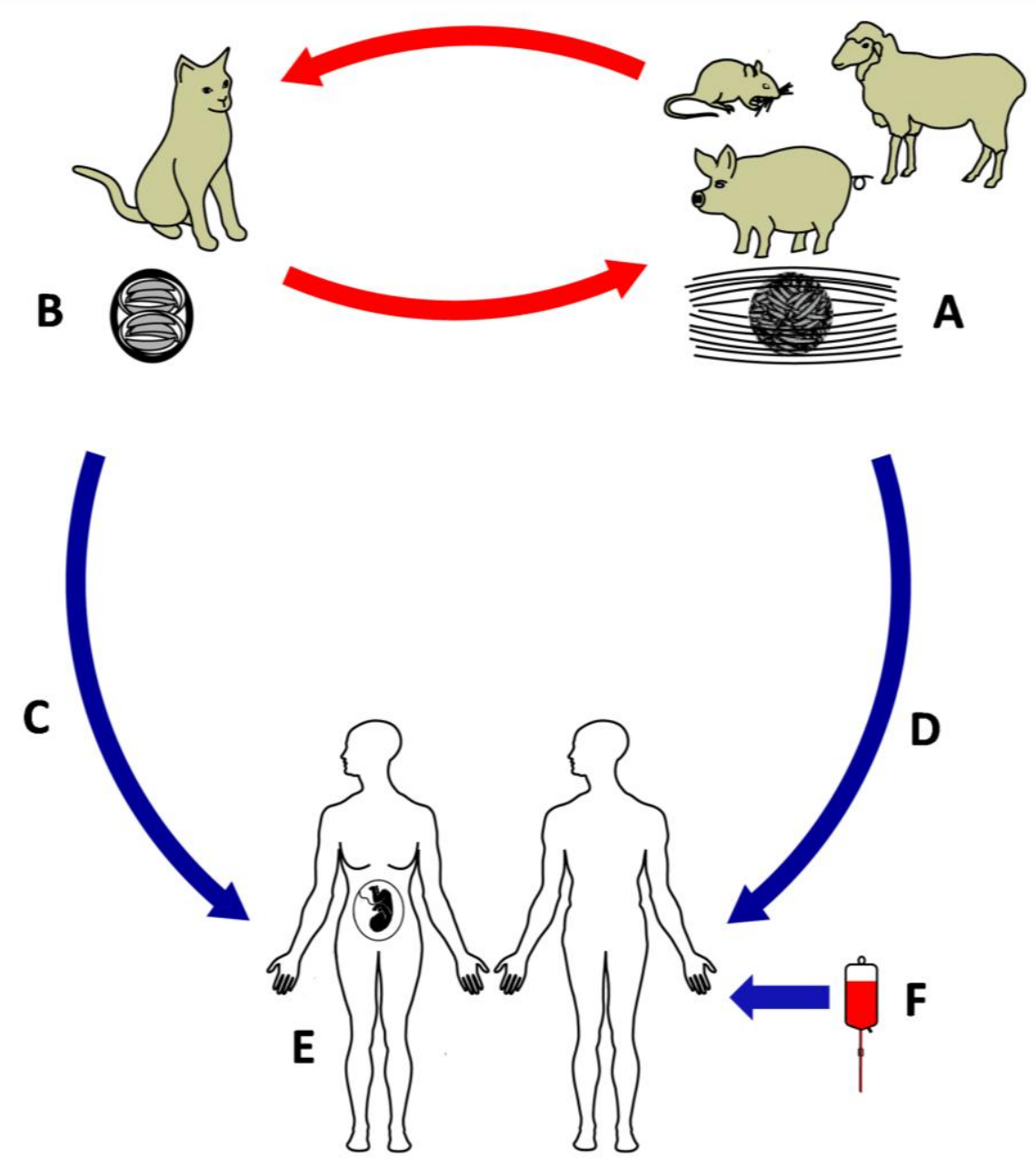

\section{Abb. 1.2 Der Lebenszyklus von Toxoplasma gondii}

Die sexuelle Replikation (rot) von T.gondii erfolgt in der Katze nach Aufnahme von Gewebszysten (A) in Beutetieren. Im Dünndarmepithel des Endwirts findet dann eine 3-18 Tage dauernde Schizogonie und Gamogonie statt, an deren Ende Oozysten mit dem Katzenkot ausgeschieden werden. Nach ca. 5 Tagen Sporulation sind die Oozysten infektiös (B) und können entweder erneut Beutetiere der Katze infizieren, oder sich asexuell in weiteren Zwischenwirten vermehren. Für den Menschen stellen Katzenkot, Oozystenkontaminierte Lebensmittel, Wasser (C), sowie nicht- oder unzureichend gegartes Fleisch Parasit-positiver Nutztiere (D) wichtige Infektionswege dar. Kongenitale, diaplazentare Infektionen des Ungeborenen (E) sowie verseuchte Organ- oder Bluttransfusionen (F) können ebenfalls zu klinisch bedeutenden Infektionen durch T. gondii führen (Abbildung modifiziert nach Centers for Disease Control and Prevention (CDC 2002)). 


\subsection{Die klinische Bedeutung der Toxoplasmose}

\subsubsection{Epidemiologie}

Die beim Menschen bestimmte Durchseuchungsrate von $T$. gondii-Infektionen variiert weltweit sehr stark und hängt u.a. von geographischen, klimatischen und Hygienebezogenen Faktoren ab. So weisen z. B. feuchtwarme Küstenregionen und Regionen mit dichter Besiedlung eine signifikant höhere Prävalenz für Toxoplasmose auf als trockene Wüstengegenden (Julvez et al. 1996; Chacin-Bonilla et al. 2001). In Deutschland ist die Erfassung von konnatalen Toxoplasmose-Fällen mit der Einführung des Infektionsschutzgesetzes (IfSG) 2001 und einer nicht-namentlichen Meldepflicht stark verbessert worden. Aufgrund von i. d. R. geringen klinischen Hinweisen auf eine Toxoplasmose muss zum Zeitpunkt einer Geburt jedoch von einer hohen Dunkelziffer ausgegangen werden (Robert-Koch-Institut 2007). In Deutschland nimmt man bei schwangeren Frauen eine Seroprävalenz von 26-54\% an, die mit dem Lebensalter kontinuierlich ansteigt (Gross 2004; Robert-Koch-Institut 2007). In Ländern wie Frankreich oder Brasilien wird sogar eine Durchseuchungsrate von bis zu 75-80\% angenommen (Miller et al. 2009).

Die z. T. sehr hohe Seroprävalenz von Mensch und Tier mit Toxoplasmen ist nicht zuletzt der starken Umwelt-Resistenz infektiöser Oozysten geschuldet, die bis zu 18 Monate unter unterschiedlichsten klimatischen Bedingungen im Erdreich überleben können (Frenkel et al. 1975). Es wurde nachgewiesen, dass T. gondii-Zysten im Kot von Katzen durch starke Regenfälle oder Überschwemmungen in Flüsse, Trinkwasserreservoirs und angrenzende Ozeane gespült werden (Lindsay \& Dubey 2009), wo sie vor allem in tropischen und subtropischen Ländern (Bahia-Oliveira et al. 2003), aber auch in Teilen Europas (Ertug et al. 2005) das Oberflächen-Trinkwasser kontaminieren können. Die Gefahr der OozystenIngestion mit dem Trinkwasser ist durch die hohe Resistenz der Zysten gegenüber herkömmlichen chemischen (Ozon, Natriumhypochlorit, u.a.) und physikalischen Desinfektionsmitteln (UV-Bestrahlung) der Trinkwasseraufbereitung besonders groß (Wainwright et al. 2007a; Wainwright et al. 2007b). In der Literatur sind mehrere Toxoplasmose-Epidemien bei Bewohnern von Küsten- bzw. Flussregionen beschrieben, die T. gondii-kontaminiertem Trinkwasser zugeschrieben werden (Bowie et al. 1997; Balasundaram et al. 2010). Während die Trinkwasseraufbereitung als Risikofaktor einer Toxoplasma-Epidemie immer weiter in den Fokus rückt, ist die Diagnose bei einer Mehrzahl von Toxoplasmose-Ausbrüchen jedoch oft nur schwer zu stellen. Kriterien wie 
(i) das plötzliche Auftreten von Symptomen einer Toxoplasmose, (ii) der serologische Nachweis akuter Toxoplasmose (insbesondere T. gondii-spezifisches IgG und IgM), sowie (iii) regional und zeitlich gehäufte Fälle sind bei der Einordnung einer Epidemie richtungsweisend (Demar et al. 2007).

\subsubsection{Klinik}

Der klinische Verlauf einer Infektion mit Toxoplasma gondii hängt stark vom Immunstatus des Patienten ab. Bei Menschen mit einem intakten Immunsystem verläuft sie in der Regel sehr blande und wird von den Betroffenen größtenteils nicht wahrgenommen (Hill \& Dubey 2002). Meist beschränkt sich eine akute Infektion auf wenige unspezifische, selbstlimitierende Symptome wie Fieber und zervikale bzw. okzipitale Lymphadenopathien. Einen ernsten Verlauf stellt hingegen die akute Retinochorioiditis dar, die sich durch starke granulomatöse Entzündungen und nekrotisierende Retinitis manifestieren kann (Montoya \& Liesenfeld 2004; Balasundaram et al. 2010). Es sind zudem schwere, fulminante Verläufe einer Toxoplasmose mit multipler Organbeteiligung bei immunkompetenten Menschen bekannt (Burnett et al. 1998; Demar et al. 2007).

Neben oben genannten Verläufen wird die klinisch relevante Toxoplasmose in eine Reaktivierung einer latenten Infektion immunsupprimierter Patienten und eine Erstinfektion während der Schwangerschaft mit anschließender pränataler Toxoplasmose des Fetus unterschieden (Gross 2004). Organtransplantierte, therapeutisch immunsupprimierte Menschen sind durch T. gondii-Infektionen in besonderem Maße gefährdet. Durchschnittlich zwei Monate post transplantationem kann eine Toxoplasmose fiebrige Myokarditis, Enzephalitis oder Pneumonie auslösen (Derouin \& Pelloux 2008) und insbesondere bei Erstinfektion die Überlebenschancen der Patienten mindern (Doesch et al. 2010).

Toxoplasma gondii nimmt unter den mit hoher Mortalität verbundenen opportunistischen Infektionserkrankungen bei Patienten mit erworbenem Immunschwächesyndrom (AIDS) eine entscheidende Rolle ein (Bonnet et al. 2005). Bis zur Einführung der hochaktiven antiretroviralen Therapie (HAART) manifestierten sich $T$. gondii-Infektionen bei bis zu $50 \%$ aller AIDS-Patienten in der schweren Form einer Toxoplasma-Enzephalitis (TE) (Dubey \& Beattie 1988; Happe et al. 2002). Für HIV-Infizierte liegt die Prävalenz einer TE unter Monotherapie bei 5,4\%, wohingegen eine Kombinationstherapie die Infektionsrate auf 2,2\% senkt (Sacktor et al. 2001). Trotz erfolgreicher Behandlung ist die zerebrale 
Toxoplasmose immer noch eine der häufigsten Ursachen für AIDS-assoziierte ZNS-Pathologien und Haupttodesursache für Patienten mit dem erworbenen Immunschwächesyndrom AIDS (Luft \& Remington 1992; Contini 2008).

Während der Schwangerschaft kann eine T. gondii-Erstinfektion zu einer temporären Parasitämie von Tachyzoiten und $\mathrm{zu}$ fokalen Läsionen der Plazenta führen, die eine transplazentare Infektion des Fetus nach sich ziehen können (Hill \& Dubey 2002). Das Krankheitsbild des Fetus wird dabei neben der Erregervirulenz und der Infektionsdosis v.a. vom Gestationsalter bestimmt: Im ersten Trimenon ist die Übertragungsrate auf das Ungeborene niedrig und steigt bis zum Ende der Schwangerschaft auf ca. 70-80\%. Gegensätzlich dazu nimmt das Risiko klinischer Symptome im Verlauf der Entwicklung von ca. $60-75 \%$ auf ca. $10 \%$ ab (Lopes et al. 2007; Montoya \& Remington 2008). Erfolgt eine Infektion in der frühen Schwangerschaft, kann es zu schweren Schädigungen wie der klassischen Trias Retinochorioiditis, Enzephalitis und Hydrozephalus sowie zerebraler Kalzifizierung und Retardierung, psychomotorischen, neurologischen oder wachstumsassoziierten Störungen bis sogar zum Spontanabort kommen. Spätschäden nach einer subklinischen kongenitalen Infektion können z. T. Monate und Jahre postnatal auftreten (Hill \& Dubey 2002; Montoya \& Liesenfeld 2004; Lopes et al. 2007; Montoya \& Remington 2008).

Nachdem man bei $T$. gondii-positiven Ratten einen stark geminderten Fluchtinstinkt gegenüber Katzen, dem Endwirt von T. gondii, nachgewiesen hat (Berdoy et al. 2000), wurde ein möglicher parasitärer Einfluss auf das menschliche Verhalten in psychologischen Untersuchungen näher betrachtet. Studien bestätigten signifikante, geschlechtsspezifische Unterschiede bei T. gondii-infizierten Menschen im Vergleich mit nicht-infizierten Kontrollpersonen wie z. B. ein reduziertes Regelbewusstsein bei Männern und ein aufgeschlosseneres Verhalten bei Frauen (Flegr \& Havlicek 1999; Lindova et al. 2006; Flegr 2007). Schlussfolgerungen dieser Beobachtungen werden in der wissenschaftlichen Literatur jedoch kritisch diskutiert. 


\subsubsection{Diagnostik}

Der indirekte, serologische Nachweis von Toxoplasma-spezifischem Immunglobulin G (IgG) gilt für immunkompetente Patienten initial als diagnostische Methode der Wahl. Bei immunsupprimierten Patienten zeigt ansteigendes IgG die Möglichkeit der Reaktivierung einer latenten Toxoplasmose an, fehlendes IgG hingegen weist z.B. bei Schwangeren auf die Gefahr einer Primärinfektion hin (Montoya \& Liesenfeld 2004; Montoya \& Remington 2008). Heutzutage eingesetzte labordiagnostische Methoden wie der Sabin-Feldman Dye Test, IFAT, Subklassen-spezifische ELISA, IgG-Aviditätstest und Agglutinationstests können neben dem Infektionsstatus auch akut-erworbene oder chronische Toxoplasmosen differenzieren (Montoya \& Liesenfeld 2004; Iqbal \& Khalid 2007). Immunglobulin M wird während der ersten Woche nach Infektion gebildet und fällt innerhalb weniger Monate wieder ab. Da dieser Zeitraum aber extrem variabel sein kann und ein Nachweis oft falsch-positiv ausfällt, dient fehlendes IgM meist zu einer Ausschlussdiagnostik der akuten Toxoplasmose (Bobic et al. 1991; Liesenfeld et al. 1997). IgA, das ebenfalls zur Bestimmung einer akuten Toxoplasmose herangezogen wird, gilt als sensitiverer Marker und wird daher in Kombination mit IgG in der perinatalen Diagnostik eingesetzt (Stepick-Biek et al. 1990).

Durch einen ungenügenden Titer-Anstieg während einer Infektion kann der direkte Nachweis von T. gondii durch Mausinokulation, Zellkultur und PCR notwendig sein (Montoya 2002). Vor allem die diagnostisch richtungsweisende Real-Time-PCR kann mit nahezu jedem Probenmaterial, wie z.B. aus einer bronchoalveolären Lavage bei Pneumonie (Petersen et al. 2006) durchgeführt werden. Die PCR-Analyse von Amnionflüssigkeit oder Nabelschnurblut stellt zusammen mit der Ultraschalluntersuchung eine Standardmethode der pränatalen Toxoplasma-Diagnostik dar, wobei die Präzision der Methode mit einer Sensitivität von 64-97\% und einem negativen bzw. positiven prädiktiven Wert von $88 \%$ und $100 \%$ abhängig vom Gestationsalter stark schwankt (Hohlfeld et al. 1994; Montoya \& Remington 2008). Eine Amniozentese zur Proben-Gewinnung sollte zudem nicht vor der 18. Schwangerschaftswoche erfolgen und einer Abortrate von ca. 1\% entgegengestellt werden (Montoya \& Remington 2008; Tabor \& Alfirevic 2009). 


\subsubsection{Therapie}

Immunkompetente Kinder und Erwachsene werden bei asymptomatischer bzw. unkomplizierter Toxoplasmose für gewöhnlich nicht medikamentös behandelt (Montoya \& Liesenfeld 2004). Toxoplasmen-Erstinfektionen von Schwangeren werden in Deutschland ab der 17. SSW antibiotisch mit dem Makrolid Spiramycin therapiert, da man annimmt, dass hiermit eine diaplazentare Infektion des Ungeborenen mit $T$. gondii verhindert werden kann. Bestätigt sich jedoch eine Übertragung auf den Fetus, erfolgt ein Wechsel auf eine Kombinationstherapie mit Pyrimethamin ${ }^{4}$, Sulfadiazin ${ }^{5}$ und Folinsäure ${ }^{6}$ (Montoya \& Remington 2008). Transplantierte, immunsupprimierte Patienten erhalten die prophylaktisch hochwirksame Kombination Trimethoprim und Sulfamethoxazol (alternativ Clindamycin), an einer Toxoplasma-Enzephalitis erkrankte Patienten werden mit Pyrimethamin und Sulfadiazin bzw. Atovaquone therapiert. Nach Behandlung des Akutstadiums einer Toxoplasmose muss im Anschluss eine sekundäre Prophylaxe mit halber Dosierung der Medikation garantiert werden bis eine Immunkompetenz wieder hergestellt ist bzw. die CD4+-Zellzahl bei AIDS-Patienten >200/ $\mu$ l liegt und die Viruslast therapeutisch über mind. 6 Monate unter Kontrolle ist (Montoya \& Liesenfeld 2004).

\subsubsection{Prävention}

In der primären Prävention sind nicht oder nicht ausreichend gegarte Fleischprodukte für bis zu 50\% aller humanen Toxoplasmose-Erkrankungen entscheidend (Slifko et al. 2000) und müssen als Hauptrisikofaktor für eine T. gondii-Infektion angesehen werden (Roghmann et al. 1999). In einer europaweiten Fallkontrollstudie konnten je nach Region 30-63\% der Infektionen dem Verzehr von zystenhaltigen Fleischprodukten und bis zu 17\% dem Kontakt mit Erdreich zugeschrieben werden (Cook et al. 2000). Die Ingestion von infektiösen Oozysten aus dem Erdboden sowie der Konsum von Wasser und ungekochtem Gemüse könnten die Seroprävalenz von 22-48\% bei Menschen, die sich nicht von Fleisch ernähren, erklären (Hall et al. 1999; Roghmann et al. 1999; Chacin-Bonilla et al. 2001). Hieraus resultierend sollten T. gondii-negative Schwangere auf den Verzehr von

\footnotetext{
4 Pyrimethamin hemmt kompetitiv die Dihydrofolatreduktase des Folsäurestoffwechsels von Protozoen. Es ist potentiell teratogen und sollte nicht im 1. Trimenon eingenommen werden. Da Pyrimethamin eine vorübergehende, Dosis-abhängige KnochenmarkDepression auslösen kann, ist eine engmaschige Blutbild-Kontrolle indiziert.

5 Sulfadiazin ist ein Sulfonamid, das inhibitorisch in den Folsäure-Stoffwechsel von T. gondii eingreift. Auf ausreichende Flüssigkeitszufuhr ist hierbei zu achten, da der Wirkstoff in der Niere auskristallisieren kann.

${ }^{6}$ Folinsäure wird für die Prävention und Reduktion der Hämatotoxizität von Pyrimethamin substituiert.
} 
rohem Fleisch verzichten, da nur das ausreichende Erhitzen bei $>66^{\circ} \mathrm{C}$ infektiöse Gewebszysten im Fleisch abtötet (Dubey et al. 2005). Darüberhinaus sollten die gefährdeten Personen rohes Gemüse und Früchte ausreichend waschen und Erd- und Gartenarbeiten meiden. Direkter Kontakt mit Katzen hingegen erweist sich nicht als signifikanter Risikofaktor (Cook et al. 2000), jedoch sollten Katzenklos nur von nicht gefährdeten Personen mit heißem Wasser gereinigt werden. Auf ausreichende Handhygiene nach Kontakt mit den genannten Risikofaktoren ist zu achten.

Eine Infektion mit $T$. gondii kann darüberhinaus durch Tachyzoiten-kontaminierte Bluttransfusionen, Gewebe- und Organtransplantate, insbesondere Herz, Lunge und Leber erfolgen und z. T. schwere Komplikationen verursachen (Hermanns et al. 2001; Derouin \& Pelloux 2008). Die epidemiologische Bedeutung dieser Übertragungswege ist zwar noch nicht ausreichend geklärt; jedoch profitiert ein durch serologisches Screening von Spender und Empfänger identifizierter Hoch-Risiko-Patient von einer Prophylaxe mit Cotrimoxazol (Derouin \& Pelloux 2008).

Neben den genannten Risikofaktoren und Infektionswegen nimmt man an, dass ein niedriger sozioökonomischer Status in der Gesellschaft eine umso höhere Seroprevalenz begünstigt (Bahia-Oliveira et al. 2003). Präventiv muss in der Bevölkerung Aufklärung über Hygiene-Maßnahmen stattfinden und kontaminiertes Trinkwasser kontrolliert bzw. aufbereitet werden (Isaac-Renton et al. 1998).

Durch sekundäre Prävention wie ein Schwangeren-Screening kann die Serokonversionsrate um bis zu $40 \%$ reduziert werden, durch primäre Prävention sogar um bis zu 63\% (Foulon et al. 1994). Der Erfolg eines Screening-Programms ist jedoch stark von der Prävalenz einer Region abhängig. Der epidemiologische Fokus in der Bekämpfung und Prävention der Toxoplasmose lag in vergangenen Jahrzehnten vornehmlich auf der kongenitalen Infektion. Neuere Daten legen jedoch nahe, dass T. gondii auch bei nichtschwangeren immunkompetenten Patienten v.a. durch Retinochorioiditis deutliche Morbidität verursacht (Havelaar et al. 2007).

Ein humaner Impfstoff wird vielfach diskutiert, zurzeit ist jedoch nur eine Impfung von Schafen gegen Abort (Ovilis Toxovax, Intervet International) kommerziell erhältlich (Innes \& Vermeulen 2006). 


\subsection{Die Immunantwort des Wirtes auf eine Infektion mit T. gondii}

\subsubsection{Die Immunreaktion auf T. gondii}

In der frühen Phase einer akuten Infektion mit Toxoplasma gondii kommt es bei immunkompetenten Individuen zu einer ausgeprägten Immunreaktion. Das primäre Ziel des Wirtes ist es, eine schnelle Replikation der eingedrungenen Tachyzoiten und einhergehende Schädigungen zu verhindern. So werden bei einer Toxoplasmen-Parasitämie im starken Maße proinflammatorische Zytokine produziert. Insbesondere Interleukin-12 wird initial von phagozytierenden Zellen wie Makrophagen und neutrophilen Granulozyten sowie antigenpräsentierenden Dendritischen Zellen (DCs) als Antwort auf mikrobielle Stimuli sezerniert. Über den STAT4-Signalweg aktiviert IL-12 Natürliche Killer (NK)-Zellen und bringt diese zur Ausschüttung von IFN- $\gamma$ (Gazzinelli et al. 1993). Darüberhinaus ist Interleukin-12 äußerst wichtig für die Differenzierung von $\mathrm{CD}^{+}{ }^{+}$und $\mathrm{CD} 8^{+}-\mathrm{T}-\mathrm{Lympho-}$ zyten (Reis e Sousa et al. 1997), welche wiederum auf T. gondii-infizierte Zellen zytotoxisch wirken (Montoya et al. 1996).

Interferon- $\gamma$ stellt neben IL-12 einen der wichtigsten Mediatoren in der Immunabwehr gegen Infektionen mit intrazellulären Protozoen dar (Suzuki et al. 1988; Lykens et al. 2010). Als wesentlicher Regulator der Immunantwort ist IFN- $\gamma$ in die Aktivierung einer Vielzahl von Genen involviert, die u.a. Zellwachstum, Apoptose und die AntigenPräsentation durch MHC-Moleküle der Klasse I und II steuern (Boehm et al. 1997). Es steht zudem eine Reihe antimikrobieller Maßnahmen der Immunabwehr wie u.a. die Expression der induzierbaren Stickoxidsynthase (iNOS) unter dem Einfluss von IFN- $\gamma$ (Lüder et al. 2003a). Experimente mit murinen Wirten zeigten, dass die Abwesenheit von IFN- $\gamma$ (Scharton-Kersten et al. 1996) oder die Inaktivierung dieses Zytokins (Yap \& Sher 1999) zu einer gesteigerten Mortalität durch eine unkontrollierte Vermehrung bzw. Reaktivierung von $T$. gondii führt. Andererseits wird ein überschießender Ausstoß der proinflammatorischen Mediatoren IL-12, IFN- $\gamma$ und TNF- $\alpha$ bei T. gondii-infizierten Mäusen - ohne eine hemmende Kontrolle von IL-10 - ebenfalls mit einer erhöhten Mortalität im Zusammenhang gesehen (Gazzinelli et al. 1996). Gleichwohl ist v.a. im Rahmen einer akuten Toxoplasmose initial eine schnelle und starke Aktivierung der zellulären Immunantwort essentiell für die Bekämpfung des Erregers. Hierbei werden insbesondere 
NK-Zellen und T-Lymphozyten als Quellen der INF- $\gamma$-Produktion gesehen (Hunter et al. 1994; Fukao et al. 2001).

\subsubsection{Die HLA-Signalkaskade}

Eine adäquate Reaktion des Immunsystems auf eine Infektion mit Toxoplasma gondii setzt unter anderem die Identifizierung von Parasit-positiven Zellen voraus. Dies erfolgt durch die Präsentation von prozessierten T. gondii-Antigenen auf der Zelloberfläche von antigenpräsentierenden Zellen (APCs) mittels humaner Leukozyten-Antigene (HLA), die im Haupthistokompatibilitäts-Komplex (MHC) des Menschen kodiert sind. MHC-Moleküle der Klasse I (HLA-A, -B, -C) werden von allen kernhaltigen Zellen konstitutiv - d.h. ohne vorherige Zellaktivierung - exprimiert und präsentieren Antigenpeptide an $\mathrm{CD} 8^{+}-$ T-Lymphozyten; eine Hochregulation der Molekül-Expression kann durch IFN- $\gamma$, TNF- $\alpha$ und andere Faktoren jedoch induziert werden (Vidovic et al. 1990). MHC-Klasse II (HLA-DR, -DP, -DQ) und gebundene Peptide werden CD4+-T-Lymphozyten hingegen ausschließlich von professionellen APCs, d.h. Makrophagen / Monozyten, dendritische Zellen und B-Lymphozyten präsentiert. Die Expression von MHC-Klasse II kann ebenfalls durch verschiedene Zytokine hochreguliert werden.

Die Signalkaskade, die zu einer Expression von MHC-Molekülen auf der Zelloberfläche führt, wird durch Interferon- $\gamma$ mit Bindung an seinen Rezeptor (IFNGR) initiiert (Abb. 1.3). Kontakt mit den R1- und R2-Untereinheiten aktiviert daraufhin Tyrosinkinasen (JAK1 bzw. JAK2), die die intrazellulären Domänen des Rezeptors phosphorylieren (Boehm et al. 1997; Stark 2007). Der im Zytoplasma lokalisierte monomere Transkriptionsfaktor STAT1 $\alpha$ (Signal transducer and activator of transcription 1 alpha) wird durch eine Bindung an die Rezeptor-Untereinheit phosphoryliert, vereinigt sich zu einem Dimer und gelangt anschließend in den Nukleus, wo der Kontakt mit PromotorenBindungsstellen erfolgt. Gleichzeitig erfolgt durch IFN- $\gamma$ und - über einen indirekten Weg - STAT1 $\alpha$ eine Aktivierung des Proteins SOCS1 (suppressor of cytokine signalling 1), das in einer negativen Rückkopplung die katalytische Aktivität der Tyrosinkinasen sowie den Zugang von STAT1 $\alpha$ zu den intranukleären Bindungsstellen blockiert (Saito et al. 2000; Kile \& Alexander 2001). Im Nukleus aktiviert STAT1 $\alpha$ durch Kontakt mit der Interferon-Gamma Activated Sequence (GAS) eine Region der DNA, die als Promotor für IFN- $\gamma$-abhängige Gene dient (Muhlethaler-Mottet et al. 1998). Der in Folge produzierte Transkriptionsfaktor IRF-1 (interferon-regulatory factor-1) führt zusammen mit STAT1 $\alpha$, 
IRF-2 (Xi \& Blanck 2003) und dem ubiquitär vorkommenden USF-1 (upstream stimulatory factor 1) zur Transkription von CIITA (class II transactivator). CIITA stellt den essentiellen Regulator sowohl der konstitutiven als auch der IFN- $\gamma$-induzierten Expression von MHC-Molekülen dar (Steimle et al. 1994; Muhlethaler-Mottet et al. 1998; Harton \& Ting 2000) und löst die Translation der Rezeptoren in das Endoplasmatische Retikulum (ER) aus. Endogene, durch Proteasen lysierte Antigene gelangen über spezielle Peptid-Transporter (TAP, transporter associated with antigen processing) in das ER. Neusynthetisierte MHC-Klasse-I-Moleküle werden im ER zunächst mittels Calnexin stabilisiert, bis $\beta 2$-Mikroglobulin an den Komplex bindet und diesen vervollständigt. Ein Peptid-Beladungskomplex (PLC, peptide loading complex) unterstützt die Bindung von Peptid und MHC-Klasse-I-Molekül (Panter et al. 2012), woraufhin über den GolgiApparat die Präsentation an der Zelloberfläche erfolgt. Ein lysosomaler Weg führt hingegen über Endosomen, die Antigene von extrazellulär aufnehmen, diese spalten und nach Fusion mit einem vom ER gelösten Kompartiment mit MHC-Klasse-II-Molekülen freigeben. Eine invariante Kette sowie das Peptid CLIP (class-II-associated invariant chain peptide) verhindern bis zum Kontakt mit dem Antigen eine vorzeitige Beladung der Bindungsstelle des Moleküls (Sette et al. 1995). Nach Dissoziation der blockierenden Peptide und Bindung des Antigens an den HLA-Rezeptor wird der Peptid-MHC-Komplex über den sekretorischen Pathway an der Zelloberfläche präsentiert. T-Zellen, die die Antigene erkennen, werden daraufhin aktiviert und zerstören die infizierte Zelle oder produzieren Zytokine, die anderen Zellen wie Makrophagen oder B-Zellen bei der Infektabwehr helfen. Ein kongenitaler Mangel an MHC-Oberflächenmolekülen kann daher zu schwerwiegenden Krankheitsbildern führen (z.B. bare lymphocyte syndrome), die aufgrund von rezidivierenden, vom Organismus teils unkontrollierbaren Infektionen oft mit einer infausten Prognose und hoher Letalität in jungen Jahren assoziiert sind (Klein et al. 1993). 


\section{Einleitung}

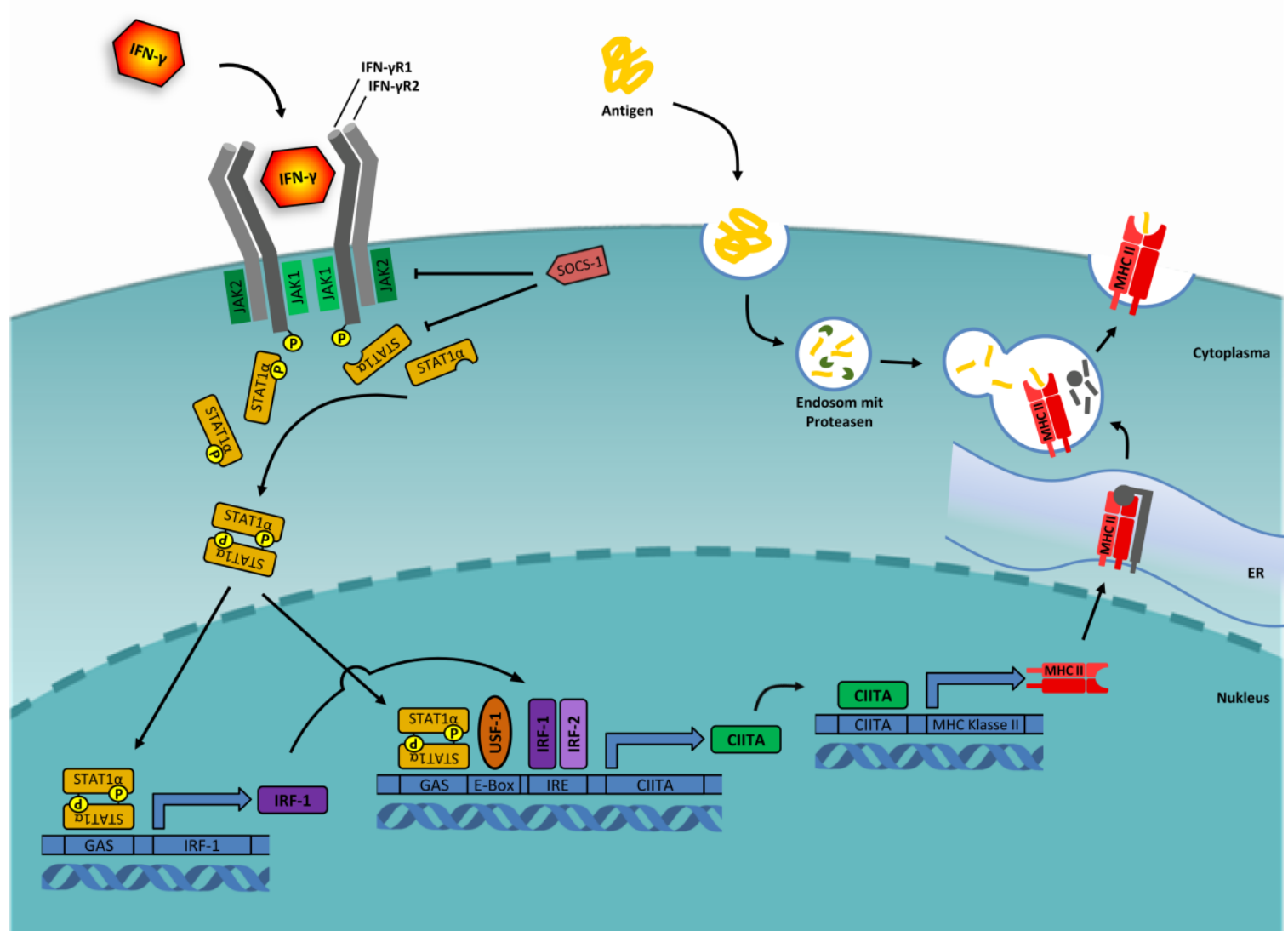

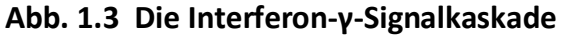

Schematisch ist die Interferon- $\gamma$-Signalkaskade am Beispiel für MHC-Klasse II dargestellt. Durch Bindung von IFN- $\gamma$ an den IFN- $\gamma$-Rezeptor (IFNGR), werden über die Untereinheiten R1 und R2 Tyrosinkinasen (JAK1 und JAK2) aktiviert, die die intrazellulären Rezeptordomänen phosphorylieren. Das hierdurch auf den monomeren Transkriptionsfaktor STAT1a (Signal transducer and activator of transcription 1 alpha) übertragene Phosphat lässt STAT1 $\alpha$ dimerisieren und in den Nukleus translozieren. Letztgenannte Reaktionen können durch SOCS1 (suppressor of cytokine signalling 1) im Sinne einer negativen Rückkopplung inhibiert werden. Im Nukleus aktiviert STAT1 $\alpha$ durch Kontakt mit der Interferon-Gamma Activated Sequence (GAS) die Synthese des Transkriptionsfaktors IRF-1 (interferon-regulatory factor-1) und zusätzlich mit IRF-2 und USF-1 (upstream stimulatory factor 1) wird die Transkription von CIITA (class /l transactivator) initiiert. CIITA induziert anschließend die Synthese von MHC-Molekülen in das Endoplasmatische Retikulum (ER), welche sich mit durch Proteasen lysierten Antigenen verbinden. Hierzu disloziert die invariante Kette sowie das Peptid CLIP (class-II-associated invariant chain peptide) vom MHC-Molekül, die freie Peptid-Bindungsstelle wird mit Antigen beladen und die Präsentation des Peptid-MHC-Komplexes an der Zelloberfläche kann erfolgen. 


\subsection{Ziele dieser Arbeit}

Toxoplasma gondii hat für sein Überleben im immunkompetenten Wirt verschiedene Evasionsmechanismen entwickelt, durch die effektive Immunantworten vermieden bzw. moduliert werden. So stellen für $T$. gondii als obligat intrazellulären Erreger die parasitophoren Vakuolen (PV) einen vor Fusion mit Endosomen oder Lysosomen geschützten Raum dar (Schwab et al. 1994). Zudem sind umfangreiche Eingriffe beispielsweise in die antiparasitär wirkende Wirtszell-Apoptose in der Literatur beschrieben (Nash et al. 1998; Lüder \& Gross 2005; Hippe et al. 2009). Die für eine erfolgreiche Immunantwort wichtigen proinflammatorischen Zytokine Interleukin-12 und Tumornekrosefaktor werden in Abhängigkeit des Genotyps des Parasiten durch Eingriff in STAT3Signalkaskaden und Histonveränderungen effektiv gehemmt (Butcher et al. 2001; Butcher et al. 2005; Leng \& Denkers 2009). Außerdem hemmen virulente Parasiten vom Genotyp I die Aktivierung von IRG-Proteinen (p47 Girasen), die zum intrazellulären Abtöten des Parasiten beitragen können (Fentress et al. 2010; Steinfeldt et al. 2010).

Frühere Arbeiten zeigten darüberhinaus, dass T. gondii auch die Aktivierung von Mausmakrophagen hemmen kann (Lüder et al. 1998; Lang et al. 2006; Lang et al. 2012). Da IFN- $\gamma$ das zentrale Zytokin einer erfolgreichen Immunabwehr gegen T. gondii ist (Suzuki et al. 1988; Lykens et al. 2010), dürfte dies für das Überleben des Parasiten im immunkompetenten Wirt und die Etablierung einer persistenten Infektion von zentraler Bedeutung sein. So konnte z.B. gezeigt werden, dass infizierte Mausmakrophagen signifikant weniger MHC-Klasse-II-Moleküle nach Stimulation mit IFN- $\gamma$ exprimieren als nichtinfizierte (Lüder et al. 1998), und dass dies zu einer verminderten Antigenpräsentation an CD4 ${ }^{+}$-T-Zellen führt (Lüder et al. 2001). Ob Toxoplasma auch einen inhibitorischen Einfluss auf die MHC-Expression in Makrophagen des Menschen hat, wurde bisher nicht untersucht.

Das Ziel der vorliegenden Arbeit war es daher zu untersuchen, ob ein inhibitorischer Einfluss von T. gondii auch auf die IFN- $\gamma$-induzierte MHC-Expression von Monozyten / Makrophagen des Menschen zu beobachten ist. Mittels Durchflusszytometrie, Immunfluoreszenz und qRT-PCR wurde dabei untersucht, in welchem Ausmaß eine mögliche Hemmung der MHC-Expression durch eine Infektion mit Toxoplasmen stattfindet. Dabei sollte auch untersucht werden, ob der Toxoplasmose-Infektionsstatus der Blutspender, von denen die Monozyten des peripheren Blutes (PBMC) für diese Untersuchungen stammen, 
das MHC-Expressionsmuster vor und nach in-vitro-Infektion mit T. gondii beeinflusst. Hierzu wurden die MHC-Klasse-I- und -II-Expressionen auf Monozyten aus T. gondiipositiven bzw. -negativen Spendern verglichen und mögliche Ursachen für Unterschiede diskutiert. Durch eine Analyse der Transkriptionsfaktoren der IFN- $\gamma$-Signalkaskade sollten abschließend auch auf genetischer Ebene weitere Erkenntnisse über den hemmenden Einfluss von T. gondii auf die MHC-Expression von Monozyten des Menschen erlangt werden. 


\section{Material und Methoden}

\subsection{Material}

\subsubsection{Zelllinien}

$\begin{array}{ll}\text { Zelllinie } & \begin{array}{l}\text { Erläuterung } \\ \text { THP-1 }\end{array} \\ & \begin{array}{l}\text { Humane Monozyten einer Leukämie-Tumorzelllinie, } \\ \text { die als Suspensionszellen gehalten wurden. }\end{array} \\ \text { PBMC-Monozyten } & \begin{array}{l}\text { Primäre, humane Monozyten, welche aus mononukleären } \\ \text { Zellen des peripheren Blutes von Blutspenden gewonnen } \\ \text { wurden (2.2.1.2). Diese Zellen adhärierten in Zellkultur. }\end{array} \\ & \text { Murine, adhärente Fibroblasten, die als Wirtszellen zur } \\ \text { L929-Fibroblasten } & \text { Vermehrung von T. gondii dienten. } \\ & \text { Tachyzoiten des Maus-avirulenten Stammes NTE }\end{array}$

\subsubsection{Zellkulturmedien und Zusätze}

Soweit nicht anders erwähnt, stammten die Zellkulturmedien und -additive von Biochrom (Berlin).

\begin{tabular}{ll} 
Medien & Zusammensetzung \\
\hline RPMI 1640 (Roswell & Instantpulver (Instamed T 121-10), $300 \mathrm{mg} / \mathrm{L}$ L-Glutamin, \\
Park Memorial Institute) & $2000 \mathrm{mg} / 1 \mathrm{NaHCO}_{3}$, eingestellt auf $\mathrm{pH} 7,2$ und sterilfiltriert \\
& \\
DMEM & Instantpulver (Instamed T 043-10), $580 \mathrm{mg} / \mathrm{L}$ L-Glutamin, \\
(Dulbecco's MEM) & $3700 \mathrm{mg} / 1 \mathrm{NaCO}_{3}, 4,5 \mathrm{~g} / 1$ Glukose eingestellt auf pH 7,2 und \\
& sterilfiltriert
\end{tabular}

\section{Medienzusätze}

Penicillin / Streptomycin, $10.000 \mathrm{U} / \mathrm{ml}-10.000 \mu \mathrm{g} / \mathrm{ml}$

EDTA, $1 \%$

Glukose, $10 \%(\mathrm{w} / \mathrm{v})$ 
Trypsin, $0,25 \%$

HEPES-Puffer, $1 \mathrm{M}$

Natrium-Pyruvat (Na-Pyruvat), $100 \mathrm{mM}$

Nicht-essentielle Aminosäuren (NEAA), 100x

FCS (Fötales Kälberserum), hitzeinaktiviert

Dulbecco's Phosphat-gepufferte Saline (PBS)

\section{Zellkulturmedien}

THP-1-Medium RPMI 1640, $10 \%$ FCS, 100 U/ml Penicillin, $100 \mu \mathrm{g} / \mathrm{ml}$ Streptomycin, $1 \mathrm{mM}$ Na-Pyruvat, $10 \mathrm{mM}$ HEPES, 2,5 g/l Glukose

L929-Medium DMEM, $1 \%$ FCS, 100 U/ml Penicillin, $100 \mu \mathrm{g} / \mathrm{ml}$ Streptomycin, $1 \mathrm{mM}$ Na-Pyruvat, 1x NEAA

T. gondii-Medium RPMI 1640,1\% FCS, $100 \mathrm{U} / \mathrm{ml}$ Penicillin, $100 \mu \mathrm{g} / \mathrm{ml}$ Streptomycin

PBMC-Medium RPMI 1640, $10 \%$ FCS, 100 U/ml Penicillin, $100 \mu \mathrm{g} / \mathrm{ml}$ Streptomycin

Bestimmung der Zellvitalität: Trypanblau, $0,1 \%$ in PBS

\subsubsection{Chemikalien und Reagenzien}

\begin{tabular}{ll} 
Chemikalie / Reagenz & Hersteller \\
\hline Agarose & Roth, Karlsruhe \\
Diethylpyrocarbonat (DEPC) & Sigma, München \\
Dimethylsulfoxid (DMSO) & Sigma, München \\
Ethanol & Merck, Darmstadt \\
Ethidiumbromid & Merck, Darmstadt \\
Ficoll-Paque ${ }^{\circledR}$ Plus & GE Healthcare, Freiburg \\
Mowiol & Calbiochem, München \\
Paraformaldehyd (PFA) & Merck
\end{tabular}


Phorbol 12-Myristat 13-Acetat (PMA)

Propidiumjodid

Rinderserum-Albumin

(bovine serum albumin, BSA)

Saponin
Sigma, München

Sigma, München

Sigma, München

Sigma, München

Soweit nicht anders erwähnt, stammten die verwendeten Standard-Chemikalien und -reagenzien von den Firmen Merck (Darmstadt), Roth (Karlsruhe), Roche (Mannheim) oder Sigma (München).

\title{
2.1.4 Antikörper
}

\author{
Primärantikörper \\ Maus $\mathrm{IgG}_{1}$ anti humanes HLA-A, -B, -C (MHC-Klasse I) \\ Maus IgG $\operatorname{Ian}_{2 \mathrm{a}}$ anti humanes HLA-DR (MHC-Klasse II) \\ Maus $\mathrm{IgG}_{2 \mathrm{a}}$ anti humanes HLA-DR, -DP, -DQ (MHC-Klasse II) \\ Maus $\operatorname{IgG}_{2 \mathrm{a}}$ anti humanes CD14, FITC \\ Maus $\operatorname{IgG}_{2 \mathrm{a}}$ Isotyp Kontrolle G155-178, FITC \\ Maus IgG $2 \mathrm{a}$ Isotyp Kontrolle G155-178 \\ Maus $\mathrm{IgG}_{1}$ Isotyp Kontrolle MOPC-21 \\ Kaninchen anti-Toxoplasma, Serum (Eigenherstellung)
}

\section{Sekundärantikörper und Konjugate}

Cy2 (Carbocyanin)-konjugiertes Esel F(ab') ${ }_{2}$-Fragment anti-Maus IgG

Cy5 (Indodicarbocyanin)-konjugiertes Esel $\mathrm{F}\left(\mathrm{ab}^{\prime}\right)_{2}$-Fragment anti-Kaninchen IgG

Phycoerythrin (PE)-konjugiertes Ziege F(ab') ${ }_{2}$-Fragment anti-Maus IgG

Alle Primärantikörper wurden, wenn nicht anders beschrieben, von BD Pharmingen, Heidelberg, bezogen. Lieferant aller Sekundärantikörper und Konjugate war Dianova, Hamburg. 


\subsubsection{DNA-Molekulargewichtsmarker}

1 kb-DNA-Leiter: 250, 500, 750, 1.000, 1.500, 2.000, 2.500, 3.000, 3.500, 4.000, 5.000, 6.000, 8.000, 10.000 bp; (MBI Fermentas, St. Leon-Rot)

\subsubsection{Oligonukleotide}

$\begin{array}{ll}\text { Oligonukleotid } & \mathbf{5}^{\prime}-\mathbf{3}^{\prime} \text { - Sequenz } \\ \text { humanes } \beta \text {-Actin forward } & \text { TAT CCA GGC TGT GCT ATC CC } \\ \text { humanes } \beta \text {-Actin reverse } & \text { CCA TCT CTT GCT CGA AGT CC } \\ \text { humanes IRF1 forward } & \text { CTG TCA GCA GCA CTC TCC C } \\ \text { humanes IRF1 reverse } & \text { TGT CAA TTT CTG GCT CCT CC } \\ \text { humanes CIITA forward } & \text { CAA GTC CCT GAA GGA TGT GGA } \\ \text { humanes CIITA reverse } & \text { TCC CCG ATC TTG TTC TCA CT } \\ \text { humanes HLA-A2 forward } & \text { GCG GCT ACT ACA ACC AGA GC } \\ \text { humanes HLA-A2 reverse } & \text { CCA GGT AGG CTC TCA ACT GC } \\ \text { humanes HLA-DR } \alpha \text { forward } & \text { AAA GCG CTC CAA CTA TAC TCC GA } \\ \text { humanes HLA-DR } \alpha \text { reverse } & \text { ACC CTG CAG TCG TAA ACG TCC }\end{array}$

Oligonukleotide wurden von Sigma, München, bezogen.

\subsubsection{Reaktionskits}

\begin{tabular}{|c|c|}
\hline Anwendung & Reaktionskit \\
\hline RNA Isolation & GenElute Mammalian Total RNA Kit (Sigma, München) \\
\hline reverse Transkription & Omniscript Reverse Transcriptase (Qiagen, Hilden) \\
\hline Ribonuklease Inhibitor & RNasin $10 \mathrm{U} / \mu 1$ (Promega, Madison, USA) \\
\hline LightCycler PCR & $\begin{array}{l}\text { LightCycler® FastStart DNA Master }{ }^{\text {Plus }} \text { SYBR Green I (Roche, } \\
\text { Mannheim) }\end{array}$ \\
\hline
\end{tabular}

\subsubsection{Zytokine}

Interferon- $\gamma$, human (hIFN $\gamma$ ), rekombinant (BD Pharmingen, Heidelberg) 


\subsubsection{Enzyme}

Taq-Polymerase von Thermus aquaticus, (Roche, Mannheim)

Omniscript Reverse Transkriptase (Qiagen, Hilden)

\subsubsection{Geräte}

\begin{tabular}{ll} 
Gerät & Spezifikation \\
Durchflusszytometrie & FACS-Calibur (BD Biosciences, Heidelberg) \\
LightCycler & LightCycler $^{\circledR}$ 2.0 Real-Time-PCR-System \\
& (Roche, Mannheim) \\
Mikroskope & Fluoreszenzmikroskop Modell DM R \\
& (Leica, Heidelberg) \\
& Konfokales Laserscanmikroskop TCS SP2 \\
& (Leica, Heidelberg) \\
& Leica DM IL (Leica, Heidelberg) \\
& Zeiss Axiostar Plus (Zeiss, Göttingen) \\
& Ultraspec 1000 (GE Healthcare) \\
Photometer & BioDoc II Digital Imaging System \\
Transilluminator & (Biometra, Göttingen) \\
Faage & Feinwaage LP 6200 S (Sartorius, Göttingen) \\
\hline
\end{tabular}

Ansonsten wurden Standardgeräte von laborüblichen Herstellern verwendet.

\subsubsection{Verbrauchsmaterialien}

Materialien für die Zellkultur wurden von Nunc (Wiesbaden), Falcon (Heidelberg), Corning Costar (Bodenheim), Greiner (Frickenhausen) und Eppendorf (Hamburg) bezogen. 


\subsection{Methoden}

\subsubsection{Zellkultur}

Die Arbeiten mit den Zellkulturen fanden ausschließlich unter sterilen Bedingungen an Laminar-Flow-Sicherheitswerkbänken statt. Die Zellen wurden in einem Inkubator / Brutschrank bei $37^{\circ} \mathrm{C}$ und $5 \% \mathrm{CO}_{2}$ in gesättigter Wasserdampfatmosphäre kultiviert. Permanente Zelllinien wurden regelmäßig auf Kontaminationen mit Mycoplasmen mittels PCR entsprechend der Angabe der Hersteller (VenorGeM, Minerva Biolabs) untersucht und waren stets Mycoplasma-negativ.

\subsubsection{THP-1}

Bei den Zellen der Linie THP-1 handelt es sich um humane Monozyten, die ursprünglich aus dem Blut eines Patienten mit akuter monozytischer Leukämie isoliert worden sind. THP-1-Zellen besitzen Monozyteneigenschaften wie die Fähigkeit zur Phagozytose, Esterase-Aktivität und Produktion von Lysozymen (Tsuchiya et al. 1980) und wurden in Nährmedium als Suspensionskultur gehalten. Bei Stimulation durch den Phorboldiester PMA (mit $20 \mathrm{mM}$, soweit nicht anders erwähnt) adhärierten die Zellen jedoch und differenzierten $\mathrm{zu}$ reifen Makrophagen, die vergleichbare Merkmale wie primäre Monozyten (2.2.1.2) aufwiesen (Tsuchiya et al. 1982).

Für die Kultur der THP-1-Zellen wurde RPMI-1640-Medium mit 10\% FCS, 100 U/ml Penicillin, $100 \mu \mathrm{g} / \mathrm{ml}$ Streptomycin, $1 \mathrm{mM}$ Na-Pyruvat, $10 \mathrm{mM}$ HEPES und 2,5 g/l Glukose angereichert. Die Monozyten wurden zweimal pro Woche im Verhältnis 1:2 mit frischem Medium gemischt und im Brutschrank inkubiert.

\subsubsection{PBMC-Monozyten}

Primäre humane Monozyten wurden aus dem Blut von Blutspendern des Instituts für Transfusionsmedizin, Göttingen gewonnen. Die Verwendung humanen Probenmaterials für das vorliegende Projekt erfolgte gemäß der vorliegenden Genehmigung (Nr. 28/3/08) durch die Ethikkommission der Medizinischen Fakultät der Universität Göttingen. Die Monozyten wurden aus den mononukleären Zellen des peripheren Blutes (PBMC) von Buffy Coats isoliert. Vor der Isolation der Zellen wurde von jedem Buffy Coat zunächst ca. 0,5 ml Blutplasma durch Zentrifugation gewonnen, das zum Nachweis von Toxoplasma-spezifischem IgG und IgM verwendet wurde (2.2.1.6). Toxoplasma-positive Blutspender konnten so von nicht-infizierten unterschieden werden (3.3). 
Zur Gewinnung der PBMC wurden die Zellen des Buffy Coats mittels Dichtegradientenzentrifugation mit Ficoll-Paque ${ }^{\circledR}$ abhängig von ihrer Dichte in verschiedene Fraktionen aufgetrennt (Fuss et al. 2009). Somit konnten Monozyten zusammen mit anderen mononukleären Zellen von Blutplasma und Erythrozyten separiert werden. Hierzu wurde die Buffy-Coat-Blutspende mit einem Verdünnungsmedium aus RPMI 1640, $100 \mathrm{U} / \mathrm{ml}$ Penicillin und $100 \mu \mathrm{g} / \mathrm{ml}$ Streptomycin im Verhältnis 1:2 aufgefüllt und vorsichtig in ein 50-ml-Falcon-Röhrchen auf eine 15-ml-Ficoll-Paque®-Schicht gefüllt. Dabei wurde darauf geachtet, dass sich beide Phasen nicht vermischten. Anschließend wurde für 30 min bei 900 x g mit geringer Beschleunigung und Abbremsung (Stufe 2) zentrifugiert. Aufgrund der verschiedenen Dichten der Blutbestandteile ergab sich dadurch eine unterschiedlich starke Migration und somit eine klar differenzierte Fraktionierung der flüssigen und korpuskulären Anteile (Abb. 2.1).

\section{Vor Zentrifugation}

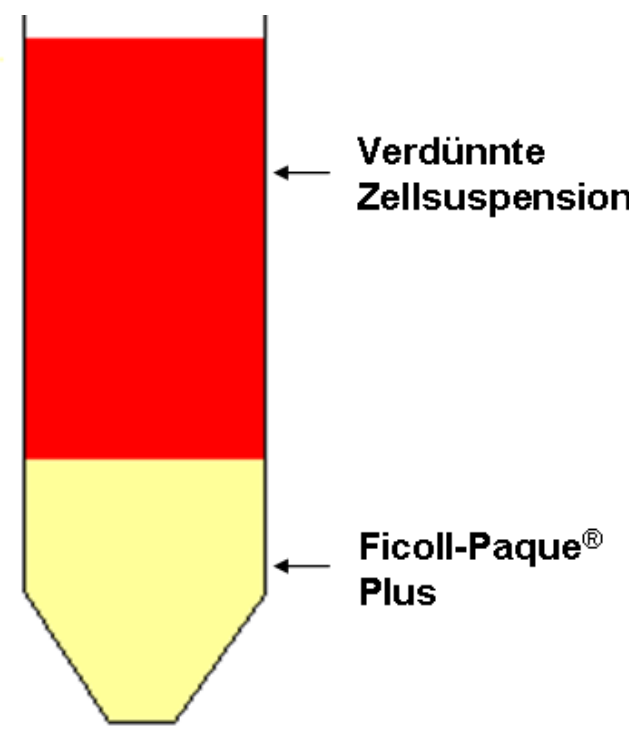

\section{Nach Zentrifugation}

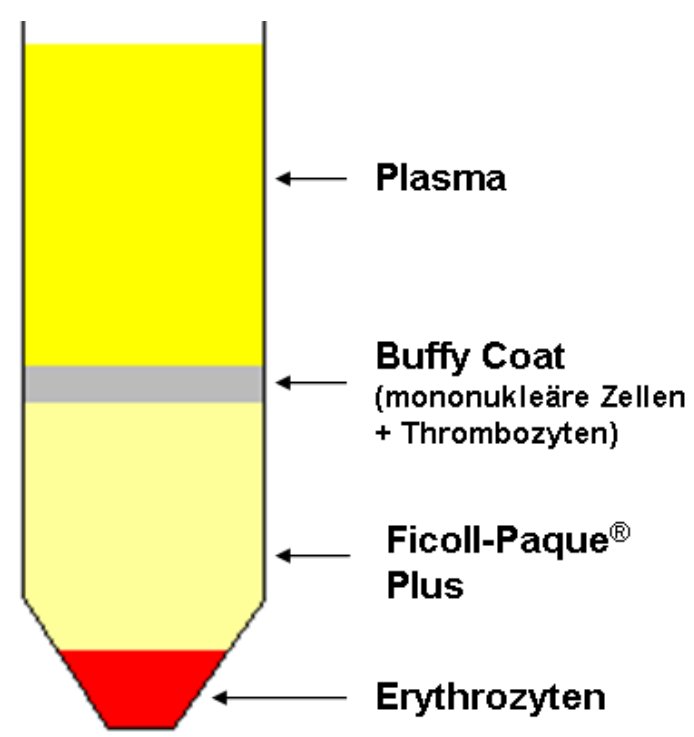

Abb. 2.1 Dichtegradientenzentrifugation mit Ficoll-Paque ${ }^{\circledR}$ Plus

Aufgrund verschiedener Dichten und Sedimentationskonstanten lagerten sich die Blutzelltypen nach Zentrifugation in unterschiedlichen Schichten im 50-ml-Falcon-Röhrchen an. Nach Entfernen der zu oberst liegenden Plasma-Phase wurde die Phase der mononukleären Zellen (PBMC) vorsichtig isoliert und weiter aufgereinigt.

Die mononukleären Zellen (PBMC) des Buffy Coat wurden vorsichtig aus der Interphase isoliert und zweimal für 10 min bei $400 \mathrm{x}$ g in Verdünnungsmedium gewaschen; abschließend erfolgte eine Zellzahlbestimmung. 
Mit dem Ziel, nur die primären Monozyten zu erhalten, wurden nun alle gewonnenen mononukleären Zellen (PBMC) in $12 \mathrm{ml}$ Verdünnungsmedium resuspendiert, in Zellkulturschalen ausgesät und für $2 \mathrm{~h}$ inkubiert. Da Monozyten im Gegensatz zu anderen PBMC-Zellen an der Oberfläche von Zellkulturschalen aus Plastik adhärieren (Lenzner et al. 1998), konnten sie danach zweimal vorsichtig mit 10 ml PBMC-Medium (RPMI 1640, 10\% FCS, $100 \mathrm{U} / \mathrm{ml}$ Penicillin, $100 \mu \mathrm{g} / \mathrm{ml}$ Streptomycin) gespült und von anderen, nicht adhärenten Zellen gereinigt werden. Für spätere Infektionsversuche wurden die Zellkulturschalen mit $12 \mathrm{ml}$ PBMC-Medium aufgefüllt.

\subsubsection{L929-Fibroblasten}

Für die Kultivierung von T. gondii wurden adhärente, murine Fibroblasten der Zelllinie L929 als Wirtszellen verwendet. Die Zellen wurden in 6-Loch-Platten in DMEM-Medium mit $1 \%$ FCS, $100 \mathrm{U} / \mathrm{ml}$ Penicillin, $100 \mu \mathrm{g} / \mathrm{ml}$ Streptomycin, $1 \mathrm{mM}$ Na-Pyruvat und 1x nicht-essentiellen Aminosäuren (NEAA) kultiviert. Zweimal pro Woche wurden die Fibroblasten vom Boden der Zellkulturplatten mit einem Zellschaber abgekratzt und in Medium resuspendiert. In jede Vertiefung einer neuen 6-Loch-Platte wurden ca. 7 Tropfen der Zellsuspension mit etwa $4 \mathrm{ml}$ frischem Medium gemischt und inkubiert. Die übrige Zellsuspension wurde für die Kokultur mit Toxoplasmen verwendet (siehe unten).

\subsubsection{Toxoplasma gondii}

Die vorliegenden Versuche wurden mit $T$. gondii-Tachyzoiten des Maus-avirulenten Stammes NTE durchgeführt (Gross et al. 1991). Die Tachyzoiten wurden in murinen L929-Fibroblasten als Wirtszellen vermehrt und für Infektionsversuche von den Fibroblasten wieder getrennt.

Zur Kultivierung wurden in verschiedenen Mischungsverhältnissen L929-Zellsuspension (siehe oben) und Toxoplasmen-Suspension in eine 12-Loch-Platte getropft und in frischem RPMI-1640-Medium mit 1\% Hitze-inaktiviertem fötalem Kälberserum (FCS), $100 \mathrm{U} / \mathrm{ml}$ Penicillin sowie $100 \mu \mathrm{g} / \mathrm{ml}$ Streptomycin kultiviert. Hatten die Toxoplasmen den überwiegenden Teil der Wirtszellen lysiert, waren großteils vital und wiesen ihre typische bogenförmige Gestalt auf, wurden sie zweimal pro Woche in L929-Fibroblasten subkultiviert. 


\subsubsection{Einfrieren und Auftauen von Zellen}

Für das Einfrieren der THP-1-Zellen befanden sich die Monozyten in ihrer exponentiellen Wachstumsphase und wiesen eine hohe Vitalität auf. Die Zellen wurden aus der Zellkulturflasche isoliert, mit Hilfe einer Neubauer-Zählkammer gezählt und auf eine Dichte von $1 \times 10^{7}$ Zellen pro ml eingestellt. In Kryoröhrchen wurde ein Teil Zellsuspension mit einem Teil Einfriermedium aus 40\% des THP-1-Zellkulturmediums, 40\% hitzeinaktiviertem FCS und 20\% Dimethylsulfoxid (DMSO) gemischt und sofort im Styropor-Block bei $-80^{\circ} \mathrm{C}$ tiefgefroren. Für die dauerhafte Lagerung wurden die Kryoröhrchen am nächsten Tag in flüssigen Stickstoff überführt.

Da das im Einfriermedium enthaltene DMSO im flüssigen Zustand den Zellstoffwechsel stark schädigen kann, mussten die Zellen sehr schnell aufgetaut werden. Hierzu wurden die Kryoröhrchen zuerst mit 70\%igem Ethanol desinfiziert und danach in einem Wasserbad $\left(37^{\circ} \mathrm{C}\right)$ angetaut, bis sich der Inhalt von der Röhrchenwand löste. Unter der Sterilbank wurden die Röhrchen erneut mit Ethanol desinfiziert und der Inhalt in vorbereitete 50-mlFalcon-Röhrchen mit $40 \mathrm{ml}$ Zellkulturmedium überführt. Die Zellsuspension wurde mit $400 \mathrm{x}$ g für $5 \mathrm{~min}$ zentrifugiert, das Pellet in frischem Zellkulturmedium resuspendiert und in einer Zellkulturflasche ausgesät.

\subsubsection{Serologischer Nachweis von T. gondii}

Vor der Isolation von PBMC-Monozyten aus Buffy Coats von Blutspendern (2.2.1.2) wurden Plasma-Proben entnommen und mittels indirekten Immunfluoreszenztests bzw. ELISA (beide bioMérieux) auf Toxoplasma-spezifische Antikörper untersucht. Fiel einer der Tests positiv aus, wurden Immunglobuline (Ig) der Gruppe M, G und A mittels ELISA genauer differenziert, sowie in Immunoblots (eigene Herstellung) bestätigt. Die serologischen Analysen haben ergeben, dass 4 der 12 untersuchten Proben Toxoplasma-positiv waren (3.3, Tabelle 3.1).

\subsubsection{Infektionsversuche mit humanen Monozyten}

\subsubsection{Isolation von T. gondii}

Für Infektionsversuche mit humanen Monozyten und T. gondii wurden T. gondii-L929Kokulturen benutzt, die einen hohen Anteil lysierter Wirtszellen und frei schwimmender Toxoplasmen aufwiesen. Dies war in der Regel nach 10 Tagen Kultivierung der Fall. Zur Isolation der Toxoplasmen wurde die Parasiten-Wirtszell-Suspension bei $35 \mathrm{x} \mathrm{g}$ für 5 min zentrifugiert, um die Wirtszellen von der Suspension zu trennen und als Pellet zu verwer- 
fen. Der Überstand wurde anschließend bei $1.300 \mathrm{x}$ g für $10 \mathrm{~min}$ zentrifugiert und das Toxoplasmen-Pellet durch zweimaliges Waschen mit $T$. gondii-Medium und Zentrifugieren für 10 min bei 1.300 x g aufgereinigt. Die isolierten Toxoplasmen wurden mit Medium der Versuchskultur (THP-1 bzw. PBMC) resuspendiert und die Anzahl der Parasiten in einer Neubauer-Zählkammer bestimmt.

\subsubsection{Infektionsversuche mit primären Monozyten aus PBMC}

Primäre, aus Buffy Coats von Blutspenden isolierte Monozyten (2.2.1.2) wurden mit Toxoplasmen in Parasit-zu-Wirtszellverhältnissen von 1,5:1 und 3:1 infiziert bzw. uninfiziert belassen. Zum Zwecke einer vergleichbaren Stimulation mit Interferon- $\gamma$ wurden die Ansätze mit PBMC-Medium ad $10 \mathrm{ml}$ Volumen aufgefüllt und für $2 \mathrm{~h}$ in den Brutschrank gestellt. Im Anschluss erfolgte die Zugabe von Interferon- $\gamma$ in einer Konzentration von 1,0 ng/ml. Nach $24 \mathrm{~h}$ Inkubation wurde eine Re-Stimulation mit der gleichen Menge Interferon- $\gamma$ durchgeführt. Weitere $24 \mathrm{~h}$ später konnten die Zellen schließlich für die FACS-Analyse verwendet (2.2.3) werden.

\subsubsection{Infektionsversuche mit THP-1}

Für Infektionsversuche mit THP-1-Zellen, denen sich eine FACS-Analyse anschloss, wurde eine Suspension aus je $8 \mathrm{ml}$ THP-1-Medium (RPMI-1640-Medium mit 10\% FCS, $100 \mathrm{U} / \mathrm{ml}$ Penicillin, $100 \mu \mathrm{g} / \mathrm{ml}$ Streptomycin, $1 \mathrm{mM}$ Na-Pyruvat, $10 \mathrm{mM}$ HEPES und 2,5 g/l Glukose) und $5 \times 10^{6}$ Zellen in Zellkulturschalen ausgesät. Ansätze für Immunfluoreszenztests wurden in 24-Loch-Platten auf Deckgläschen kultiviert. Pro Deckgläschen wurden $1,5 \times 10^{5}$ THP-1-Zellen ausgesät. Zellkulturen für qRT-PCR wurden in

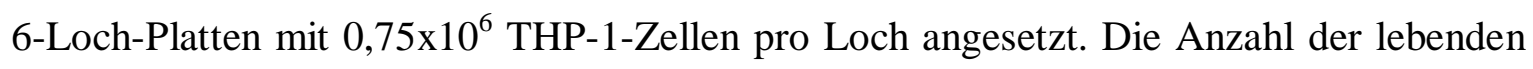
Zellen wurde jeweils mit einer Neubauer-Zählkammer und dem Vitalfarbstoff Trypanblau bestimmt. In Vorversuchen rief der monozytenaktivierende Phorboldiester PMA keine zusätzlichen positiven Effekte für die FACS-Analyse der THP-1-Zellen hervor; es wurde daher für Versuche mit Durchflusszytometrie auf PMA verzichtet. Da in Immunfluoreszenztests (IFT) jedoch adhärierte Zellen leichter zu analysieren waren, wurden THP-1-Zellen hierfür mit 20 nM PMA aktiviert. Die Populationen für die PCR-Analyse wurden ebenso mit 20 nM PMA behandelt. Das PMA-haltige Medium der PCR- und IFTAnsätze wurde nach $24 \mathrm{~h}$ Inkubation durch zweimaliges Waschen mit THP-1-Medium entfernt. 
T. gondii wurde wie oben beschrieben isoliert und zu den FACS-Zellkulturen in einem Parasit-zu-Wirtszellverhältnis von 2,5:1, 5:1, 10:1 und 20:1 zu jeweils zwei Ansätzen gegeben bzw. zwei Ansätze wurden als Kontrollen nicht-infiziert belassen. Für die vergleichbare Interferon- $\gamma$-Stimulation wurden alle Populationen mit Medium ad $10 \mathrm{ml}$ Volumen aufgefüllt. Ansätze für Immunfluoreszenztests wurden mit T. gondii in Parasitzu-Wirtszellverhältnissen von 2:1 und 5:1 infiziert bzw. uninfiziert belassen. Die THP-1Zellen der PCR-Ansätze wurden mit T. gondii-Infektionsraten von 5:1 und 10:1 infiziert, wobei eine Kontrollgruppe Toxoplasma-negativ blieb. Nach zweistündiger Inkubation, die der effizienten Invasion der Toxoplasmen in die Monozyten diente, wurde die Hälfte der Ansätze aller Versuchsreihen mit Interferon- $\gamma$ stimuliert. Die Konzentration betrug soweit nicht anders erwähnt - 1,0 ng/ml. Vorversuche hatten gezeigt, dass diese Konzentration eine optimale HLA-Expression ermöglicht. Nach 24 h Inkubationszeit wurden die Zellen für die RNA-Isolation wie in 2.2.5.1 beschrieben weiterbehandelt. Die Ansätze für die FACS-Analysen und Immunfluoreszenztests wurden hingegen mit Interferon- $\gamma$ restimuliert und 24 h später den FACS-Analysen (2.2.3) zugeführt bzw. für die Immunfluoreszenztests (2.2.4) weiterbehandelt.

In weiteren Experimenten der FACS-Versuchsreihe wurde untersucht, inwieweit sich unterschiedliche Interferon- $\gamma$-Konzentrationen auf die Hemmung der HLA-Expression durch T. gondii auswirkten. Hierfür wurden $5 \times 10^{6}$ THP-1-Zellen ausgesät und nach $24 \mathrm{~h}$ die Hälfte der Ansätze mit T. gondii in einem Parasit-zu-Wirtszellverhältnis von 10:1 infiziert. Nach zweistündiger Inkubation wurden jeweils infizierte und nicht-infizierte Populationen mit Interferon- $\gamma$ in Konzentrationen von 0,01, 0,1, 1,0, 10,0 und 100,0 ng/ml stimuliert. Nach $24 \mathrm{~h}$ Inkubation wurden die Zellen erneut nach demselben Schema stimuliert und weitere $24 \mathrm{~h}$ später wie in 2.2 .3 beschrieben durchflusszytometrisch analysiert.

\subsubsection{Durchflusszytometrie}

Das Prinzip der Durchflusszytometrie bzw. FACS (fluorescence activated cell sorting)Analyse besteht darin, mit Fluoreszenzfarbstoffen - z.B. Fluorochrom-konjugierten Antikörpern - markierte Zellen an einem Laserstrahl vorbeizuleiten und die Emission des Fluoreszenzfarbstoffs von einzelnen Zellen $\mathrm{zu}$ messen (Abb. 2.2). Die Intensität des gemessenen Lichts gibt proportional Aufschluss über die Menge der gebundenen Antikörper bzw. die Expression von Antigenen auf den untersuchten Zellen. 


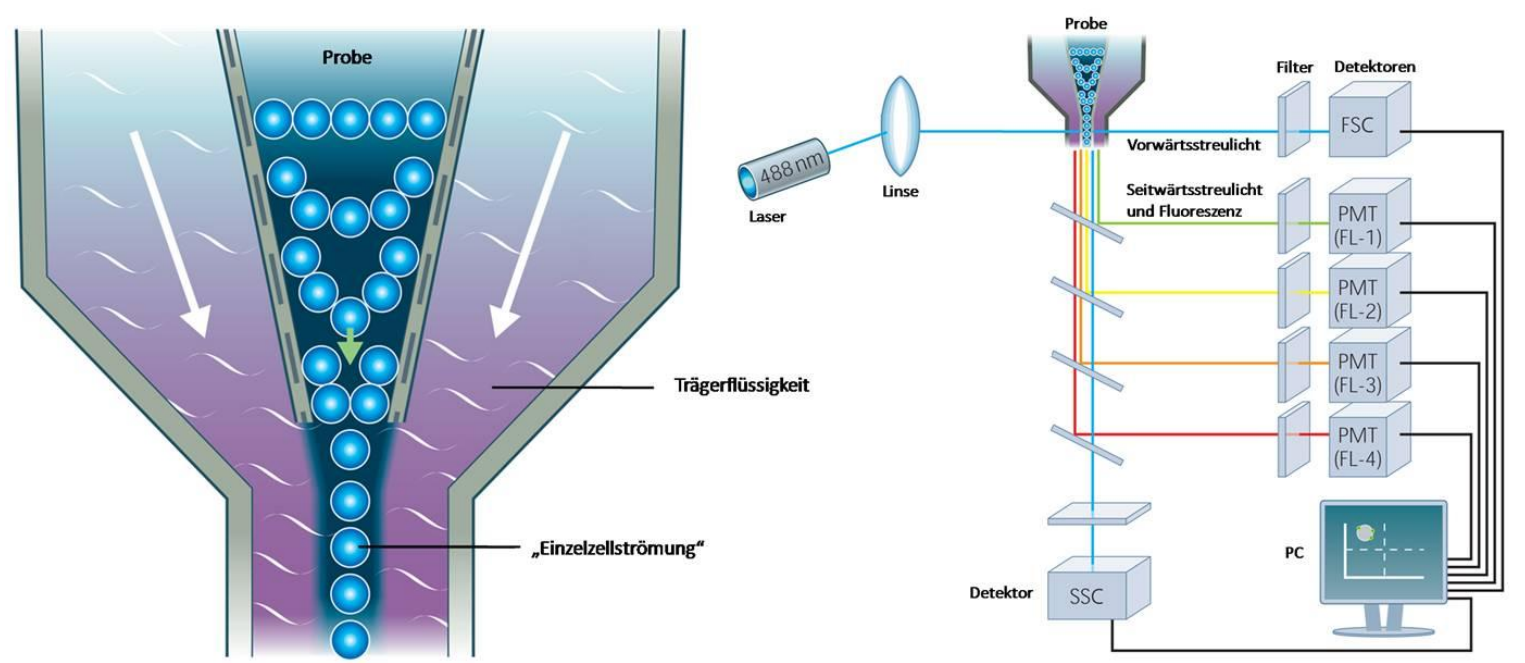

\section{Abb. 2.2 Das Prinzip der Durchflusszytometrie}

Die mit Fluoreszenzfarbstoffen markierten Zellen werden in einer Suspension dem Zytometer zugeführt. Eine vorbeifließende Trägerflüssigkeit („Hüllstrom“) erzeugt einen Sog und zieht die Probenflüssigkeit durch einen sich verjüngenden Austrittskanal. Somit entsteht eine laminare „Einzelzellströmung“ (single flow), die die Zellen isoliert an einem Laser vorbeiführt, eine so genannte hydrodynamische Fokussierung. Die Zellen lenken den Laserstrahl auf charakteristische Weise ab, was als Vorwärts- und Seitwärtsstreulicht (FSC forward scatter, SSC side scatter) von Detektoren (Photomultipliern, PMT photomultiplier tube) gemessen wird. Die FSC- und SSC-Werte erlauben Aussagen über die Größe und Granularität der Zellen. Die emittierte Fluoreszenz (FL-1, FL-2 etc.) beschreibt in ihrer Art und Intensität die gebundenen Fluoreszenzfarbstoffe und somit z.B. die Expression der zu untersuchenden Oberflächen-Antigene. (Abb. modifiziert nach AbD Serotec, www.abdserotec.com)

Für die Analyse im Durchflusszytometer wurden die Infektionsansätze der permanenten Zelllinie THP-1 (2.2.2.3) und primärer Monozyten aus PBMC (2.2.2.2) in 50-mlZentrifugen-Röhrchen gefüllt; adhärente Zellen wurden, soweit nötig, mit Zellkulturschabern vom Boden der Zellkulturplatten gelöst. Die Monozyten wurden 5 min bei 400 x g zentrifugiert, der Überstand verworfen und das Zellpellet mit $10 \mathrm{ml}$ PBS pro Ansatz gewaschen. Nach erneuter Sedimentation (wie oben) wurden die Zellen in $1 \mathrm{ml}$ PBS resuspendiert und die Zellzahl mit Hilfe einer Neubauer-Zählkammer und Trypanblau

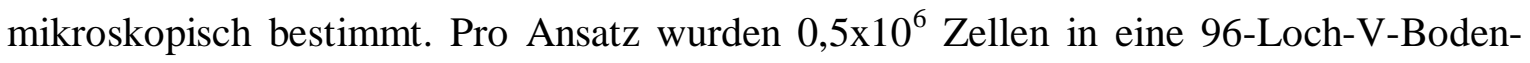
Platte gegeben, zentrifugiert $\left(400 \mathrm{x} \mathrm{g}, 5 \mathrm{~min}, 4^{\circ} \mathrm{C}\right)$ und nach Absaugen des Überstandes mit $50 \mu 1$ Blockierlösung pro Well 30 min bei $4{ }^{\circ} \mathrm{C}$ inkubiert. Die Blockierlösung diente hierbei zum Absättigen von unspezifischen Proteinbindungsstellen und zum Blockieren von Fc-Rezeptoren. Die Blockierlösung wurde anschließend abzentrifugiert (400 x g, $5 \mathrm{~min}, 4^{\circ} \mathrm{C}$ ), die Zellen mit $100 \mu 1$ Inkubationslösung gewaschen und erneut wie oben angegeben zentrifugiert. Anschließend inkubierten die Ansätze $30 \mathrm{~min}$ bei $4^{\circ} \mathrm{C}$ in $50 \mu 1$ der spezifischen Primärantikörper bzw. Isotypkontroll-Antikörper gelöst in Inkubationslösung (Tabelle 2.1, Tabelle 2.2). Die Versuchsansätze mit anti-CD14+ und den entspre- 
chenden Isotypkontrollen wurden danach zweimal mit Inkubationslösung gewaschen und dann für die Zytometrie-Messung in 1\% PFA in PBS fixiert. Hierbei wurde also eine sogenannte direkte Immunfluoreszenz durchgeführt, da der anti-CD14+-Primärantikörper mit FITC (Fluorescein-Isothiocyanat) konjugiert war. Die übrigen Proben wurden einmal mit Inkubationslösung gewaschen und nach erneuter Sedimentierung (400 x g, 5 min, $4^{\circ} \mathrm{C}$ ) mit $50 \mu 1$ Phycoerythrin (PE)-konjugierten Sekundärantikörpern in Inkubationslösung bei $4^{\circ} \mathrm{C}$ für 30 min inkubiert. Nach dreimaligem Waschen mit Inkubationslösung und anschließender Zentrifugation wurden die Versuchsansätze in 1\% PFA in PBS fixiert. Die anschließende Analyse erfolgte mit dem Durchflusszytometer FACS-Calibur (BD Biosciences, Heidelberg).

Tabelle 2.1 Blockier- und Inkubationslösung für FACS-Analysen

\begin{tabular}{|l|cccc|}
\hline \multicolumn{3}{|l}{ Blockier- und Inkubationslösung } \\
\hline Blockierlösung & PBS & $1 \% \mathrm{BSA}$ & $0,1 \% \mathrm{NaN}_{3}$ & $1 \mathrm{mg} / \mathrm{ml}$ norm. humanes Serum \\
\hline Inkubationslösung & PBS & $1 \% \mathrm{BSA}$ & $0,1 \% \mathrm{NaN}_{3}$
\end{tabular}

Tabelle 2.2 Antikörper für die FACS-Färbung

\section{Primärantikörper}

Maus $\mathrm{IgG}_{1}$ anti humanes HLA-A, -B, -C (MHC-Klasse I)

$2 \mu \mathrm{g} / \mathrm{ml}$

Maus $\mathrm{IgG}_{2 \mathrm{a}}$ anti humanes HLA-DR (MHC-Klasse II)

$2 \mu \mathrm{g} / \mathrm{ml}$

Maus $\operatorname{IgG}_{2 \mathrm{a}}$ anti humanes HLA-DR, -DP, -DQ (MHC-Klasse II)

$2 \mu \mathrm{g} / \mathrm{ml}$

Maus $\operatorname{IgG}_{2 \mathrm{a}}$ anti humanes CD14, FITC

$2 \mu \mathrm{g} / \mathrm{ml}$

Maus $\operatorname{IgG}_{2 \mathrm{a}}$ Isotyp Kontrolle G155-178, FITC

$2 \mu \mathrm{g} / \mathrm{ml}$

Maus $\operatorname{IgG}_{2 \mathrm{a}}$ Isotyp Kontrolle G155-178

$2 \mu \mathrm{g} / \mathrm{ml}$

Maus $\mathrm{IgG}_{1}$ Isotyp Kontrolle MOPC-21

$2 \mu \mathrm{g} / \mathrm{ml}$

\section{Sekundärantikörper und Konjugate}

Phycoerythrin (PE)-konjugiertes Ziege F(ab') ${ }_{2}$-Fragment anti-Maus IgG

$1: 50$ 


\subsubsection{Immunfluoreszenztest (IFT)}

Die intra- und extrazelluläre Expression von HLA-Molekülen in Abhängigkeit von der Infektion mit $T$. gondii wurde auf Einzelzellebene durch indirekte Immunfluoreszenzfärbung und anschließender Mikroskopie analysiert. Hierbei wurden die zu untersuchenden Strukturen mit spezifischen Primärantikörpern und fluorochromkonjugierten Sekundärantikörpern markiert. Außerdem wurde die Gesamtzellpopulation mit Propidiumiodid sichtbar gemacht. Durch hochauflösende, konfokale Laserscanmikroskopie konnten die Fluorchrome Carbocyanin (Cy2) und Indodicarbocyanin (Cy5) auf Grund ihrer unterschiedlichen Emissionsspektren gleichzeitig dargestellt werden.

Für den Immunfluoreszenztest wurden die THP-1-Zellen 24 h nach der zweiten Interferon- $\gamma$-Stimulation in sterilem PBS gewaschen und $1 \mathrm{~h}$ in $4 \%$ Paraformaldehyd (PFA) und 0,1 M Natriumcacodylat / HCl, pH 7,4 bei RT fixiert. Nach zweimaligem Waschen in PBS inkubierten die Zellen für $10 \mathrm{~min}$ in $50 \mathrm{mM} \mathrm{NH} \mathrm{NH}_{4}$ in PBS, um die Hintergrundfärbung zu minimieren. Nach erneutem fünfminütigem Waschen in PBS wurden die Ansätze für $1 \mathrm{~h}$ bei RT in IFT-Blockierungslösung (1\% BSA und $0,1 \mathrm{mg} / \mathrm{ml}$ Saponin in PBS) inkubiert, um unspezifische Bindungsstellen zu blockieren. Außerdem bewirkte das Saponin eine gleichzeitige Permeabilisierung der Zellwand und damit ein Eindringen von Antikörpern in die Zellen. Die Zellen wurden danach einmal mit $0,1 \mathrm{mg} / \mathrm{ml}$ Saponin in PBS gewaschen und hinterher mit Primärantikörpern markiert. Dabei wurde entweder mit anti-HLA-A, -B, -C und anti-Toxoplasma oder mit anti-HLA-DR, -DP, -DQ und antiToxoplasma Antikörpern inkubiert (Tabelle 2.3). Die Deckgläschen wurden hierzu mit der Zellseite nach unten in je einen $30 \mu$ l-Tropfen der Antikörper in IFT-Blockierungslösung gelegt. Nach 1 h Inkubation bei RT wurden überschüssige Antikörper durch dreimaliges Waschen in $0,1 \mathrm{mg} / \mathrm{ml}$ Saponin in PBS (jeweils $10 \mathrm{~min}$ ) entfernt. Anschließend wurden die Zellen mit Cy2-konjungiertem Esel anti-Maus IgG und Cy5-konjugiertem Esel antiKaninchen IgG verdünnt in IFT-Blockierungslösung wie für die Primärantikörper beschrieben inkubiert (Tabelle 2.3). Um ungebundene Antikörper zu entfernen, wurden die Zellen anschließend dreimal für $10 \mathrm{~min}$ in $0,1 \mathrm{mg} / \mathrm{ml}$ Saponin in PBS und noch einmal für 5 min in PBS gewaschen. Die Gesamtpopulation der THP-1-Zellen wurde dargestellt, indem sie für 2 min mit $5 \mu \mathrm{g} / \mathrm{ml}$ Propidiumiodid inkubiert wurden. Nach abschließendem zweimaligem Waschen in PBS wurden die Deckgläschen in entmineralisiertem Wasser gewaschen und zellseitig mit einem $10 \mu 1$ Tropfen Mowiol auf einem Objektträger fixiert und über Nacht bei RT getrocknet. Die Lagerung der Objektträger erfolgte bis zur Aus- 
wertung mittels konfokaler Laserscanmikroskopie (TCS SP2, Leica, Heidelberg) bei $4^{\circ} \mathrm{C}$ in Dunkelheit.

Tabelle 2.3 Antikörper für den Immunfluoreszenztest

\begin{tabular}{|c|c|c|c|}
\hline Primärantikörper & & Sekundärantikörper & \\
\hline $\begin{array}{l}\text { Maus } \mathrm{IgG}_{1} \text { anti human } \\
\text { HLA-A, -B, -C }\end{array}$ & $1: 100$ & $\begin{array}{l}\text { Cy2-konjugiertes Esel F(ab') }{ }_{2}- \\
\text { Fragment anti-Maus IgG }\end{array}$ & $1: 50$ \\
\hline $\begin{array}{l}\text { Maus } \operatorname{IgG}_{2 \mathrm{a}} \text { anti human } \\
\text { HLA-DR, -DP, -DQ }\end{array}$ & $1: 100$ & $\begin{array}{l}\text { Cy2-konjugiertes Esel F(ab') } \\
\text { Fragment anti-Maus IgG }\end{array}$ & $1: 50$ \\
\hline $\begin{array}{l}\text { Kaninchen anti-Toxoplasma, } \\
\text { Serum }\end{array}$ & $1: 1000$ & $\begin{array}{l}\text { Cy5-konjugiertes Esel F(ab') }{ }_{2}^{-} \\
\text {Fragment anti-Kaninchen IgG }\end{array}$ & $1: 100$ \\
\hline
\end{tabular}

\subsection{5 qRT-PCR}

Durch reverse Transkription und quantitative Real-Time-Polymerasekettenreaktion (qRT-PCR) wurde der Einfluss von T. gondii auf die Interferon- $\gamma$-induzierten mRNAMengen von HLA-Molekülen sowie ausgewählten Transkriptionsfaktoren humaner Monozyten untersucht. Hierbei wurde mRNA sowohl der Transkriptionsfaktoren IRF-1 und CIITA als auch der HLA-Moleküle HLA-A und HLA-DR $\alpha$ mit Hilfe des Enzyms Reverse Transkriptase in cDNA umgeschrieben und anschließend mittels spezifischer Primer IRF-1, CIITA, HLA-A, HLA-DR $\alpha$ durch LightCycler-PCR amplifiziert. Konstitutiv exprimiertes $\beta$-Actin wurde zur Normalisierung der mRNA-Menge verwendet. Die kontinuierlich gemessene Fluoreszenz während des PCR-Vorgangs erlaubte eine quantitative Aussage über die in der Probe enthaltene Menge cDNA und - rückschließend mRNA. Dies ermöglichte im Ergebnis eine Beurteilung der Expressionsmuster der analysierten Gene in den unterschiedlich behandelten Zellpopulationen.

\subsubsection{RNA-Isolation}

Die THP-1-Zellen wurden $24 \mathrm{~h}$ nach der Interferon- $\gamma$-Stimulation mit einem Zellkulturspatel vom Boden der 6-Loch-Platten gelöst und in 50-ml-Falcon-Röhrchen gefüllt. Die 6-Loch-Platten wurden mit DEPC-PBS nachgespült und restliche Zellen mit der Zellsuspension in den Röhrchen zusammengeführt. Das DEPC-PBS sorgte dabei für eine schnelle Inhibition von Ribonukleasen und stand somit dem vorzeitigen Abbau von mRNA entgegen. Die RNA-Isolation erfolgte mit dem GenElute Mammalian Total RNA Kit (Sigma, München) entsprechend den Angaben des Herstellers. Am Ende des Protokolls wurde die membrangebundene RNA in $100 \mu$ l Ribonuklease-freiem Wasser 
eluiert. Man erhielt mit dieser Methode RNA-Moleküle von mindestens 200 bp; kleinere RNA-Moleküle konnten so aus der Membran gewaschen werden. Die Proben wurden bei $-80^{\circ} \mathrm{C}$ eingefroren und eine geringe Menge für die Konzentrationsbestimmung mit Hilfe der Photometrie zurückbehalten. Die Absorption der eluierten RNA wurde bei einer Verdünnung von $1: 10$ bei $260 \mathrm{~nm}$ gemessen; $40 \mu \mathrm{g} / \mathrm{ml}$ mRNA entsprachen dabei einer Absorptionseinheit. Im Anschluss wurde die RNA-Menge nach folgender Formel bestimmt:

\section{RNA-Konzentration $[\mu \mathrm{g} / \mathrm{ml}]=0 D 260 \times 40[\mu \mathrm{g} / \mathrm{ml}] \times$ Verdünnungsfaktor}

\section{Formel 2.1 Berechnung der RNA-Konzentration}

Die RNA-Konzentration berechnet sich aus der optischen Dichte (OD260) multipliziert mit einer RNA-Absorptionseinheit $(40 \mu \mathrm{g} / \mathrm{ml})$ und dem Faktor der Verdünnung.

\subsubsection{Reverse Transkription}

Für die quantitative RT-PCR wurde mit Hilfe der reversen Transkription und Oligo-dTPrimern einzelsträngige, komplementäre cDNA anhand der mRNA-Matrize erstellt. Dazu wurde das retrovirale Enzym Reverse Transkriptase genutzt, das vor allem von RNAViren wie z.B. HIV zur Transkription ihres RNA-Genoms in DNA verwendet wird. Das Enzym benötigt zu Synthesebeginn ein Startermolekül (Primer) in Form eines kurzen einzelsträngigen Oligonukleotids. Hierfür wurde ein Oligo-dT-Primer eingesetzt.

Für die reverse Transkription wurde in Eppendorf-Reaktionsgefäßen zunächst auf Eis ein Reaktionsmix gemäß Pipettierschema und mit Hilfe des Omniscript Reverse Transkriptase Kits (Qiagen, Hilden) angesetzt.

Tabelle 2.4 Reaktionsmix für reverse Transkription

\begin{tabular}{|c|c|}
\hline $\begin{array}{l}\text { Reakti } \\
\text { (Meng }\end{array}$ & $\begin{array}{l}\text { nsmix für reverse Transkription } \\
\text { a pro DNA-Probe) }\end{array}$ \\
\hline $3,0 \mu 1$ & RT-Puffer \\
\hline $2,0 \mu 1$ & dNTP \\
\hline $0,4 \mu 1$ & Oligo-dT-Primer \\
\hline $1,0 \mu 1$ & Ribonuklease Inhibitor $(10 \mathrm{U} / \mu \mathrm{l})$ \\
\hline $1,0 \mu \mathrm{l}$ & Reverse Transkriptase $(4 \mathrm{U} / \mu \mathrm{l})$ \\
\hline
\end{tabular}

Die RNA-Proben wurden mit je einem Ansatz des Reaktionsmix in Eppendorf-Gefäße gemischt. Um in jedem Reaktionsgefäß die gleiche Konzentration RNA sicherzustellen, 
richtete sich das RNA-Volumen jeder Probe nach der Probe mit der geringsten Konzentration RNA. Das fertige Reaktionsgemisch wurde ad $30 \mu$ l Volumen mit Ribonukleasefreiem Wasser aufgefüllt und auf einem Schüttler für $2 \mathrm{~h}$ bei $37^{\circ} \mathrm{C}$ inkubiert. Anschließend wurde die cDNA bei $-20^{\circ} \mathrm{C}$ gelagert.

\subsubsection{Quantitative PCR}

Mit Hilfe der quantitativen Polymerasekettenreaktion (qPCR) mit dem LightCycler (Roche, Mannheim) wurde anschließend die Menge an spezifischer cDNA als Maß der Interferon- $\gamma$-induzierten Expression von HLA-Molekülen, CIITA und IRF-1 in infizierten und nicht-infizierten Populationen auf Transkriptionsebene bestimmt. Die in den Proben enthaltene cDNA der Transkriptionsfaktoren IRF-1 und CIITA sowie von HLA-A und HLA-DR $\alpha$ wurde hierzu mittels spezifischer Primer im LightCycler amplifiziert. Bei der qPCR folgte nach jedem Amplifikations-Zyklus eine Bestimmung des DNA-Gehaltes durch die Messung des Doppelstrang-DNA-bindenden Fluoreszenzfarbstoffs SYBR Green. Je mehr der gesuchten DNA in der Probe enthalten war, desto weniger Zyklen waren notwendig, um den Schwellenwert (Crossing Point [CP]) einer signifikant messbaren Fluoreszenz von SYBR Green zu erreichen. Um Unterschiede bei der RNAIsolierung oder der Reversen Transkription zwischen den einzelnen Proben vernachlässigen zu können, wurde eine relative Quantifizierung von HLA-A, HLA-DR $\alpha$, CIITA und IRF-1 durchgeführt. Hierzu wurde zunächst die Effizienz der PCR anhand von Standardkurven aus cDNA Verdünnungsreihen ermittelt. Aus der Steigung der linearen Regression ließ sich die Effizienz der PCR mit Hilfe der Formel E $=10^{[-1 / \text { Steigung }]}$ errechnen. Die PCR-Ergebnisse der einzelnen Zielgene wurden mit dem ubiquitär und konstitutiv exprimierten Referenzgen $\beta$-Actin ins Verhältnis gesetzt und mit folgender Formel relativ quantifiziert (Pfaffl 2001):

Ratio $=\left(E_{\text {Zielgen }}\right)^{\Delta C P \text { (nicht-stimul. - stimul.) }} /\left(E_{\beta-\text { Actin }}\right)^{\Delta C P \text { (nicht-stimul. - stimul.) }}$

\section{Formel 2.2 Effizienz-korrigierte relative Quantifizierung von mRNA}

Bei der relativen Quantifizierung wird die Expression eines Zielgens in Bezug auf ein nicht-reguliertes ${ }_{2}$ Housekeeping Gen“ (HKG) - hier $\beta$-Actin - gesetzt. Für eine genauere Betrachtung fließen die unterschiedlichen RT-PCR-Effizienzen der untersuchten Faktoren mit in die Berechnung ein (Pfaffl 2001).

Da sich die Effizienzen der Amplifikate nicht deutlich unterschieden und jeweils etwa 2 betrugen, wurde eine Effizienz von 2 zu Grunde gelegt. Die Ratio der $\Delta \mathrm{CP}$-Verhältnisse 
zur Basis $\mathrm{E}=2$ wurde sowohl bei nicht-infizierten als auch infizierten (Parasit-zuWirtszellverhältnissen von 5:1 und 10:1) Populationen berechnet.

Für die qPCR-Reaktion wurde ein Reaktionsansatz aus einem Mastermix und der cDNA zusammengestellt. Der Mastermix beinhaltete den Primer (Sigma, Stammlösung $5 \mu \mathrm{M}$ ), den LightCycler Reaktionsmix SYBR Green (Roche), sowie $\mathrm{H}_{2} \mathrm{O}$ (Roche) und wurde auf Eis gekühlt gemischt. In $20 \mu$ l PCR-Kapillaren wurden jeweils $18 \mu 1$ Mastermix und $2 \mu 1$ DNA (1:5 verdünnt) pipettiert, 1 min bei $1000 \mathrm{x}$ g zentrifugiert und die cDNA im LightCycler amplifiziert. Der Reaktionsansatz und das Amplifikationsprotokoll sind in Tabelle 2.5 und Tabelle 2.6 angegeben. Zur Kontrolle der Größe wurden die PCR-Produkte im Anschluss an die Real-Time-PCR durch Zentrifugation aus den PCR-Kapillaren isoliert und durch Elektrophorese im Agarosegel sichtbar gemacht (2.2.6).

Tabelle 2.5 Reaktionsansatz der qPCR

\begin{tabular}{|rl|}
\hline Reaktionsansatz der qPCR \\
$2 \mu 1$ & cDNA \\
$1 \mu 1$ & Primer, forward $(5 \mu \mathrm{M})$ \\
$1 \mu 1$ & Primer, reverse $(5 \mu \mathrm{M})$ \\
$4 \mu \mathrm{l}$ & Reaktionsmix (Roche) \\
$12 \mu \mathrm{l}$ & $\mathrm{H}_{2} \mathrm{O}$ (Roche) \\
\hline
\end{tabular}

Tabelle 2.6 Amplifikationsprotokoll der qPCR

\begin{tabular}{lllc} 
Primer & Abschnitt & Temp. & Zeit \\
Alle & Initiale Denaturierung & $95^{\circ} \mathrm{C}$ & $10 \mathrm{~min}$ \\
Alle & Denaturierung * & $95^{\circ} \mathrm{C}$ & $10 \mathrm{sec}$ \\
HLA-A & Annealing * & $60^{\circ} \mathrm{C}$ & $10 \mathrm{sec}$ \\
$\beta$-Actin, IRF-1, & & & \\
CIITA, HLA-DRA & Annealing * & $64^{\circ} \mathrm{C}$ & $10 \mathrm{sec}$ \\
Alle & Extension * & $72^{\circ} \mathrm{C}$ & $10 \mathrm{sec}$ \\
Alle & Denaturierung & $95^{\circ} \mathrm{C}$ & $0 \mathrm{sec}$ \\
Alle & Annealing & $64^{\circ} \mathrm{C}$ & $60 \mathrm{sec}$ \\
Alle & Schmelzkurve & $95^{\circ} \mathrm{C}$ & $0 \mathrm{sec}$ \\
Alle & Cooling & $40^{\circ} \mathrm{C}$ & $30 \mathrm{~min}$ \\
\hline
\end{tabular}

* Amplifikation: 42 Zyklen 


\subsubsection{Agarosegel-Elektrophorese}

Als Kontrolle des oben genannten Verfahrens der qPCR wurde eine Elektrophorese in einem Agarosegel durchgeführt, in der sich die PCR-Produkte ihrer Größe nach auftrennten und anhand eines Markers in ihrer Größe bestimmt und mit der zu erwartenden Größe verglichen werden konnten. Dazu wurde mit TAE-Puffer ein 1\%iges Agarosegel angesetzt und mit $1 \mu 1$ Ethidiumbromid (Stammlösung $10 \mathrm{mg} / \mathrm{ml}$ ) pro $10 \mathrm{ml}$ Gellösung versetzt, um DNA-Fragmente mittels UV-Licht sichtbar zu machen. $10 \mu 1$ der jeweiligen DNA und je $1 \mu 1$ 10x Proben-Puffer wurden dann in die einzelnen Gel-Taschen gefüllt. Für die Größenbestimmung der DNA-Fragmente wurde in eine weitere Gel-Tasche ein $1 \mathrm{~kb}$ DNAMolekulargewichtsmarker aufgetragen. Die Elektrophorese wurde bei $120 \mathrm{~V}$ für ca. 30 min durchgeführt, die fertigen Bandenmuster wurden bei ultraviolettem Licht unter einem Transilluminator sichtbar gemacht und fotografiert.

Tabelle 2.7 Puffer für Agarosegel-Elektrophorese

\begin{tabular}{|rl}
\hline 10x Probenpuffer \\
$0.07 \%$ & Bromphenolblau \\
$33 \%$ & Glycerin \\
$7 \%$ & SDS \\
& in TES
\end{tabular}

\begin{tabular}{|ll} 
TES & \\
$0.05 \mathrm{M}$ & Tris \\
$0.005 \mathrm{M}$ & EDTA \\
$0.05 \mathrm{M}$ & $\mathrm{NaCl}$ \\
& $\mathrm{pH} 8,0$ \\
\hline
\end{tabular}

\begin{tabular}{|rl|}
\hline TAE-Puffer \\
$40 \mathrm{mM}$ & Tris \\
$1 \%$ & Essigsäure \\
$1 \mathrm{mM}$ & EDTA \\
& $\mathrm{pH} 8,0$ \\
\hline
\end{tabular}

\subsubsection{Datenverarbeitung}

Für die Datenerfassung und -analyse der Durchflusszytometrie wurde das Softwareprogramm CellQuest $^{\circledR}$ Pro (ver. 5.2.1, BD Biosciences) benutzt. Die Auswertung und graphische Darstellung erfolgte mit Microsoft Excel $^{\odot}$ und SigmaPlot ${ }^{\odot}$ bzw. für eindimensionale Histogramme und zweidimensionale Punkt-Bilder (Dot-Plots) mit CellQuest ${ }^{\circledR}$ Pro. 


\subsubsection{Statistische Analyse}

Für die statistische Analyse der Experimente kam das Softwareprogramm Statistica 8 zum Einsatz. Die Ergebnisse der Versuche wurden als Mittelwerte \pm Standardfehler (SE) des Mittelwertes von mindestens drei voneinander unabhängigen Experimenten angegeben. Durch den Student's $t$-Test bzw. Varianzanalyse (ANOVA) wurden signifikante Unterschiede zwischen den Mittelwerten zweier oder mehrerer Ansätze ermittelt. P-Werte wurden mit der Anzahl der statistischen Vergleiche multipliziert (Bonferri-Korrektur). Als signifikant wurden Werte von $\mathrm{p}<0,05$ gewertet, hochsignifikant galten Werte von $\mathrm{p}<0,01$. 


\section{Ergebnisse}

\subsection{Toxoplasma gondii inhibiert Dosis-abhängig die HLA-Expression in humanen Makrophagen}

T. gondii hat für sein Überleben im immunkompetenten Wirt verschiedene Evasionsmechanismen entwickelt, durch die effektive Immunantworten vermieden oder moduliert werden (1.3). Frühere Arbeiten mit murinen Monozyten (Lang et al. 2006) zeigten, dass ein solcher Mechanismus die Hemmung der Expression von MHC-Klasse-II-Molekülen auf der Oberfläche Toxoplasma-infizierter Wirtszellen ist. Das Ziel der vorliegenden Arbeit war es herauszufinden, inwieweit dieser Evasionsmechanismus auch nach Infektion humaner Monozyten auftritt.

Die Infektionsversuche wurden mit humanen, aus PBMC isolierten primären Monozyten durchgeführt, da Versuche mit diesen ex-vivo-Zellen Ergebnisse mit hoher Aussagekraft für den menschlichen Organismus erwarten ließen. Darüberhinaus wurde der Einfluss von T. gondii auf humane permanente Monozyten der Zelllinie THP-1 untersucht, da sie den primären Monozyten sehr ähnliche Eigenschaften aufweisen (Tsuchiya et al. 1980), aber einfacher zu kultivieren waren.

\subsubsection{Primäre Monozyten aus PBMC}

Primäre, humane Monozyten wurden aus dem peripheren Blut des Menschen isoliert (2.2.1.2) und in Parasit-zu-Wirtszell-Verhältnissen von 1,5:1 und 3:1 mit T. gondii infiziert bzw. nicht infiziert belassen. Die Hälfte der Ansätze wurde anschließend mit IFN- $\gamma$ für $48 \mathrm{~h}$ stimuliert bevor die Zellen mit Antikörpern markiert und durchflusszytometrisch analysiert wurden (2.2.2.2). Dazu wurde zunächst der Anteil an primären Monozyten an den aus PBMC isolierten Zellen untersucht (Abb. 3.1). Im Durchschnitt waren $78,8 \%( \pm 3,9 \%)$ der analysierten Zellen CD14-positiv und damit den Monozyten zuzurechnen; $11,2 \%( \pm 2,3 \%)$ betrug in der Analyse der Anteil der Isotyp-Kontrolle (Anhang, Tabelle 7.1). 

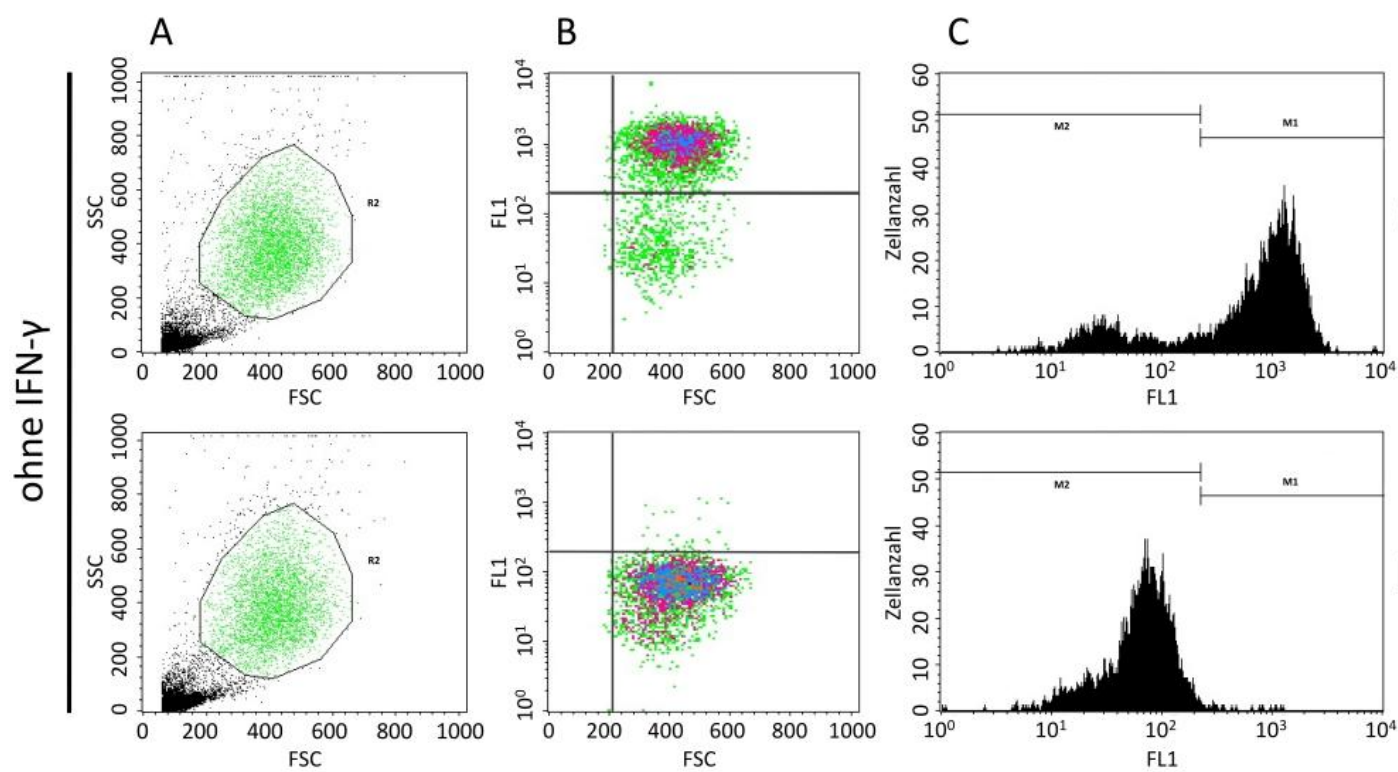

CD14+
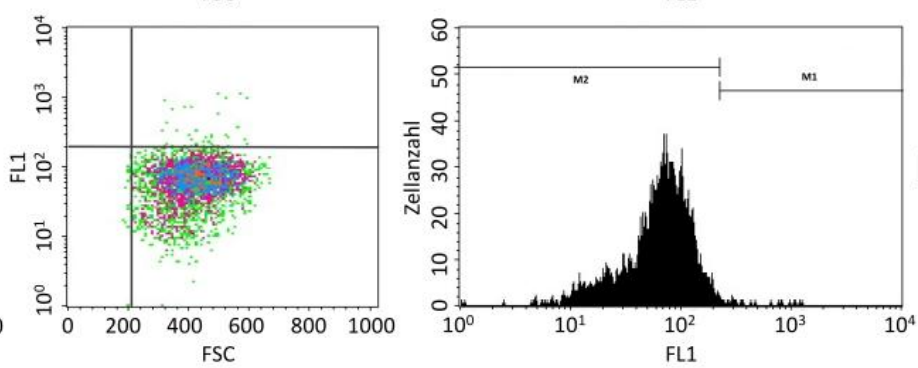

Isotyp
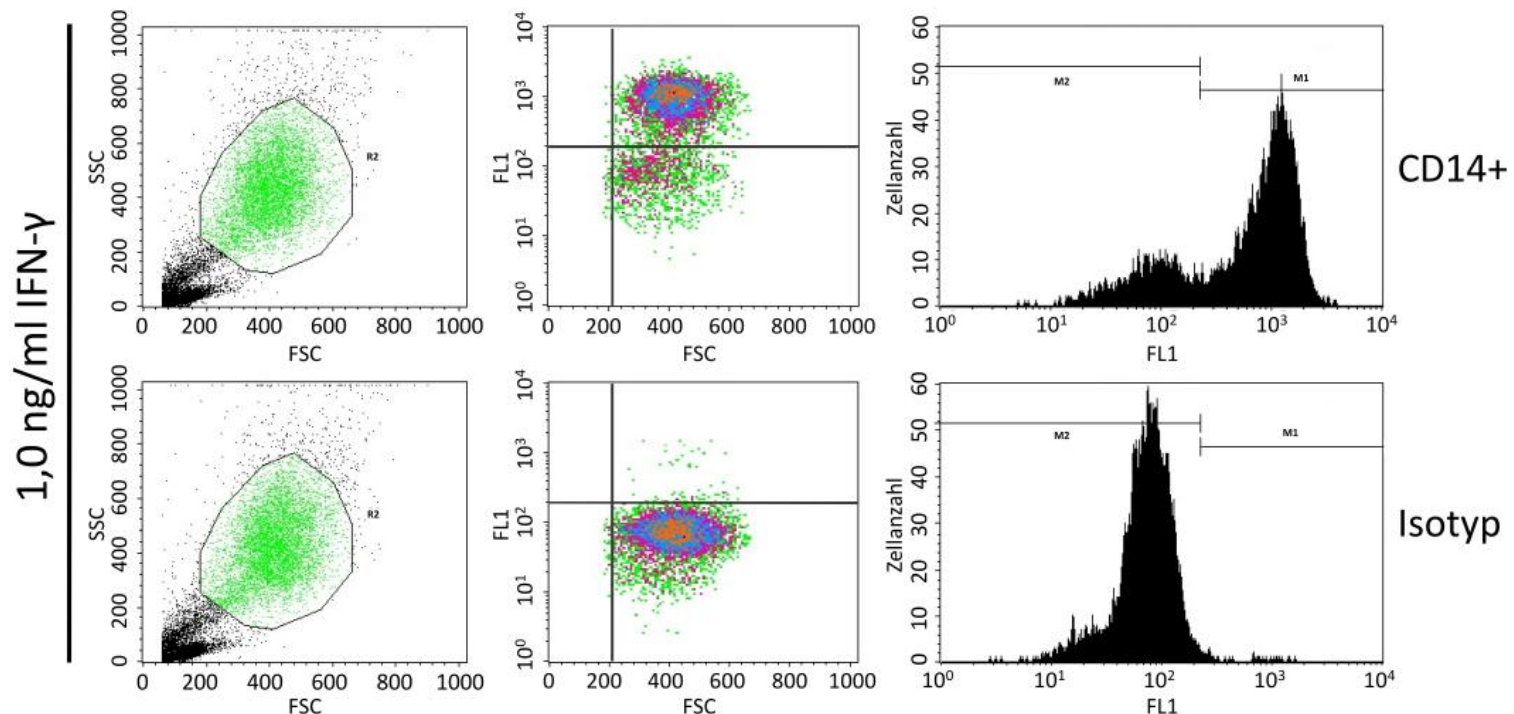

Abb. 3.1 Anteil von Monozyten (CD14 $\left.{ }^{+}\right)$in isolierten mononukleären Zellen des peripheren Blutes

Dargestellt sind Dot-Plot-Grafiken und Histogramme durchflusszytometrischer Untersuchungen von mononukleären Zellen des peripheren Blutes (PBMC), die mit Interferon- $\gamma$ stimuliert wurden bzw. unstimuliert blieben. Nach dem Setzen von FSC- und SSC-Gates (R2) in den Dot-Plot-Grafiken, konnte der Anteil CD14positiver Zellen identifiziert und den primären Monozyten zugeordnet werden. In gleicher Weise wurde mit den korrespondierenden Isotyp-Kontrollen verfahren.

Bezüglich der MHC-Klasse-I-Expression zeigten die durchflusszytometrischen Analysen, dass die konstitutive (d. h. in Abwesenheit von Interferon- $\gamma$ ) HLA-A-, -B-, -C-Expression von primären Monozyten durch T. gondii eindeutig reduziert wurde (Abb. 3.2). Nach einer Stimulation der Zellen mit Interferon- $\gamma$ wurde eine Hochregulation von HLA-A, -B, -C in nicht-infizierten primären Monozyten beobachtet. In IFN- $\gamma$-stimulierten Monozyten führte 
eine Infektion mit T. gondii jedoch zu einer starken Inhibierung der HLA-A-, -B-, -CExpression.

Primäre Monozyten exprimierten konstitutiv auch HLA-DR-, -DP-, -DQ-Moleküle und reagierten nach Interferon- $\gamma$-Zugabe im Durchschnitt nur mit einer leichten Hochregulation. Vergleichbar mit dem inhibitorischen Effekt bei HLA-A, -B, -C hemmte T. gondii die Expression von HLA-DR-, -DP-, -DQ-Molekülen in Abwesenheit von Interferon- $\gamma$ sehr deutlich (Abb. 3.2). Auch nach IFN- $\gamma$-Stimulation der Monozyten wurde eine starke Inhibition der HLA-DR-, -DP-, -DQ-Expression durch T. gondii auf der Oberfläche von primären Monozyten beobachtet (Abb. 3.2). Die Inkubation der Monozyten mit IsotypAntikörpern führte nur zu geringer Hintergrundfluoreszenz, wodurch die Spezifität der anti-HLA-Färbungen bestätigt wurde (Abb. 3.2).
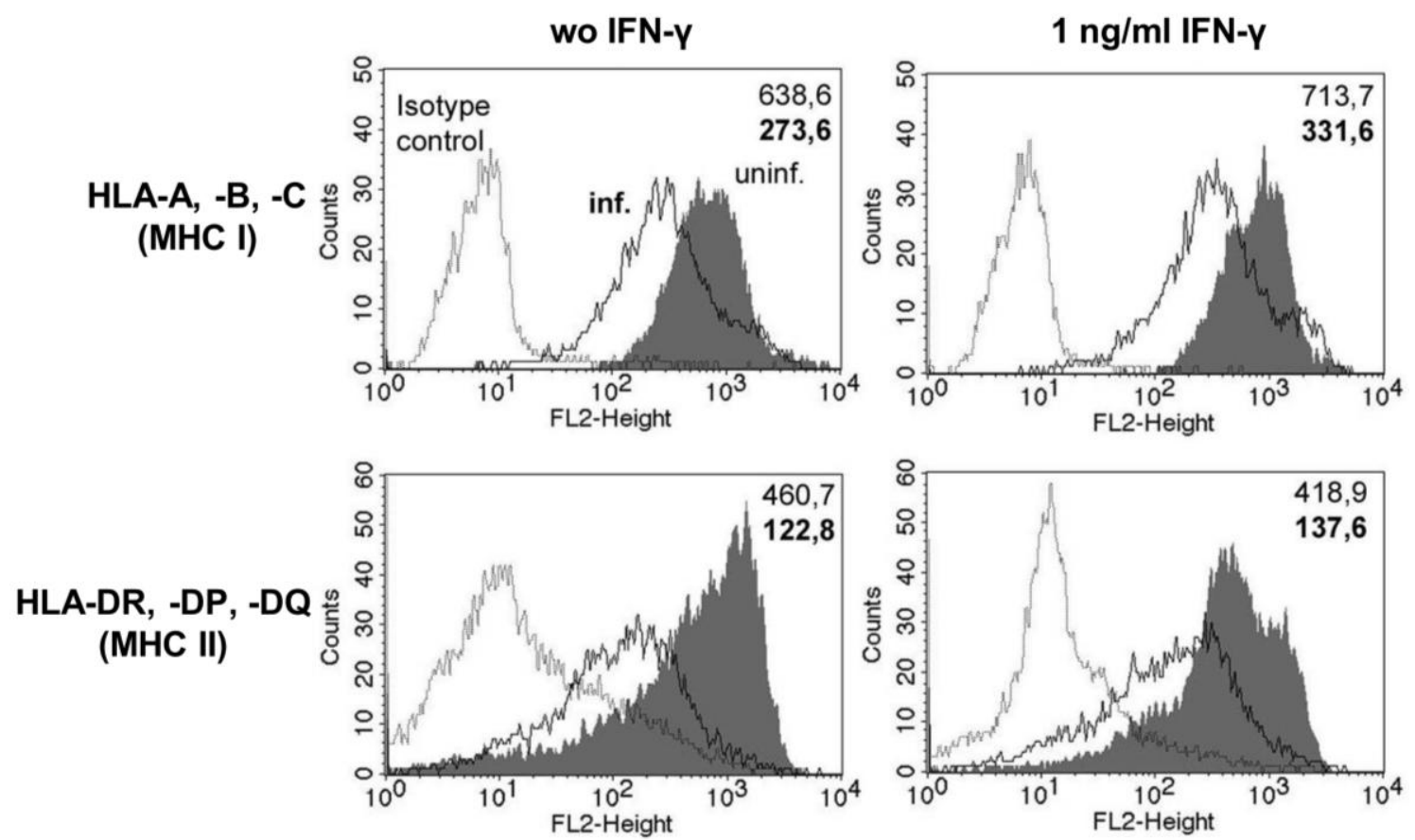

\section{Abb. 3.2 Hemmung der HLA-A-, -B-, -C- und der HLA-DR-, -DP-, -DQ-Expression nach Infektion primärer Monozyten mit T. gondii}

Aus PBMC isolierte primäre Monozyten wurden in einem Parasit-zu-Wirtszell-Verhältnis von 3:1 infiziert bzw. uninfiziert belassen. Für eine Hälfte der Ansätze schloss sich eine Stimulation mit IFN-y und nach $24 \mathrm{~h}$ eine Re-Stimulation an. $24 \mathrm{~h}$ später wurden die Zellen mit spezifischen Antikörpern oder Isotypkontroll-Antikörpern markiert und durchflusszytometrisch analysiert. Dargestellt sind die Fluoreszenzintensität als Maß der HLA-A, -B-, -C- und HLA-DR-, -DP-, -DQ-Expression und die geometrischen Mittelwerte eines exemplarischen Versuches; ähnliche Resultate zeigten andere Experimente dieser Versuchsreihe. Die HLA-Expression nichtinfizierter Zellen (grau-gefüllte Kurve / Normale Schrift) wurde mit T. gondii-infizierten Populationen (schwarze Linie / Fette Schrift) verglichen und der inhibitorische Einfluss von T.gondii auf IFN- $\gamma$-stimulierte Zellen untersucht. Die Fluoreszenzen der Isotypkontroll-Färbung (graue Linie) bei beiden MHC-Klassen bestätigten die Spezifität der Antikörperfärbung. 
Nach Auswertung der FACS-Analyse von Monozyten von 12 verschiedenen Blutspendern zeigte sich, dass die konstitutive Expression von HLA-A, -B, -C und HLA-DR, -DP, -DQ nach Infektion mit $T$. gondii im Durchschnitt nur geringfügig aber dosisabhängig abnahm (Abb. 3.3). Die Aktivierung der Monozyten mit IFN- $\gamma$ führte zu einer deutlich erhöhten Expression von HLA-A, -B, -C und HLA-DR, -DP, -DQ in nicht-infizierten Zellen, diese Hochregulation war bei gleichzeitiger Infektion mit $T$. gondii dosisabhängig vermindert (Abb. 3.3). Dabei waren bei einem Parasit-zu-Wirtszell-Verhältnis von 1,5:1 und 3:1 Interferon- $\gamma$-stimulierte, primäre Monozyten in der HLA-A-, -B-, -C-Expression statistisch signifikant gehemmt. Die durch IFN- $\gamma$ hochregulierte HLA-DR-, -DP-, -DQ-Expression war bei einem Parasit-zu-Wirtszell-Verhältnis von 3:1 sogar hoch signifikant inhibiert (Abb. 3.3).

Nach Färbung der Zellen mit Isotypkontroll-Antikörpern wurden keine statistisch signifikanten Unterscheide zwischen Toxoplasma-infizierten und nicht-infizierten primären humanen Monozyten festgestellt (Abb. 3.3).
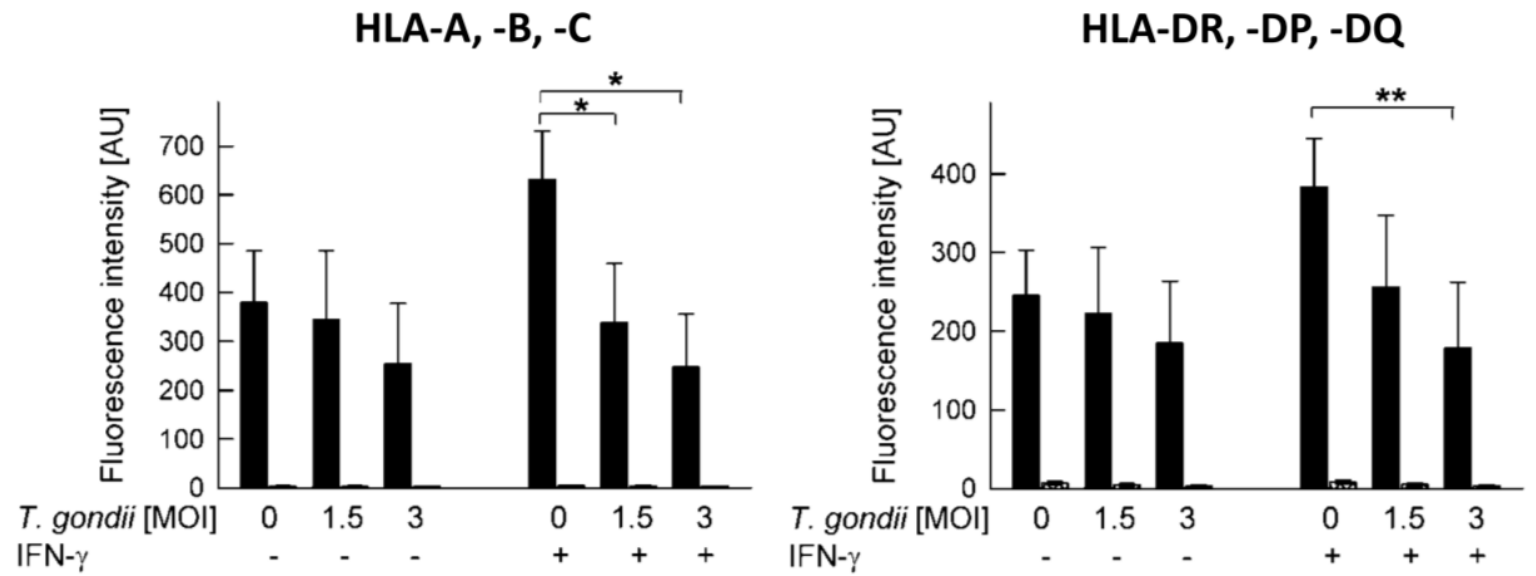

Abb. 3.3 Die Expression von HLA-Molekülen in primären Monozyten korreliert mit der T. gondii-Infektionsrate Aus PBMC isolierte Monozyten wurden in einem Parasit-zu-Wirtszell-Verhältnis von 1,5:1 und 3:1 mit T. gondii infiziert bzw. uninfiziert belassen. Anschließend wurde die Hälfte der Proben mit IFN- $\gamma$ stimuliert, $24 \mathrm{~h}$ später restimuliert und nach weiteren $24 \mathrm{~h}$ durchflusszytometrisch analysiert. Dargestellt sind die Mittelwerte der FACS-Fluoreszenzen von HLA-A, -B, -C und HLA-DR, -DP, -DQ auf der Oberfläche von IFN- $\gamma$-stimulierten und nichtstimulierten primären Monozyten von 12 verschiedenen Blutspendern (schwarze Balken). Die geringe Fluoreszenz der Isotypkontroll-Färbung zeigt die Spezifität der HLA-Antikörper (gestreifte Balken). Gekennzeichnet ist die signifikante $(* ; p<0,05)$ und hoch signifikante $(* * ; p<0,01)$ Inhibition durch T. gondii. 


\subsubsection{THP-1}

Da permanente Monozyten in größeren Mengen zu isolieren und einfacher zu kultivieren sind, und in ihren Eigenschaften primären Monozyten aus PBMC ähneln (Tsuchiya et al. 1980), wurden durchflusszytometrische Messungen auch an THP-1-Monozyten vorgenommen. Dafür wurden Zellkulturen im Parasit-zu-Wirtszell-Verhältnis von 2,5:1, 5:1, 10:1 und 20:1 infiziert, wobei eine Kontrollkultur T. gondii-frei blieb. Die Hälfte der Ansätze wurde mit Interferon- $\gamma$ stimuliert und nach $24 \mathrm{~h}$ restimuliert (2.2.2.3). Nach weiteren $24 \mathrm{~h}$ Inkubation erfolgte die Antikörper-Markierung und FACS-Analyse wie in 2.2.3 beschrieben.

Messungen im Durchflusszytometer ergaben, dass THP-1-Zellen auf ihrer Oberfläche konstitutiv, d.h. in Abwesenheit von Interferon- $\gamma$, HLA-A-, -B-, -C-Moleküle exprimierten, die nach Stimulation mit Interferon- $\gamma$ deutlich hochreguliert wurden (Abb. 3.4). Eine Infektion von THP-1-Monozyten mit T. gondii führte zur starken Inhibierung vor allem der IFN- $\gamma$-induzierten, aber in geringerem Maße auch der konstitutiven HLA-A-, -B-, -CExpression. Dabei war die Expression von HLA-A, -B, -C nach IFN- $\gamma$-Stimulation und Toxoplasma-Infektion auf ähnliche Level reduziert wie in der nicht-stimulierten $T$. gondiipositiven Kultur (Abb. 3.4).

Im Gegensatz zu primären humanen Monozyten zeigten THP-1-Zellen in Abwesenheit von Interferon- $\gamma$ nur eine geringe HLA-DR-, -DP-, -DQ-Expression, die durch T. gondii auch nur geringfügig reduziert war. IFN- $\gamma$ führte wie erwartet zu einer deutlichen Induktion der HLA-DR-, -DP-, -DQ-Expression, welche nach vorheriger Infektion mit T. gondii jedoch sehr deutlich gehemmt war (Abb. 3.4).

Die Färbung der Zellen mit Isotypkontroll-Antikörpern führte nur zu geringer Fluoreszenzintensität, wodurch die Spezifität der HLA-spezifischen Färbungen bestätigt wurde (Abb. 3.4). 


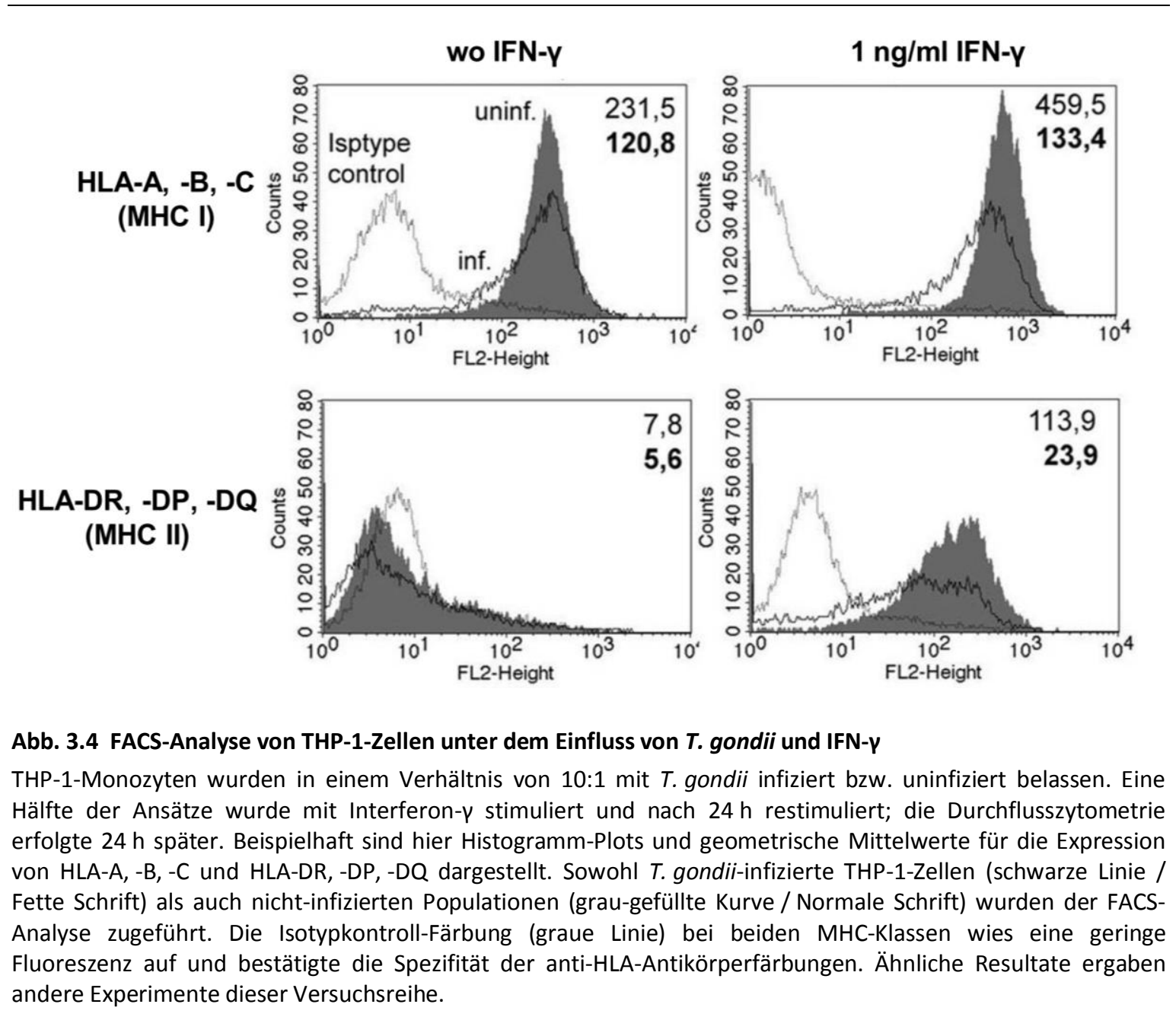

Ähnlich dem in Abb. 3.4 exemplarisch dargestellten Einzelexperiment zeigten auch die Mittelwerte aller FACS-Fluoreszenzen dieser Versuchsreihe eine konstitutive Expression von HLA-A, -B, -C und deren Interferon- $\gamma$-induzierte Hochregulation (Abb. 3.5). HLA-DR-, -DP-, -DQ-Moleküle wurden dagegen erst nach Stimulation von THP-1-Zellen mit Interferon- $\gamma$ exprimiert. Durch Einsatz von verschiedenen Infektionsraten von T. gondii konnte gezeigt werden, dass die Hemmung der Expression von HLA-A, -B, -C wie auch von HLA-DR, -DP, -DQ deutlich mit der Infektionsdosis der Parasiten korrelierte (Abb. 3.5). So führte eine steigende Dosis von T. gondii sowohl bei Interferon- $\gamma$ stimulierten als auch bei nicht-stimulierten THP-1-Populationen zu einer zunehmenden Inhibition beider MHC-Klassen. Lediglich die äußerst geringe HLA-DR-, -DP-, -DQExpression von nicht-stimulierten Monozyten unterschied sich auch nach zunehmender Infektionsdosis nicht deutlich von der $T$. gondii-freien Kontrolle.

Statistische Analysen belegten, dass die konstitutive Expression von HLA-A, -B, -C bei einer Infektionsdosis von 2,5:1 und 20:1 signifikant und bei einem Verhältnis von 10:1 
hoch signifikant gehemmt war (Abb. 3.5). Die Interferon- $\gamma$-induzierte Expression beider MHC-Klassen wurde durch T. gondii bei einem Parasit-zu-Wirtszellverhältnis von 5:1, 10:1 und 20:1 signifikant gehemmt; bei HLA-A, -B, -C führte ein Verhältnis von 10:1 zu einer hoch signifikanten Reduktion der Expression.

Nach Färbung der Zellen mit Isotypkontroll-Antikörpern wurden keine statistisch signifikanten Unterscheide zwischen Toxoplasma-infizierten und nicht-infizierten THP-1Monozyten festgestellt.
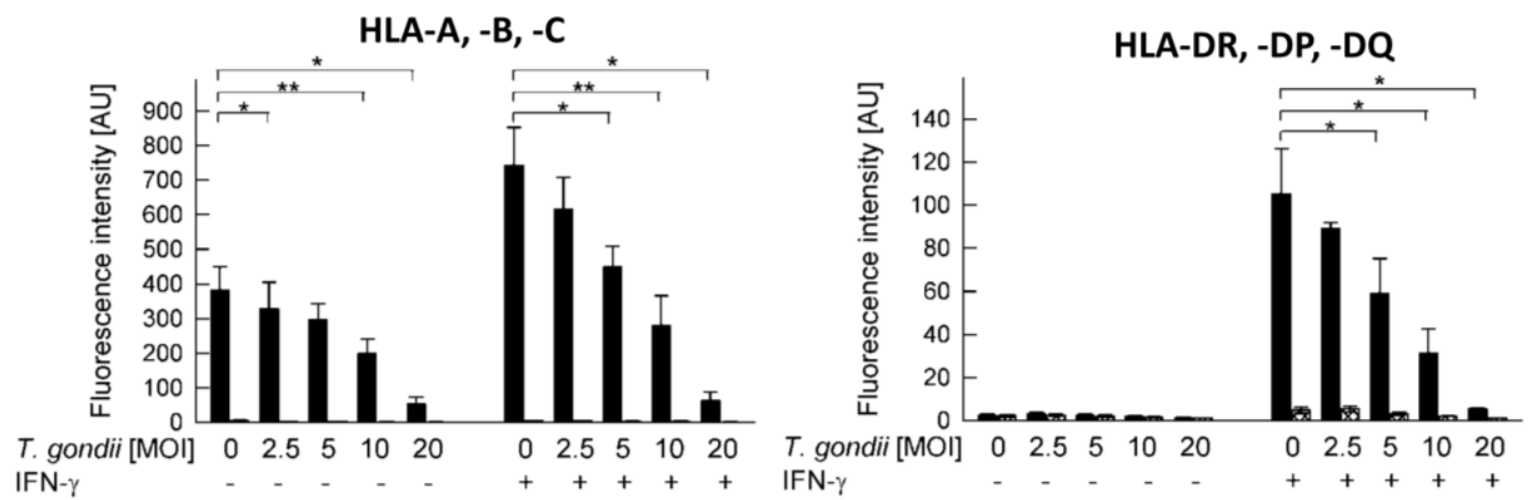

Abb. 3.5 HLA-Inhibierung in THP-1-Monozyten in Abhängigkeit der T. gondii-Infektionsrate

THP-1-Zellen wurden in Parasit-zu-Wirtszell-Relationen von 2,5:1-20:1 mit T. gondii infiziert bzw. blieben uninfiziert. Für die Hälfte der Populationen schloss sich eine Stimulation und $24 \mathrm{~h}$ später eine Re-Stimulation mit IFN- $\gamma$ an. $24 \mathrm{~h}$ später folgte die Analyse durch Durchflusszytometrie. Dargestellt sind die Mittelwerte der Fluoreszenzen von HLA-A, -B, -C und HLA-DR, -DP, -DQ mit IFN- - -stimulierten und nicht-stimulierten THP-1-Zellen (schwarze Balken). Die Spezifität der Antikörper-Färbungen wurde durch eine sehr geringe Fluoreszenz der Isotypkontroll-Färbung bestätigt (gestreifte Balken). Gekennzeichnet ist eine signifikante $(* ; p<0,05)$ bzw. hoch signifikante $\left({ }^{* *} ; p<0,01\right)$ Inhibition durch T. gondii.

Zusammenfassend zeigen diese Experimente, dass T. gondii die Expression von HLA-A, -B, -C und HLA-DR, -DP, -DQ sowohl in primären Monozyten (PBMC) als auch in permanenten Monozyten (THP-1) signifikant hemmt. Der Grad dieser Inhibition ist sowohl bei Interferon- $\gamma$-stimulierten als auch unstimulierten Populationen unmittelbar von der Infektionsdosis abhängig. 


\subsubsection{Inhibition der HLA-Expression auf Einzelzellebene}

Um Einblicke in mögliche Mechanismen der verminderten HLA-Expression durch Toxoplasma gondii zu erhalten, wurden infizierte und nicht-infizierte THP-1-Populationen mit Hilfe der Immunfluoreszenz-Mikroskopie auf Einzelzellebene untersucht. Dabei konnte die Expression von HLA-DR, -DP, -DQ, durch permeabilisierte MonozytenZellwände sowohl intra- als auch extrazellulär betrachtet (Abb. 3.6) und in Bezug zu einer T. gondii-Infektion der individuellen Zelle bzw. der gesamten Zellpopulation gesetzt werden.

Hierzu wurden THP-1-Zellen mit PMA aktiviert und im Parasit-zu-Wirtszell-Verhältnis von 2:1 und 5:1 mit Toxoplasma gondii infiziert, bzw. uninfiziert belassen. Die Hälfte der Ansätze wurde mit Interferon- $\gamma$ stimuliert und nach $24 \mathrm{~h}$ restimuliert (2.2.2.3). Nach weiteren $24 \mathrm{~h}$ Inkubation wurden die Zellen permeabilisiert, mit Antikörpern gegen HLA-DR, -DP, -DQ und T. gondii sowie entsprechenden Fluorochrom-markierten Sekundärantikörpern gefärbt. Eine anschließende Behandlung mit Propidiumiodid machte die Gesamtpopulation der Zellen für das Laserscanmikroskop sichtbar (Abb. 3.6).

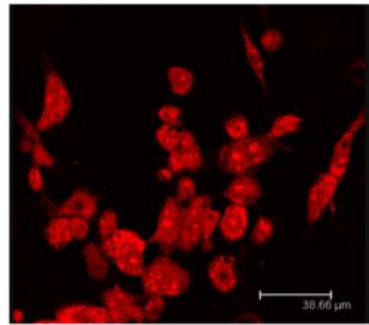

A

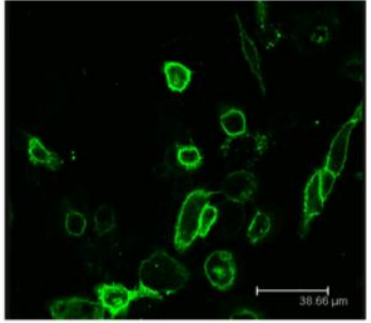

B

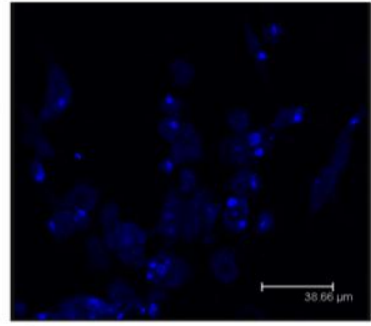

C

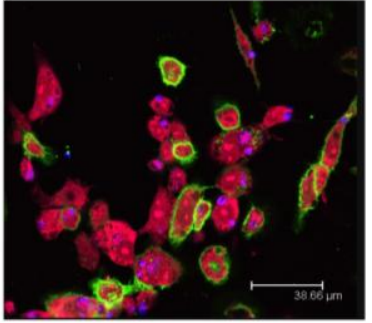

D

Abb. 3.6 Konfokale Laserscanmikroskopie (CLSM) nach Immunfluoreszenzfärbung von T. gondii-infizierten

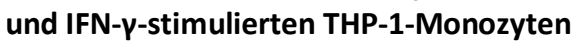

THP-1-Zellen wurden mit PMA aktiviert, im Parasit-zu-Wirtszell-Verhältnis von 2:1 mit T. gondii infiziert und mit Interferon- $\gamma$ stimuliert. Anschließend wurden die Zellen permeabilisiert, mit Antikörpern gegen HLA-DR, -DP, -DQ und T. gondii sowie Cy2- und Cy5-gekoppelten Sekundärantikörpern markiert und durch eine Behandlung mit Propidiumiodid für das Laserscanmikroskop sichtbar gemacht. Exemplarisch sind eine Gesamtzellfärbung mit Propidiumiodid (A), HLA-DR-, -DP-, -DQ-Antikörperfärbung (B), sowie eine Anfärbung mit T. gondii-Antikörpern (C) dargestellt. In (D) sind alle drei Einzelbilder überlagert dargestellt.

Die Immunfluoreszenztests und konfokale Laserscanmikroskopie (Abb. 3.7) ergaben, dass THP-1-Zellen in Abwesenheit von Interferon- $\gamma$ nur eine sehr geringe konstitutive Expression von HLA-DR, -DP, -DQ zeigten. Vergleichbar mit Ergebnissen der FACS-Versuche (3.1) reagierten permanente Monozyten nach Stimulation mit IFN- $\gamma$ mit einer deutlichen Hochregulation von HLA-DR, -DP, -DQ. Die Expression dieser Moleküle war in unstimulierten $T$. gondii-positiven Kulturen praktisch nicht vorhanden, wurde aber durch IFN- $\gamma$ 
moderat hochreguliert. Auf Einzelzellebene fiel dabei auf, dass vor allem Parasit-negative Zellen der T. gondii-infizierten Kultur eine IFN- $\gamma$-induzierte HLA-DR-, -DP-, -DQExpression aufwiesen, wohingegen Monozyten mit T. gondii-Vakuolen keine HLAExpression zeigten. Mit Hilfe der konfokalen Mikroskopie konnte - anders als bei der Durchflusszytometrie (3.1) - zusätzlich zur fehlenden Oberflächenexpression auch eine mögliche intrazelluläre HLA-Aktivität ausgeschlossen werden.

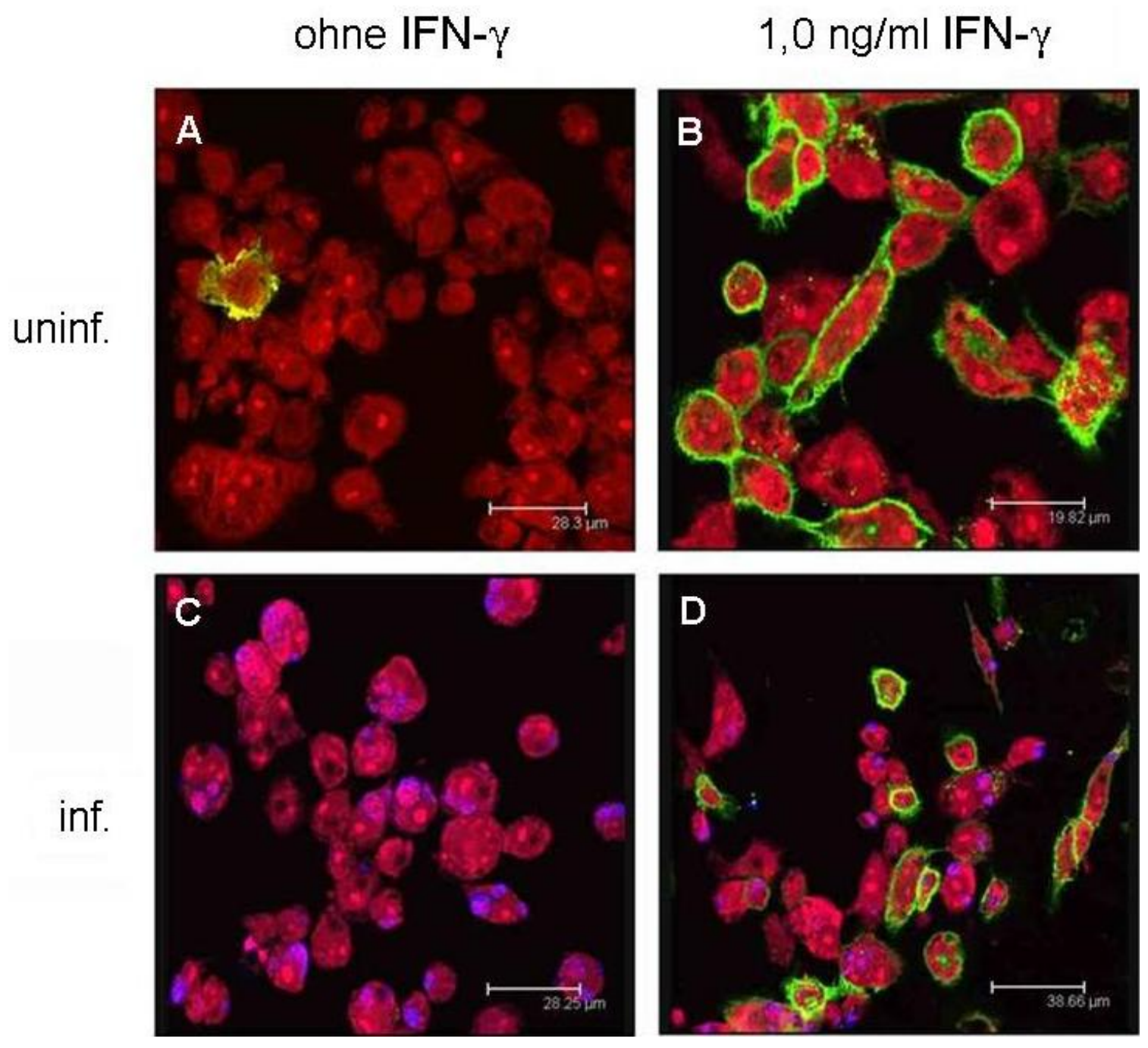

Abb. 3.7 Hemmung der IFN- $\gamma$-induzierten HLA-Expression in Parasit-positiven Wirtszellen

THP-1-Zellen wurden mit PMA aktiviert und im Parasit-zu-Wirtszell-Verhältnis von 2:1 mit $T$. gondii infiziert bzw. blieben nicht-infiziert. Die Hälfte der Ansätze wurde mit Interferon- $\gamma$ stimuliert. Anschließend wurden die Zellen permeabilisiert, mit Antikörpern gegen HLA-DR, -DP, -DQ und T. gondii sowie mit entsprechenden Sekundärantikörpern markiert und durch eine Behandlung mit Propidiumiodid für das Laserscanmikroskop als Gesamtpopulation sichtbar gemacht. Exemplarisch dargestellt ist die Immunfluoreszenz nicht-infizierter, permanenter Monozyten (rot), die in Abwesenheit von IFN- $\gamma$ nur sehr gering HLA-Moleküle exprimierten (A). Stimulierte man die Zellen mit IFN- $\gamma$ zeigte sich eine deutliche Hochregulation von HLA-DR, -DP, -DQ (grün; B). Infizierte Monozyten mit T. gondii-Vakuolen (violett) exprimierten ohne IFN- - -Einfluss praktisch keine HLA-Moleküle (C), wohingegen nach Zugabe von IFN- $\gamma$ eine moderate Expression von HLA-DR, -DP, -DQ zu beobachten war, welche sich jedoch fast ausschließlich auf nicht-infizierte Zellen in den Parasit-positiven Kulturen beschränkte (D). 
Nach mikroskopischer Zellzählung (Abb. 3.8) zeigte sich, dass der Anteil permanenter Monozyten, die konstitutiv HLA-DR-, -DP-, -DQ-Moleküle exprimieren, in T. gondiifreien Kulturen sehr gering war $(0,6 \% \pm 0,2 \%)$. Nach einer Infektion mit Toxoplasmen war die konstitutive HLA-Expression sowohl bei Parasit-negativen $(0,2 \%)$ als auch Parasit-positiven Zellen $(0,2 \%)$ fast nicht vorhanden. Nach Stimulation von T. gondiifreien Populationen mit IFN- $\gamma$ war eine deutliche Hochregulation von HLA-DR, -DP, -DQ $\mathrm{zu}$ erkennen $(39,2 \% \pm 0,2 \%)$. Die IFN- $\gamma$-induzierte Hochregulation war in T. gondiiinfizierten Kulturen besonders in Parasit-positiven Monozyten hoch signifikant inhibiert $(2,1 \% \pm 0,2 \% ; \mathrm{p}=0,0000001$; einfache Varianzanalyse). Interessanterweise wiesen aber auch Parasit-negative Zellen einer infizierten Kultur eine im Vergleich zu nicht-infizierten Populationen signifikant verminderte Expression von HLA-Molekülen auf $(28,9 \%$ $\pm 2,4 \%$ ). Dieser Effekt war in durchflusszytometrischen Versuchen (3.1) durch die fehlende Möglichkeit einer Differenzierung zwischen Parasit-positiven und -negativen Zellen einer infizierten Kultur unentdeckt geblieben.

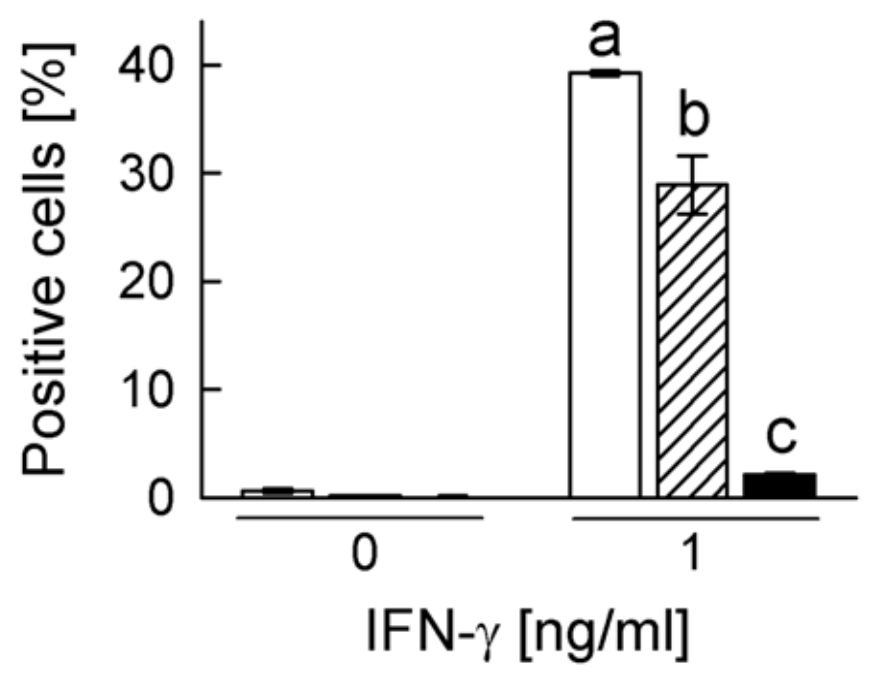

\section{Abb. 3.8 T. gondii inhibiert deutlich die HLA-Expression in Parasit-positiven permanenten Monozyten, zu einem geringeren Prozentsatz aber auch in Parasit-freien Zellen}

PMA-aktivierte THP-1-Zellen wurden mit T. gondii in einem Parasit-zu-Wirtszellverhältnis von 2:1 infiziert bzw. blieben uninfiziert. Im Anschluss an eine Stimulation der Hälfte der Ansätze mit IFN- $\gamma$ wurden die Monozyten mit Antikörpern gegen HLA-DR, -DP, -DQ und T. gondii sowie mit Sekundärantikörpern markiert. Die Gesamtpopulation wurde für das Laserscanmikroskop mit Hilfe von Propidiumiodid sichtbar gemacht. Aus vier Immunfluoreszenztests wurde der durchschnittliche prozentuale Anteil HLA-DR-, -DP-, -DQ-exprimierender Zellen bestimmt. Dargestellt sind nicht-infizierte Kulturen (weiße Balken) sowie Parasit-negative (gestrichelte Balken) und Parasit-positive (schwarze Balken) Zellen einer Toxoplasma-infizierten Kultur mit bzw. ohne IFN- $\gamma$ Stimulation. Statistisch signifikante Unterschiede der Mittelwerte aus vier unabhängigen Experimenten wurden durch ANOVA identifiziert. Gruppen, die mit unterschiedlichen Buchstaben markiert sind, unterscheiden sich signifikant. 
Zusammenfassend ist festzuhalten, dass Versuche mit indirekter Immunfluoreszenz (IFT) eine Inhibition der HLA-Molekül-Expression im Zytoplasma sowie auf der Oberfläche humaner Monozyten durch Toxoplasma gondii auf Einzelzellebene bestätigt haben. Es kam unter Interferon- $\gamma$ zu einer deutlichen Hochregulation von HLA-DR, -DP, -DQ, die durch T. gondii in Parasit-positiven Zellen besonders ausgeprägt inhibiert war. Zusätzlich zeigte sich eine deutlich reduzierte HLA-Expression bei Parasit-negativen Zellen einer infizierten Kultur. 


\subsection{Die Inhibition der HLA-Expression durch T. gondii findet über einen weiten Konzentrationsbereich von Interferon-y statt.}

Ein essentieller Teil der Immunantwort auf T. gondii ist mit dem Monozytenstimulierenden Zytokin Interferon- $\gamma$ assoziiert (Suzuki et al. 1988). Nach einer Infektion mit T. gondii kommt es aufgrund einer IFN- $\gamma$-Ausschüttung zu verstärkter Präsentation von MHC-Molekülen der Klasse I und II auf der Zelloberfläche Antigen-präsentierender Zellen $(A P C)$, zu denen ebenfalls die hier untersuchten humanen Monozyten zählen. $\mathrm{Zu}$ klären galt es demnach, ob eine erhöhte IFN- $\gamma$-Konzentration zu einer stärkeren MHCExpression und damit zur Kompensation der durch $T$. gondii hervorgerufenen Inhibition führen würde.

THP-1-Monozyten wurden ausgesät und zur Hälfte mit $T$. gondii in einem Parasit-zuWirtszell-Verhältnis von 10:1 infiziert. Nach 2 h Inkubation wurden sowohl infizierte als auch nicht-infizierte Populationen mit IFN- $\gamma$ in Konzentrationen von 0,01, 0,1, 1,0, 10,0 und 100,0 ng/ml stimuliert bzw. als Kontrolle unstimuliert belassen. $24 \mathrm{~h}$ später erfolgte eine Restimulation mit IFN- $\gamma$ und nach weiteren $24 \mathrm{~h}$ eine FACS-Analyse der HLAExpression (2.2.3).

Die durchflusszytometrische Analyse zeigte in nicht-infizierten Monozyten eine konstitutive Expression von HLA-A, -B, -C (Abb. 3.9), die bei einer Stimulation mit 0,1 ng/ml Interferon- $\gamma$ deutlich hochreguliert wurde. Eine Konzentration von 1,0 und $10 \mathrm{ng} / \mathrm{ml} \mathrm{des}$ Zytokins führte letztlich zu einer maximalen HLA-Expression, die mit einer höheren Konzentration von $100 \mathrm{ng} / \mathrm{ml}$ Interferon- $\gamma$ nicht weiter gesteigert werden konnte. Die IFN- $\gamma$-unabhängige HLA-A-, -B-, -C-Expression war in Gegenwart von T. gondii im Vergleich zur Kontrolle stark supprimiert und ließ sich auch durch Zugabe von IFN- $\gamma$ in unterschiedlichen Konzentrationen nicht wesentlich steigern. Die HLA-Expression verblieb vielmehr unabhängig von der eingesetzten IFN- $\gamma$-Konzentration auf einem der konstitutiven Expression vergleichbaren Niveau (Abb. 3.9).

Nicht-infizierte THP-1-Zellen exprimierten konstitutiv praktisch keine HLA-DR-, -DP-, -DQ-Moleküle (Abb. 3.9), regulierten diese jedoch bei einer Stimulation mit mindestens $1 \mathrm{ng} / \mathrm{ml}$ IFN- $\gamma$ deutlich hoch. Die HLA-Expression erreichte bei Zugabe von $10 \mathrm{ng} / \mathrm{ml}$ IFN- $\gamma$ ein Maximum, wobei eine Konzentration von 100 ng/ml wieder zu einer deutlichen Abnahme führte. Genauso wie in Parasit-freien Kulturen war bei T. gondii-infizierten 
Monozyten keine konstitutive HLA-DR-, -DP-, -DQ-Expression zu beobachten. Ab einer Konzentration von $1,0 \mathrm{ng} / \mathrm{ml}$ induzierte Interferon- $\gamma$ eine moderate Hochregulation der HLA-Moleküle, die jedoch auch bei einer Erhöhung der Konzentration auf 10,0 ng/ml bzw. 100,0 ng/ml nicht weiter gesteigert werden konnte, sondern auf relativ konstantem Niveau verblieb (Abb. 3.9).

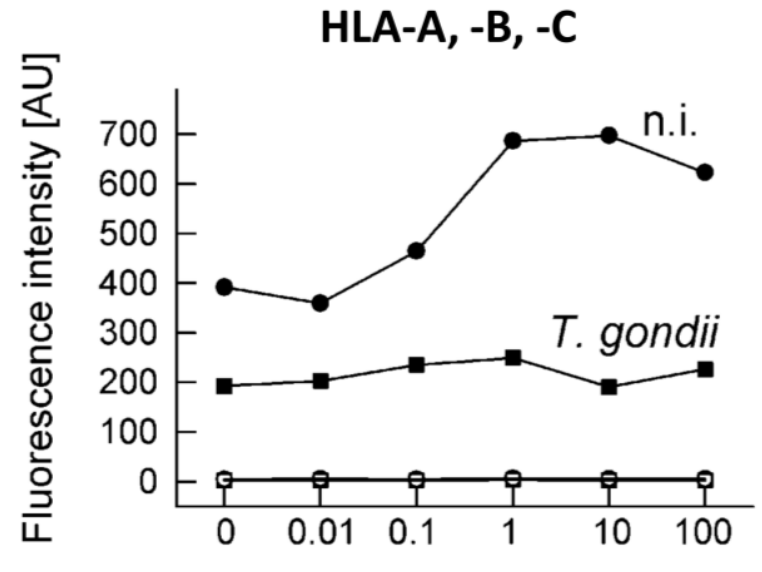

IFN- $\gamma[\mathrm{ng} / \mathrm{ml}]$

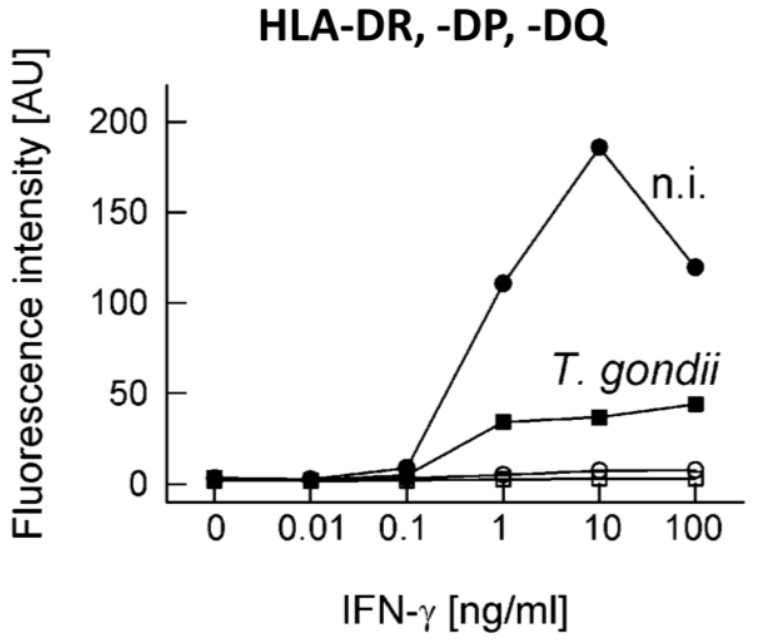

IFN- $\gamma[\mathrm{ng} / \mathrm{ml}]$

Abb. 3.9 Unterschiedliche IFN- $\boldsymbol{\gamma}$-Konzentrationen heben die $T$. gondii-induzierte HLA-Inhibition nicht auf Permanente Monozyten (THP-1) inkubierten ohne oder mit T. gondii in einem Parasit-zu-Wirtszell-Verhältnis von 10:1. Bis auf eine Kontrollpopulation wurden alle Ansätze danach mit 0,01, 0,1, 1,0, 10,0 oder 100,0 ng/ml Interferon- $\gamma$ stimuliert, restimuliert und durchflusszytometrisch analysiert. Dargestellt sind die FACSFluoreszenzen der Expression von HLA-A, -B, -C und HLA-DR, -DP, -DQ in T. gondii-infizierten Kulturen (schwarze Quadrate) und nicht-infizierten Populationen (schwarze Punkte) in Abhängigkeit von der IFN- - -Konzentration. Eine sehr geringe Fluoreszenz der Isotypkontroll-Färbung (weiße Punkte) zeigte die Spezifität der HLAAntikörperfärbung.

Die Ergebnisse dieser Versuche machten deutlich, dass T. gondii sowohl die HLA-A-, -B-, -C- als auch HLA-DR-, -DP-, -DQ-Expression in humanen Monozyten unabhängig von der INF- $\gamma$-Konzentration deutlich inhibiert. Der stimulierende Effekt des Zytokins kann den hemmenden Einfluss von $T$. gondii offensichtlich auch bei hohen Konzentrationen nicht kompensieren. 


\subsection{Unterschiede in der HLA-Expression in primären Monozyten von T.gondii-positiven bzw. -negativen Individuen}

Da die Versuche der Durchflusszytometrie unter anderem mit primären Monozyten durchgeführt wurden, die aus Buffy-Coat-Blutspenden isoliert worden waren (2.2.1.2), war es von Interesse, das Verhalten der ex-vivo-isolierten Zellen in den Versuchen in den Kontext ihres physiologischen Lebensraums zu setzen. Das heißt, es sollte der T. gondiiInfektionsstatus des jeweiligen Blutspenders geklärt und ein eventueller Zusammenhang mit den entsprechenden Versuchsergebnissen der betroffenen Zellpopulation identifiziert werden.

Für die Ermittlung des Infektionsstatus der Blutspender wurden aus den Buffy Coats zu Beginn der Isolation von primären Monozyten ca. 0,5 ml Blutplasma entnommen und mit Hilfe von indirekten Immunfluoreszenztests (IIFT) bzw. ELISA auf $T$. gondii untersucht (2.2.1.6). Zur Abgrenzung der akuten von einer chronischen Phase einer Toxoplasmose wurden ferner Erreger-spezifische humane Immunglobuline (IgG, $\operatorname{IgM}$ und $\operatorname{IgA}$ ) bestimmt.

Die Untersuchungen ergaben für 4 von 12 Buffy Coats ein positives Ergebnis (Abb. 3.10, Tabelle 3.1). Zudem waren in diesen Fällen IgG-Antikörper vorhanden, jedoch keine IgModer IgA-Antikörper, was auf eine chronische Toxoplasma-Infektion hindeutet. Bei einer der positiven Proben war der IgG-Titerwert jedoch sehr stark erhöht (>300 IU / ml). Dies kann auf eine akute, abklingende Infektion des Blutspenders hinweisen. Für 6 der 12 Proben war das Ergebnis negativ, es lag keine T. gondii-Infektion vor. Bei zwei Buffy Coats konnte die Untersuchung leider nicht durchgeführt werden.

Das Ergebnis der Buffy-Coat-Serologie (40\% T. gondii-positiv) kann mit der Prävalenz von T. gondii in der deutschen Bevölkerung von 26-54\% (Gross 2004) verglichen werden. 


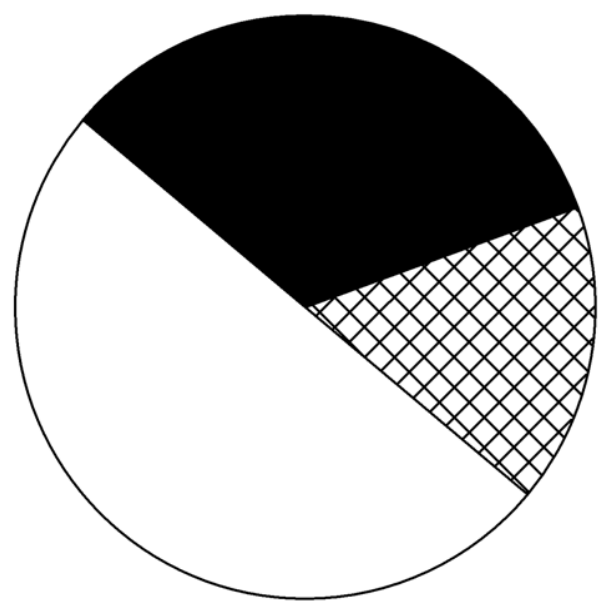

Abb. 3.10 Verteilung von T. gondii-positiven und -negativen Blutspenden

Vor der Isolation von primären Monozyten aus Buffy Coats bzw. PBMC wurden ca. 0,5 ml Blutplasma gewonnen und mit IIFT (indirekter Immunfluoreszenztest) sowie Erreger-spezifischen Immunglobulinen der Klasse G, M und A auf $T$. gondii untersucht. Von 12 Blutspenden waren 4 im IIFT positiv und wiesen $T$. gondii-Antikörper im Serum auf (schwarz). Negativ war das Ergebnis hingegen in 6 Blutspenden (weiß). Bei 2 Serum-Proben (schraffiert) konnte keine Untersuchung vorgenommen werden.

Tabelle 3.1 Serumanalyse Buffy Coats

\begin{tabular}{|lllll|}
\hline Nr. & IIFT & IgG & IgM & IgA \\
\hline 1 & Positiv (1:64) & 27 IU / ml & Negativ & Negativ \\
2 & n.b. ${ }^{*}$ & & & \\
3 & Positiv (1:16) & $6 \mathrm{IU} / \mathrm{ml}$ & Negativ & Negativ \\
4 & Negativ & & \\
5 & n.b. $*$ & & \\
6 & Positiv (1:16) & 13 IU / ml & Negativ & Negativ \\
7 & Negativ & & & \\
8 & Negativ & & & \\
9 & Negativ & & & Negativ \\
10 & Positiv (1:1024) & $>300 \mathrm{IU} / \mathrm{ml}$ & Negativ & \\
11 & Negativ & & & \\
12 & Negativ & & & \\
\hline
\end{tabular}

* nicht bestimmt 
Im Anschluss an die oben beschriebenen serologischen Analysen wurde ein möglicher Zusammenhang zwischen dem Infektionsstatus der Blutspender und den Resultaten der durchflusszytometrischen Versuche mit primären Monozyten (3.1.1) untersucht. D. h. die Expression der HLA-Moleküle von vier Proben von seropositiv getesteten Buffy Coats wurde dem Versuchsaufbau entsprechend nach T. gondii-Infektionsdosis und IFN- $\gamma$ Stimulation differenziert in Mittelwerten zusammengefasst. In gleicher Weise wurde mit den Proben von sechs seronegativen Blutspendern verfahren.

Hierbei zeigte sich, dass primäre Monozyten aus Toxoplasma-negativen Blutspenden konstitutiv HLA-A, -B, -C exprimierten, wobei eine Infektion mit Toxoplasmen in einem Parasit-zu-Wirtszellverhältnis von 3:1 dieser Expression entgegenwirkte (Abb. 3.11). Eine Interferon- $\gamma$-induzierte Hochregulation der HLA-Moleküle wurde durch T. gondii Infektionsdosis-abhängig deutlich reduziert. Verglich man diese Ergebnisse nun mit denen Toxoplasma-positiver Buffy Coats ergaben sich sehr ähnliche Ergebnisse, die Fluoreszenz-Werte stellten sich insgesamt jedoch viel ausgeprägter dar: Chronisch Infizierte exprimierten insgesamt signifikant stärker HLA-A, -B, -C ( $\mathrm{p}=0,0047$; ANOVA). Eine T. gondii-Infektion mit einem Parasit-zu-Wirtszellverhältnis von 3:1 hemmte bei nicht-stimulierten Monozyten die konstitutive HLA-Expression. Genauso wie in Erreger-negativen Buffy Coats korrelierte die Inhibierung der IFN- $\gamma$-abhängigen Hochregulation mit der Infektionsdosis von T. gondii (Parasit-zu-Wirtszellverhältnisse von 1,5:1 und 3:1; Abb. 3.11).

Primäre Monozyten aus T. gondii-negativen Blutspenden zeigten in FACS-Analysen eine deutliche Infektionsdosis-abhängige Hemmung der Expression von HLA-DR, -DP, -DQ. Dies traf sowohl für die konstitutive als auch Interferon- $\gamma$-bedingte HLA-Aktivität zu. Ähnlich wie bei HLA-A-, -B-, -C-Molekülen wiesen Zellpopulationen aus Toxoplasmainfizierten Blutspenden eine signifikant erhöhte Expression von HLA-DR, -DP, -DQ auf ( $\mathrm{p}=0,000014$; ANOVA). Ebenfalls zeigte sich eine von der T. gondii-Infektionsdosis abhängige Hemmung der HLA-Expression, wobei jedoch erst bei einem Parasit-zuWirtszellverhältnisse von 3:1 eine deutliche Hemmung eintrat (Abb. 3.11). 

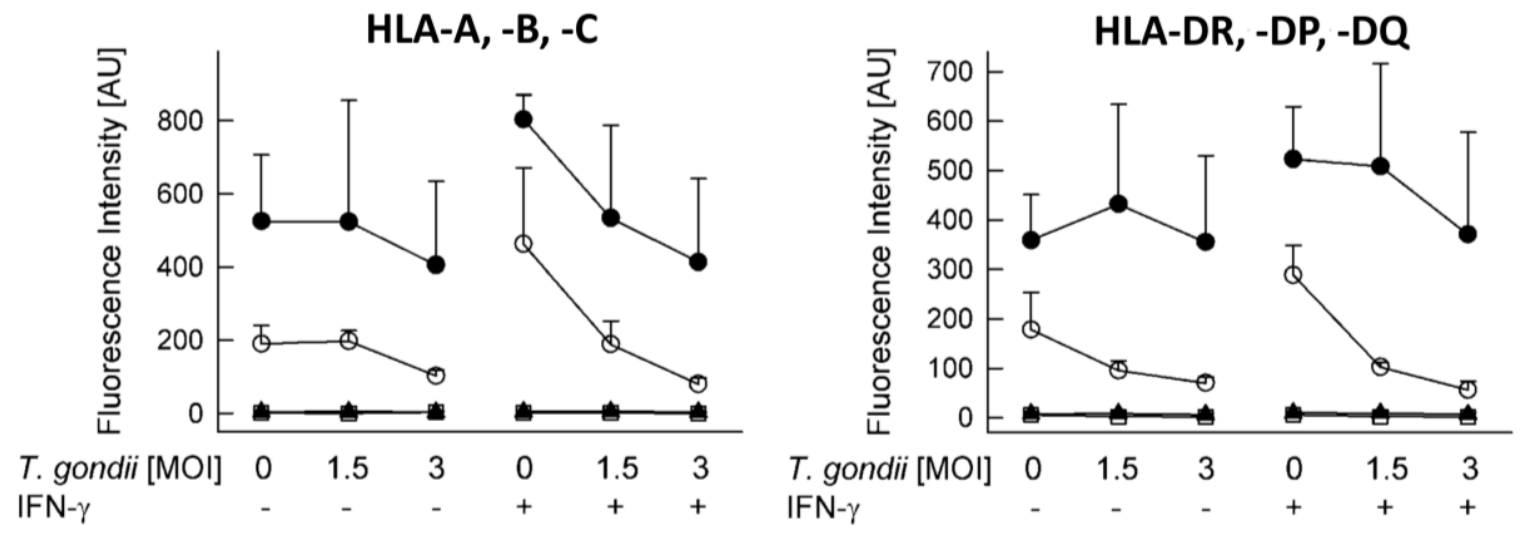

Abb. 3.11 T. gondii-positive Blutspender zeigen im Vergleich zu Parasit-negativen Spendern eine deutlich höhere HLA-Expression

Aus PBMC isolierte primäre Monozyten wurden ohne oder mit T. gondii in einem Parasit-zu-Wirtszellverhältnis (MOI) von 1,5:1 und 3:1 inkubiert und zur Hälfte anschließend mit IFN- $\gamma$ stimuliert. Es folgte eine Markierung mit HLA-spezifischen Antikörpern und eine FACS-Analyse. Dargestellt sind die Mittelwerte \pm SEM von HLA-A-, -B-, -Cund HLA-DR-, -DP-, -DQ-Fluoreszenzen von Monozyten von vier T. gondii-positiven (schwarze Punkte) und sechs T. gondii-negativen (weiße Punkte) Blutspendern. Die Isotypkontroll-Färbungen von Zellen seropositiver (schwarze Dreiecke) und -negativer Spender (weiße Quadrate) zeigen durch sehr geringe Fluoreszenz die Spezifität der anti-HLA-Antikörper-Färbung an.

Zusammenfassend lässt sich feststellen, dass die Inhibierung der konstitutiven Expression und IFN- $\gamma$-abhängigen Hochregulation durch T. gondii sowohl bei Zellen aus Parasitpositiven als auch -negativen Blutspenden mit der Infektionsdosis korrelierte. In Zellpopulationen aus T. gondii-infizierten Blutspenden war im Vergleich mit Monozyten aus nichtinfizierten Personen ein insgesamt deutlich gesteigertes Expressions-Niveau von HLA-A, -B, -C und HLA-DR, -DP, -DQ zu erkennen.

Darüberhinaus spiegelt sich die Prävalenz von Toxoplasma gondii in der deutschen Bevölkerung von 26-54\% (Gross 2004) in der serologischen Analyse der Blutspenden wider $(40 \%)$. 


\subsection{Die Inhibition der HLA-Expression auf mRNA- Ebene}

In vorangegangenen Versuchen der Durchflusszytometrie (3.1) und Immunfluoreszenz (3.1.3) konnte der hemmende Einfluss von T. gondii auf die HLA-Expression humaner Monozyten auf Proteinebene gezeigt werden. Für das nähere Verständnis dieses EvasionsMechanismus' war der Einfluss von T. gondii jedoch auch auf mRNA-Ebene von Bedeutung. Insbesondere die vermutete Unterdrückung der Transskriptionsfaktoren IRF-1 und CIITA, die entscheidend an der Regulation der HLA-Expression beteiligt sind, war neben der Analyse von HLA-A und HLA-DR $\alpha$ für die vorliegende Arbeit von besonderem Interesse.

\subsubsection{Transkriptionsfaktoren der HLA-Kaskade werden Erreger- dosis-abhängig durch $T$. gondii gehemmt}

Um die Inhibition der Interferon- $\gamma$-induzierten HLA-Expressionskaskade durch $T$. gondii auf molekularer Ebene zu untersuchen, wurden THP-1-Zellen ausgesät (2.2.2.3) und mit PMA aktiviert. Nach 24 h Inkubation wurden die Ansätze mit T. gondii in Parasit-zuWirtszellverhältnissen von 5:1 und 10:1 infiziert bzw. nicht-infiziert belassen. Eine Hälfte der Ansätze wurde $2 \mathrm{~h}$ später mit Interferon- $\gamma$ stimuliert und für $24 \mathrm{~h}$ inkubiert. Die anschließende Analyse mit Hilfe der qRT-PCR (2.2.5) umfasste sowohl die Transskriptionsfaktoren IRF-1 und CIITA als auch die MHC-Moleküle HLA-A und HLA$\mathrm{DR} \alpha$. Zusätzlich wurde konstitutiv exprimiertes $\beta$-Actin für die Normalisierung der mRNA-Menge bestimmt. 
$\underline{\text { IRF-1 }}$

In Toxoplasma-infizierten permanenten Monozyten zeigten Analysen der Transkripte des Transkriptionsfaktors IRF-1 eine deutliche Hemmung der IFN- $\gamma$-induzierten relativen mRNA-Expression (Abb. 3.12). Verglichen mit nicht-infizierten Kulturen (13,7-fache Induktion durch IFN- $\gamma$ ) wurde bei $T$. gondii-positiven Populationen bei einer Erregerdosis von 5:1 ein signifikanter Rückgang der relativen mRNA-Menge (5,7-fach) beobachtet. Ein Parasit-zu-Wirtszell-Verhältnis von 10:1 führte zu einer hoch signifikanten Suppression der IFN- $\gamma$-induzierten Genexpression von IRF-1 (2,4-fach).

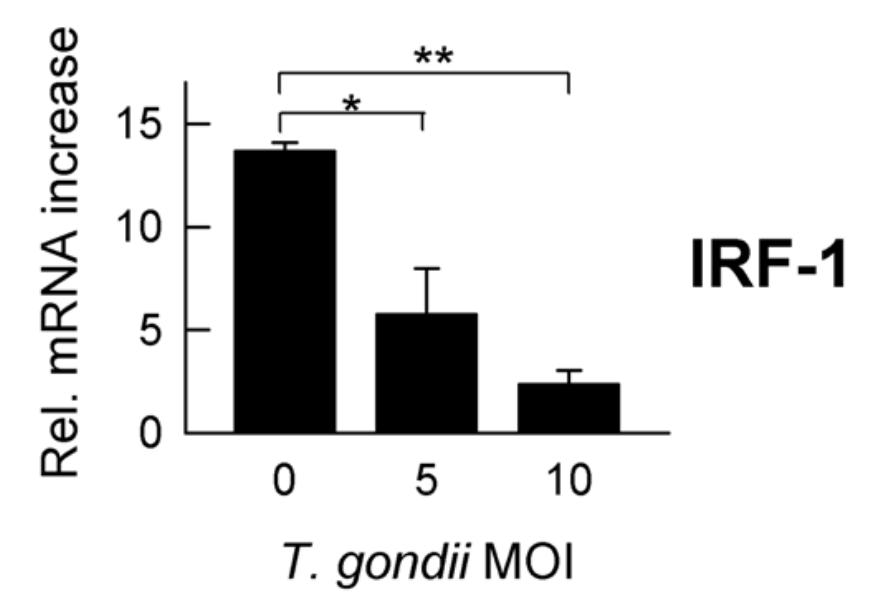

Abb. 3.12 Signifikante Hemmung der IFN- $\gamma$-induzierten Transkripte von IRF-1 durch $T$. gondii.

PMA-aktivierte THP-1-Zellen wurden in einem Parasit-zu-Wirtszell-Verhältnis (MOI) von 5:1 und 10:1 mit T. gondii infiziert bzw. nicht-infiziert belassen. Anschließend wurden die Kulturen mit Interferon- $\gamma$ stimuliert und nach $24 \mathrm{~h}$ mit Hilfe der qRT-PCR analysiert. Die Säulen zeigen die Hochregulation der mRNA-Menge von IRF-1 nach Stimulierung mit IFN- $\gamma$ in T.gondii-infizierten und nicht-infizierten Kulturen im Vergleich zu nichtstimulierten Kontrollen. Dargestellt sind die Mittelwerte \pm SEM von drei unabhängigen Experimenten, wobei signifikante $(* ; p<0,05)$ und hoch signifikante $\left({ }^{* *} ; p<0,01\right)$ Unterschiede zwischen T.gondii-positiven und -negativen Populationen gekennzeichnet sind. 


\section{CIITA}

Untersuchungen mit Hilfe der qRT-PCR ergaben, dass der Transkriptionsfaktor CIITA in THP-1-Zellen nach einer Infektion mit Toxoplasmen stark in seiner Expression inhibiert wird (Abb. 3.13). In nicht-infizierten Zellpopulationen (54,1-fache Induktion durch IFN- $\gamma$ ) konnte nach einer T. gondii-Infektion in einem Parasit-zu-Wirtszell-Verhältnis von 5:1 eine sehr deutliche Hemmung der mRNA-Expression von CIITA nachgewiesen werden (10,1-fach). Die Reduktion des Transkriptionsfaktors war im Vergleich mit nichtinfizierten Kulturen bei einer T. gondii-Infektionsdosis von 10:1 signifikant (4,0-fach).

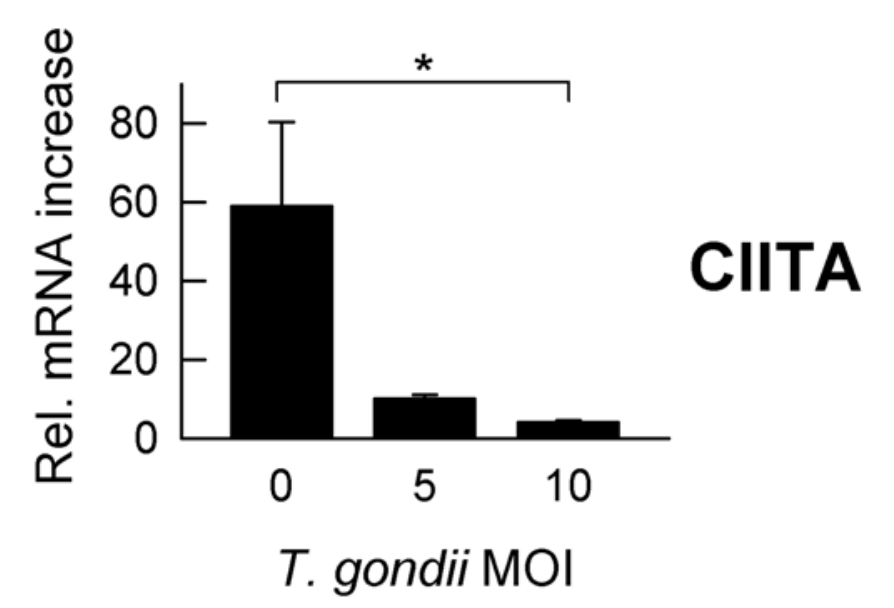

Abb. 3.13 Der inhibitorische Einfluss von T. gondii auf die relative mRNA-Menge von CIITA ist signifikant.

Permanente Monozyten (THP-1) wurden mit PMA aktiviert und mit T. gondii in einem Parasit-zu-WirtszellVerhältnis (MOI) von 5:1 und 10:1 infiziert bzw. nicht-infiziert belassen. Auf die anschließende Stimulation mit Interferon- $\gamma$ folgte die Analyse mittels qRT-PCR. Dargestellt sind die Mittelwerte \pm SEM der relativen mRNAExpression von CIITA in drei unabhängigen Experimenten. Der signifikante Unterschied zwischen Erregerpositiven und -negativen Kulturen ist markiert $(* ; p<0,05)$. 
HLA-DR $\alpha$

Vergleichbar mit Ergebnissen der qRT-PCR der Transkriptionsfaktoren IRF-1 und CIITA korrelierte die Hemmung der mRNA-Expression des MHC-Moleküls HLA-DR $\alpha$ durch T. gondii mit der Infektionsdosis (Abb. 3.14). Während es im Vergleich mit nichtinfizierten Kulturen (178,1-fache Induktion durch IFN- $\gamma$ ) bei einem Parasit-zu-WirtszellVerhältnis von 5:1 zu einer deutlichen Inhibierung der HLA-DR $\alpha$-Aktivität durch T. gondii kam (95,6-fach), war die Reduktion bei einem Parasit-zu-Wirtszell-Verhältnis von 10:1 sogar signifikant (47,7-fach).

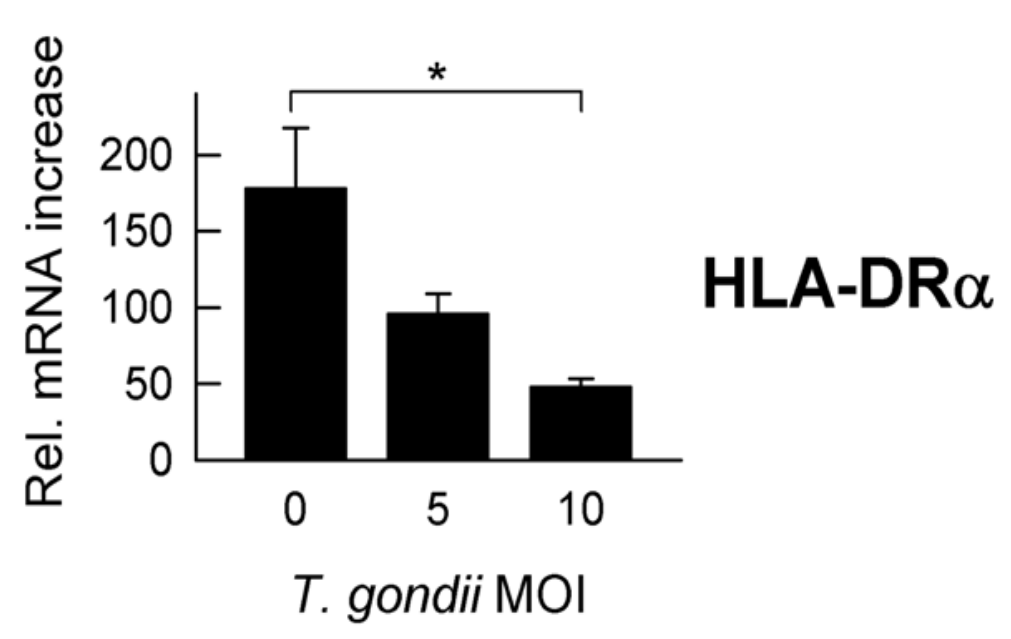

Abb. 3.14 Die relative mRNA-Expression von HLA-DR $\alpha$ wird durch $T$. gondii deutlich reduziert

PMA-behandelte THP-1-Monozyten wurden in einem Parasit-zu-Wirtszell-Verhältnis (MOI) von 5:1 und 10:1 mit T. gondii infiziert bzw. nicht-infiziert belassen. Die Kulturen wurden mit Interferon- $\gamma$ stimuliert und der Analyse durch qRT-PCR zugeführt. Dargestellt ist die relative mRNA-Expression von HLA-DR $\alpha$ in T. gondii-infizierten und nicht-infizierten Populationen. Die Säulen zeigen die Mittelwerte \pm SEM von drei unabhängigen Experimenten. Signifikanz ist durch ein Sternchen gekennzeichnet $(* ; p<0,05)$. 
HLA-A

Bei Betrachtung von HLA-A (MHC-Klasse I) fällt ähnlich wie bei HLA-DR $\alpha$ (MHCKlasse II) ein Infektionsdosis-abhängiger Rückgang der Expression von mRNA in T. gondii-positiven Populationen auf (Abb. 3.15). Erreger-freie Monozyten (2,49-fache Induktion durch IFN- $\gamma$ ) zeigten nach einer Toxoplasma-Infektion in einem Parasit-zuWirtszell-Verhältnis von 5:1 einen deutlichen Rückgang der relativen mRNA-Expression (1,92-fach). Signifikant wurde die Inhibierung der Transkripte, sobald die Zellpopulationen mit T. gondii in einem Parasit-zu-Wirtszell-Verhältnis von 10:1 infiziert wurden (1,25-fach).

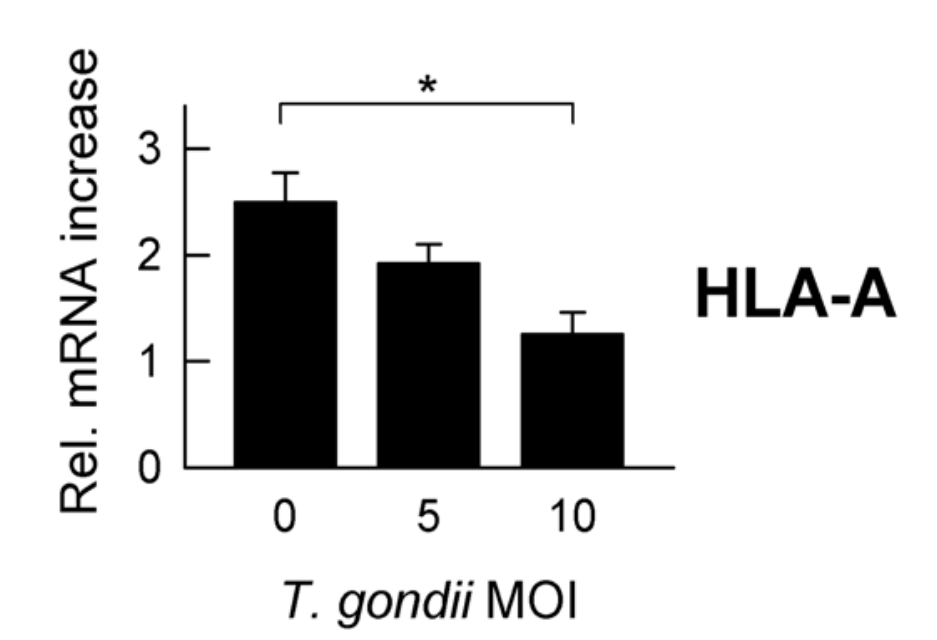

Abb. 3.15 T. gondii inhibiert dosisabhängig die relative mRNA-Expression von HLA-A

THP-1-Zellen wurden mit PMA aktiviert, mit T. gondii in einem Parasit-zu-Wirtszell-Verhältnis (MOI) von 5:1 und 10:1 infiziert bzw. nicht-infiziert belassen und mit Interferon- $\gamma$ stimuliert. Die Analyse der Transkripte erfolgte im Anschluss durch qRT-PCR. Die Säulen zeigen die Mittelwerte \pm SEM der relativen mRNA-Expression von HLA-A in drei unabhängigen Experimenten. Die signifikante Suppression der Genaktivität von HLA-A durch T. gondii ist gekennzeichnet $(* ; p<0,05)$.

Zusammenfassend ist festzuhalten, dass der inhibitorische Eingriff durch T. gondii in die Expressionskaskade von MHC-Molekülen der Klasse I und II nicht auf die Proteinebene beschränkt bleibt. Vielmehr ist ebenso auf mRNA-Ebene eine signifikante, dosisabhängige Reduktion der Transkripte beider MHC-Klassen nachweisbar. 


\subsubsection{Validierung der qRT-PCR-Ergebnisse durch Agarosegel- Elektrophorese}

In Versuchen der Quantitativen PCR konnte die Genaktivität der Transkriptionsfaktoren IRF-1 und CIITA sowie der HLA-Moleküle HLA-DR $\alpha$ und HLA-A unter dem supprimierenden Einfluss von T. gondii analysiert werden (3.4.1). Zur Validierung dieser Ergebnisse wurden die Amplifikate im Anschluss an die qPCR in einer Agarosegel-Elektrophorese der Größe nach aufgetrennt und mit Hilfe eines DNA-Standards bestimmt. Die einzelnen Proben sowie ein DNA-Molekulargewichtsmarker wurden hierfür in einem Ethidiumbromid-haltigen Agarosegel aufgetrennt (Abb. 3.16).

Die durch den DNA-Standard ermittelte Größe der DNA-Abschnitte der einzelnen Proben wurde mit den bekannten Längen der Amplifikate für die Transkriptionsfaktoren IRF-1 (285 bp) und CIITA (228 bp), den HLA-Molekülen HLA-DR $\alpha$ (273 bp) und HLA-A (200 bp) sowie dem Kontrollgen $\beta$-Actin (278 bp) verglichen. Hier bestätigten sich die Erwartungen, dass die in den qPCR-Analysen amplifizierte DNA den gewünschten GenAbschnitten entsprachen. In den Versuchen der Quantitativen PCR (3.4.1) wurde somit das jeweils gesuchte Amplikon hergestellt und analysiert. 


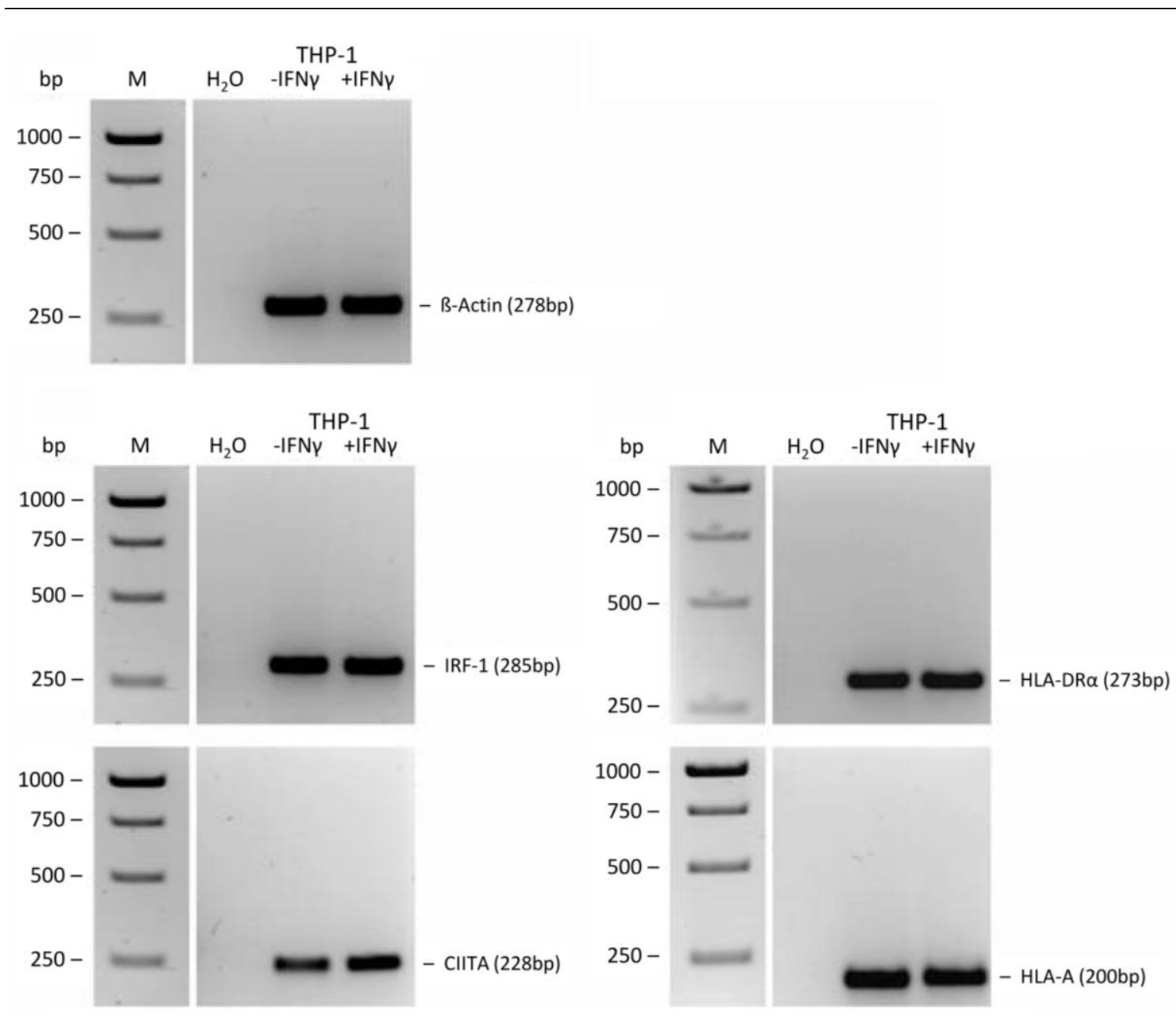

\section{Abb. 3.16 Validierung der qRT-PCR-Versuche durch Agarosegel-Elektrophorese}

Im Anschluss an Analysen mit qRT-PCR wurden die Amplifikate von IRF-1 (285 bp), CIITA (228 bp), HLA-DR $\alpha$ (273 bp), HLA-A (200 bp), B-Actin als Kontrollgen (278 bp) sowie ein DNA-Molekulargewichtsmarker (M) in Puffer gelöst und durch Agarosegel-Elektrophorese aufgetrennt. Durch den Zusatz von Ethidiumbromid im Gel konnten die dargestellten Muster unter UV-Licht sichtbar gemacht werden. In der Abbildung sind die Bandenmuster der Transkriptionsfaktoren bzw. HLA-Moleküle in Interferon- $\gamma$-stimulierten (+IFN- $\gamma)$ und nicht-stimulierten (-IFN- $\gamma)$ THP-1-Zellen sowie Wasser $\left(\mathrm{H}_{2} \mathrm{O}\right)$ als Kontrolle dem Bandenmuster des DNA-Molekulargewichtsmarkers (M) gegenüber gestellt. Mit Hilfe dieses Markers konnten die Größen der Amplifikate abgelesen und mit den erwarteten Größen verglichen werden. 


\section{Diskussion}

Für Toxoplasma gondii als persistierende, intrazellulär lebende Parasiten stellen Mechanismen zur Manipulation und Evasion des Wirts-Immunsystems eine überlebensnotwendige Funktion dar. Eine Strategie von T. gondii ist dabei die Stadienkonversion von sich schnell teilenden Tachyzoiten in langsam replizierende Bradyzoiten. Diese können in intrazellulär lokalisierten parasitophoren Vakuolen (PV) vor Wirtszelle und Immunsystem weitgehend geschützt persistieren (Joiner et al. 1994; Bohne et al. 1999). Ein anderer Mechanismus stellt die Inhibierung der durch Lipopolysaccharide (LPS) bzw. Interferon- $\gamma$ induzierbaren Stickstoffmonoxid-Synthase (iNOS) dar, wodurch eine gesteigerte Replikation des Parasiten begünstigt wird (Lüder et al. 2003a). Außerdem greift T. gondii effektiv in die antiparasitär wirkende Wirtszell-Apoptose ein: Die für den kontrollierten Zelltod essentielle Caspase-Kaskade, die Poly(ADP-ribose)-Polymerase-Aktivität sowie eine breite Anzahl von Apoptose-Induktoren werden durch eine T. gondii-Infektion in ihrer Funktion gehemmt und dadurch die Apoptose der Parasiten-infizierte Wirtszelle verhindert (Nash et al. 1998; Goebel et al. 2001; Hippe et al. 2009). Darüberhinaus interferiert T. gondii u.a. mit den für eine erfolgreiche Immunantwort essentiellen Zytokinen Interleukin-12 und Interferon- $\gamma$ und unterbindet so nachfolgende pro-inflammatorische Reaktionen (Suzuki et al. 1988; Brunda 1994; Gazzinelli et al. 1994).

Die vorliegende Arbeit befasst sich mit dem Einfluss von Toxoplasmen auf die Interferon- $\gamma$-induzierte Expression von Leukozytenantigenen (HLA) in humanen Makrophagen. Die Ergebnisse zeigen, dass $T$. gondii in die IFN- $\gamma$-regulierte Genexpression eingreift und Parasitendosis-abhängig die Expression von MHC-Klasse-I- und -II-Molekülen reduziert. Interessanterweise zeigen hierbei primäre Monozyten aus Toxoplasmaseropositiven Spendern im Vergleich mit Zellen aus seronegativen Spendern ein insgesamt deutlich gesteigertes MHC-Expressionsniveau. 


\subsection{Unterschiede in der HLA-Expression primärer Monozyten von T.gondii-infizierten und nicht- infizierten Individuen}

Die durchflusszytometrischen Experimente dieser Arbeit zeigen, dass Toxoplasma gondii die Expression von HLA-A, -B, -C sowie HLA-DR, -DP, -DQ bei aus peripherem Blut isolierten primären Monozyten des Menschen nach Infektion ex vivo hemmt. Diese Inhibierung ist sowohl bei Interferon- $\gamma$-stimulierten als auch nicht-stimulierten Zellen direkt von der T. gondii-Infektionsdosis abhängig (3.3). Ein deutlicher Unterschied stellt sich im MHC-Expressionsverhalten von primären Monozyten aus T. gondii-positiven bzw. -negativen Spendern dar: Überraschenderweise erreicht die Oberflächenfluoreszenz nach Immunfärbung, also die Menge der exprimierten MHC-Moleküle, auf Monozyten aus infizierten Spendern insgesamt deutlich höhere Werte als bei Zellpopulationen aus Toxoplasma-negativen Spendern (Abb. 3.11).

Diese Beobachtung erscheint zunächst widersprüchlich, da aus Mausmodellen bekannt ist, dass auch nicht-infizierte murine Makrophagen allein durch die Anwesenheit von z.B. aus Lysat oder Zellkultur-Überstand gewonnenen T. gondii-Antigenen in ihrer MHCExpression deutlich gehemmt werden (Lüder et al. 1998; Lang et al. 2006). Es wäre demnach zu vermuten, dass die Expression von MHC-Molekülen auch auf der Zelloberfläche von Parasit-negativen, primären Monozyten aus T. gondii-infizierten Individuen reduziert und nicht - wie in den vorliegenden Ergebnissen gezeigt - deutlich erhöht ist (3.3).

Diese auf den ersten Blick konträren Resultate könnten auf eine Dominanz bestimmter Subpopulationen von Monozyten in Abhängigkeit des Infektionsstatus ihres Wirtes zurückzuführen sein. Seit langem ist bekannt, dass beim Menschen verschiedene Subtypen von Makrophagen existieren, die sich in ihrer Differenzierung, Migration und Funktion unterscheiden (Strauss-Ayali et al. 2007; Chimma et al. 2009). Sie können anhand von Oberflächenmarkern und Adhäsionsmolekülen phänotypisch charakterisiert und je nach Expression von CD14- bzw. CD16-Glykoproteinen in „klassische“ (CD14 ${ }^{\mathrm{hi}} \mathrm{CD} 16$ ), „nicht-klassische“ $\left(\mathrm{CD} 14{ }^{\mathrm{dim}} \mathrm{CD} 16^{+}\right)$sowie „intermediäre“ $\left(\mathrm{CD} 14{ }^{\mathrm{hi}} \mathrm{CD} 16^{+}\right)$Populationen unterteilt werden. Klassische Monozyten sind zusätzlich zum CD14-CD16-Muster durch eine spezifische Ausprägung des Chemokin-Rezeptors CCR2 sowie eine starke phagozytische Aktivität und Zytokinproduktion charakterisiert. Ferner stellen sie mit ca. 90-95\% aller Monozyten den größten Subtyp dar. Nicht-klassische Monozyten hingegen 
imponieren mit einer deutlichen Expression von CCR5 und $\mathrm{CX}_{3} \mathrm{CR} 1$, einer vergleichsweise geringen Zytokinproduktion und reagieren nach LPS-Stimulus pro-inflammatorisch mit einer Ausschüttung von TNF- $\alpha$. Sie repräsentieren ca. 5-10\% aller Monozyten (StraussAyali et al. 2007; Auffray et al. 2009). Intermediäre Makrophagen, die bei gesunden Menschen ebenfalls nur einen geringen Prozentsatz der Gesamtpopulation ausmachen, sezernieren anti-inflammatorisches IL-10 und exprimieren umfangreich MHC-Klasse-IIMoleküle (Ziegler-Heitbrock et al. 1992; Chimma et al. 2009). Da bekannt ist, dass Infektionen die Zusammensetzung der Monozyten-Gesamtpopulation zu Gunsten der kleineren Subtypen stark verändern können (Strauss-Ayali et al. 2007), wäre eine solche Expansion der intermediären, vermehrt HLA-exprimierenden Population eine Erklärung für die erheblich gesteigerte HLA-Expression der Monozyten von Spendern mit chronischer Toxoplasmose. Diese Beobachtung wurde hier erstmalig für Infektionen mit dem Parasiten Toxoplasma gondii gezeigt, es wird jedoch mehrfach berichtet, dass die CD16 ${ }^{+}$-Monozyten-Subpopulation auch in anderen akuten wie auch chronischen Entzündungen bzw. Infektionen beim Menschen expandiert vorliegen können (Fingerle-Rowson et al. 1998; Nockher \& Scherberich 1998; Horelt et al. 2002; Mizuno et al. 2005). Insbesondere im Verlauf chronischer Infektionserkrankungen wie Hepatitiden (RodriguezMunoz et al. 2011; Zhang et al. 2011) oder bei HIV- bzw. AIDS-Patienten z. T. mit opportunistischen Infektionen (Dunne et al. 1996; Zembala et al. 1997; Han et al. 2009) lassen sich verstärkt, pro-inflammatorische $\mathrm{CD}^{+} 6^{+}$u.a. alveoläre MakrophagenPopulationen finden, die eine evident gesteigerte HLA-Expression aufweisen (Buhl et al. 1993; Lipman et al. 1995). Ähnliches wird interessanterweise auch für Infektionen mit Plasmodium falciparum, einem ebenfalls intrazellulär lebenden $T$. gondii-Verwandten des Phylums Apicomplexa und Erreger der Malaria tropica, beschrieben. So wird bei akuter, unkomplizierter P. falciparum-Malaria eine signifikante Reduktion klassischer Monozyten bei gleichzeitiger Zunahme von $\mathrm{CD}^{+} 6^{+}$-Monozyten des intermediären und nichtklassischen Typs, sowie eine gesteigerte Expression von HLA-DR beobachtet (Chimma et al. 2009).

Diese bei verschiedenen Infektionskrankheiten gewonnenen Erkenntnisse untermauern die Annahme, dass auch die in dieser Arbeit beschriebene, stark erhöhte HLA-Expression bei Makrophagen von T. gondii-positiven Individuen auf eine vorherrschende Expansion von Monozyten des Subtyps $\mathrm{CD} 14^{\mathrm{hi}} \mathrm{CD} 16^{+}$zurückzuführen sein könnte. Diese Hypothese 
bedarf jedoch einer experimentellen Prüfung durch genauere Charakterisierung nicht nur in Hinsicht auf MHC-Moleküle, sondern auch auf andere spezifische Oberflächenmarker. Die variablen Profile der Oberflächenproteine lassen Unterschiede in der Aktivierung der Monozyten vermuten, da beide Eigenschaften eng miteinander zusammenhängen (Gordon 2003; Raes et al. 2007; Mosser \& Edwards 2008). Monozyten der Maus werden als „klassisch“ bzw. ,alternativ“ aktiviert beschrieben. Eine derartige Aktivierung führt in der Folge zu jeweils unterschiedlichen Subpopulationen. Darüberhinaus ist die Gesamtpopulation von Monozyten einer Maus in Hinsicht auf die Oberflächenrezeptoren als sehr heterogen anzusehen (Mosser \& Edwards 2008). Da diese Eigenschaften muriner Monozyten stark mit denen des Menschen vergleichbar sind, führen weitere Überlegungen bezüglich des veränderten HLA-Expressions-Verhaltens von Monozyten Toxoplasma-positiver Menschen in Richtung einer unterschiedlichen Aktivierung / Polarisierung der Zellen in diesen Personen.

Durch verschiedenste Stimuli ihrer Umgebung aktiviert, können Makrophagen spezifische Eigenschaften annehmen und Aufgaben erfüllen (Mantovani et al. 2005). Interferon- $\gamma$ von $\mathrm{T}_{\mathrm{H}} 1$-Lymphozyten und mikrobielles LPS stellen den adäquaten Reiz einer klassischen Aktivierung von Makrophagen (M1) dar, die dadurch zu einer gesteigerten Produktion von zytotoxischen Stoffen wie TNF- $\alpha$, NO und Sauerstoffradikalen sowie proinflammatorischen Zytokinen (u.a. IL-12) und zu einer starken Zell-vermittelten Immunabwehr befähigt sind. Die alternative Aktivierung (M2) hingegen ist bis jetzt vergleichsweise lückenhaft erforscht, sie wird durch $\mathrm{T}_{\mathrm{H}}$ 2-Lymphozyten vermittelt und durch IL-4 oder IL-13 (M2a), durch Immunkomplexe zusammen mit IL-1 $\beta$ oder LPS (M2b) bzw. durch IL-10, TGF- $\beta$ oder Glucocorticoide (M2c) ausgelöst (Gordon 2003; Gordon \& Taylor 2005; Martinez et al. 2008). Seit längerem ist bekannt, dass IL-4 bei Makrophagen die Expression von MHC-Klasse-II-Molekülen induziert und in der Bekämpfung von Parasiten wie z.B. Trypanosoma cruzi, einem im Menschen intrazellulär lebenden Protozoon, eine entscheidende Rolle spielt (Cao et al. 1989; Wirth et al. 1989). Die Ergebnisse dieser Arbeit würden demnach für eine expandierte, nicht-klassisch aktivierte (M2a) Monozyten-Population sprechen. Gleichwohl wurde berichtet, dass der in europäischen Breiten dominierende $T$. gondii Typ II im Gegensatz zu den klonalen Typen I und III zu einer klassischen Aktivierung von Monozyten der Maus führt (Jensen et al. 2011). Die klassische Aktivierung (M1) ist ebenfalls mit einer gesteigerten MHC-Klasse-II-Aktivität 
verknüpft (Gordon \& Taylor 2005) und käme somit genauso als Ursache der verstärkten MHC-Expression in Monozyten von T. gondii-positiven Individuen in Frage.

Die unerwartet deutliche MHC-Expression in nicht-infizierten Monozyten von Toxoplasma-positiven Individuen könnte auch auf eine Voraktivierung der Zellen zurückzuführen sein. Es ist bekannt, dass T. gondii neben anti- auch pro-inflammatorische Effekte auf das Immunsystem seines Wirtes ausübt, da bei unzureichender Immunreaktion des Wirtes - wie z.B. bei Ausbruch von AIDS - eine unlimitierte Parasitenvermehrung zum Ableben des Wirtes führen kann (Montoya \& Liesenfeld 2004). Ein latent aktiviertes Immunsystem ist für T. gondii zur Etablierung einer chronischen Infektion demzufolge von größter Bedeutung (Denkers 2003; Miller et al. 2009). Ein Schlüsselpunkt der Immunstimulation durch den Parasiten stellt das Zytokin Interleukin-12 dar, welches u.a. von Monozyten, Granulozyten und Dendritischen Zellen nach T. gondii-Antigen-Kontakt produziert wird und zu einer Interferon- $\gamma$-abhängigen Reaktion u.a. mit verstärkter Expression von MHC-Molekülen führt (Aliberti 2005). Man geht hierbei von zwei unterschiedlichen - jedoch wahrscheinlich voneinander abhängigen - Kaskaden aus, über die $T$. gondii die Produktion von IL-12 anregen kann: So können nach Stimulation des TLR Adapterproteins MyD88 mittels löslichem Parasiten-Antigen (STAg) und der nachfolgenden Aktivierung von NFkB, sowie durch T. gondii Cyclophilin-18 (C-18) über CC-Chemokin-Rezeptoren (CCR5) stark erhöhte Level IL-12 induziert und nachfolgend eine gesteigerte MHC-Expression beobachtet werden (Denkers 2003; Aliberti 2005). Letztgenannter Weg über CCR5-Stimulation würde zudem die Hypothese der oben beschriebenen Expansion nicht-klassischer CD16 ${ }^{+}$-Monozyten bekräftigen, da diese vermehrt CCR5 exprimieren. Eine Hochregulation von HLA-Molekülen bei Parasitnegativen Makrophagen kann darüberhinaus durch T. gondii-spezifisches Glycosylphosphatidylinositol (GPI) hervorgerufen werden. Interessanterweise ist dies überwiegend STAT1- sowie Interferon- $\gamma$-unabhängig, wobei eine GPI-induzierte Aktivierung der MHC-I- und -II-Kaskade über pro-inflammatorische Zytokine wie TNFa oder den Transkriptionsfaktor IRF-1 sowie NFkB für möglich gehalten wird (Debierre-Grockiego et al. 2009). 
Zusammenfassend lässt sich festhalten, dass die Frage des $T$. gondii-Infektionsstatus eines Spenders für die Ausprägung der MHC-Expression seiner Monozyten von großer Bedeutung zu sein scheint, da chronisch mit T. gondii infizierte Wirte offensichtlich eine deutlich veränderte Zusammensetzung bzw. Polarisierung der Makrophagen-Population des peripheren Bluts aufweisen. Die MHC-Expression von aus PBMC isolierten Monozyten von Spendern mit chronischer Toxoplasmose war in dieser Arbeit - unabhängig von einer in-vitro-Infektion mit $T$. gondii oder einer Interferon- $\gamma$-Stimulation - im Vergleich mit Zellen aus T. gondii-negativen Spendern insgesamt deutlich erhöht. Dies war vom Infektionsstatus der einzelnen Zelle erstaunlicherweise unabhängig.

Es ist bemerkenswert, wie $T$. gondii in chronisch infizierten Individuen zu einer derartigen Steigerung der HLA-Expression in Monozyten führen kann. Eine ausgeprägte MHCAktivierung ist bei hochakuten Infektionen oder einer Sepsis nachvollziehbar; bei Patienten mit chronischer Toxoplasmose ist solch ein Ergebnis jedoch überraschend, da in diesem Stadium der Infektion nur relativ wenige Bradyzoiten enthaltende Zysten u.a. in ZNS oder Muskulatur, aber nicht in zirkulierenden Monozyten vorkommen, die nach heutigem Wissensstand - im Gegensatz zu Tachyzoiten in der akuten Infektionsphase als nur gering immunogen gelten (Kim \& Boothroyd 2005b; Skariah et al. 2010). Diese Beobachtung führt zu der Frage, wie diese Form der Immunstimulation durch eine geringe Anzahl von T. gondii-Zysten über längere Zeit aufrecht erhalten werden kann. Es ließe sich zum Einen vermuten, dass eine Tachyzoiten-induzierte, anfängliche Verschiebung der Subpopulationen und / oder Polarisierung der Monozyten durch einen spezifischen, noch unbekannten Stimulus der Zysten gefördert wird. Andererseits könnte man auch eine sehr stabile Polarisierung annehmen, die einmal initial hergestellt ohne zusätzlichen Stimulus jahrelang persistieren kann. Darüberhinaus müssen an diesem Punkt auch die immunologischen Konsequenzen für den Wirt beachtet werden: Es ist davon auszugehen, dass eine anhaltend erhöhte MHC-Expression zu einer besseren Antigen-Präsentation und somit zu einer permanent verstärkten Reaktivität führt. Da diese Antigene nicht nur Peptide von T. gondii, sondern auch anderer Erreger präsentieren können, müsste in fortführenden Studien z.B. ein möglicher Zusammenhang einer durch chronische Toxoplasmose gesteigerten Immunreaktivität bei anderen Infektionserkrankungen überprüft werden. 


\subsection{T. gondii inhibiert dosisabhängig die MHC- Expression in primären und permanenten humanen Monozyten}

In dieser Arbeit wurde mittels Durchflusszytometrie erstmalig gezeigt, dass eine Infektion mit Toxoplasma gondii die Expression von HLA-Molekülen in primären, aus peripherem Blut des Menschen isolierten Monozyten nach Infektionen ex vivo hemmt. Hierbei wurde sowohl die konstitutive Expression von HLA-A, -B, -C als auch die Interferon- $\gamma$ abhängige HLA-DR-, -DP-, -DQ-Expression in Abhängigkeit vom Parasit-zu-WirtszellVerhältnis inhibiert. Nicht-infizierte Monozyten vermögen zwar nach einer Stimulation mit Interferon- $\gamma$ verstärkt Moleküle beider MHC-Klassen zu exprimieren, T. gondiipositive Zellkulturen unterliegen jedoch trotz Zytokin-Stimulus einer signifikanten und von der Parasitendosis abhängigen Inhibition der Expression von MHC-Klasse I und II (3.1.1, Abb. 3.3). Dabei war es irrelevant, ob die Monozyten aus Toxoplasma-positiven oder Toxoplasma-negativen Spendern isoliert worden waren.

Nachdem frühere Arbeiten bereits belegten, dass T. gondii mit der MHC-Expression von Antigenpräsentierenden Zellen (APC) interferieren kann (Lüder et al. 1998; Lüder et al. 2001; Lüder et al. 2003b; Lang et al. 2006), waren die Ergebnisse dieser Versuche nicht überraschend. Diese früheren Experimente waren allerdings mit Astrozyten, Mikroglia sowie Knochenmarksmakrophagen (BMM, murine bone marrow derived macrophages) von Labormäusen durchgeführt worden. Nach den Ergebnissen mit Zellen der Maus ist der nun in dieser Arbeit erfolgte Schritt, eine mögliche Inhibierung der MHC-Expression in humanen Makrophagen zu untersuchen, konsequent. Der Einfluss von T. gondii auf die IFN- $\gamma$ regulierte Genexpression von humanen Zellen war bisher nur einmal untersucht worden. Dabei wurde ein inhibitorischer Einfluss von $T$. gondii auf die Interferon- $\gamma$ Signalkaskade in humanen Fibroblasten (HFF, human foreskin fibroblasts) beschrieben (Kim et al. 2007). Fibroblasten sind neben anderen Zelltypen für die intrazelluläre Vermehrung von $T$. gondii in vivo vermutlich von großer Bedeutung. In Bezug auf die Immunantwort eines Wirtes nehmen Makrophagen jedoch eine bedeutend wichtigere Rolle als Fibroblasten ein. Im Gegensatz zu Fibroblasten sind Makrophagen phagozytisch sehr aktiv und gehören zu den professionellen, Antigen-präsentierenden Zellen. Makrophagen sind auch für die Infektabwehr von T. gondii von zentraler Bedeutung (Denkers 2003; Lykens et al. 2010). Mit dem erstmaligen Nachweis, dass T. gondii einen von der Infektionsdosis abhängigen, hemmenden Einfluss auch auf die HLA-Expression von Monozyten 
des Menschen ausübt, wurde diese Lücke nun durch die vorliegende Arbeit geschlossen. Darüberhinaus ließ die Tatsache, dass es sich bei den verwendeten primären Monozyten um isolierte ex-vivo-Zellen handelt, für die Ergebnisse eine hohe Aussagekraft für den menschlichen Organismus erwarten.

\section{$\underline{\text { PBMC }}$}

Der Vergleich von Ergebnissen früherer Experimente in murinen Makrophagen (Lüder et al. 1998) mit den Resultaten dieser Arbeit lassen zahlreiche Übereinstimmungen sowie wenige Unterschiede deutlich werden: In FACS-Analysen stellte sich heraus, dass die IFN- $\gamma$-unabhängige HLA-A-, -B-, -C-Expression von Makrophagen des Menschen mit zunehmender T. gondii-Infektionsdosis zwar nicht signifikant, aber dennoch klar gehemmt wird. Im Gegensatz dazu zeigen murine, nicht-stimulierte Makrophagen keine wesentliche Veränderung ihrer konstitutiven MHC-Klasse-I (H-2D)-Expression, und zwar überraschenderweise unabhängig vom Infektionsstatus der Zellpopulation. Nach Interferon- $\gamma$ Stimulation wird die MHC-Klasse-I-Expression in humanen Makrophagen deutlich sowie die in Maus-Monozyten leicht hochreguliert, wobei eine Infektion mit T. gondii die MHC-I-Expression in beiden Fällen dosisabhängig und signifikant inhibiert. Beim Vergleich der MHC-Klasse-II-Expression zeigen humane Makrophagen bemerkenswerterweise auch in Abwesenheit von Interferon- $\gamma$ eine deutliche Expression von HLA-DR, -DP, -DQ (vgl. 4.1), die abhängig von der Infektionsdosis durch T. gondii stark gehemmt wird. Murine Monozyten exprimieren dagegen ohne Zytokin-Stimulus nur sehr geringe Mengen MHC-Klasse II (I-A/I-E), die auch mit hohen Infektionsdosen von T. gondii nur geringfügig inhibiert werden. Gemeinsam ist humanen und murinen Monozyten indes eine IFN- $\gamma$-induzierte Hochregulation von MHC-Klasse II, welche bei beiden Spezies durch T. gondii dosisabhängig und signifikant gehemmt wird.

\section{$\underline{\text { THP-1 }}$}

Zusätzlich zu den Experimenten mit primären Monozyten aus PBMCs wurde in dieser Arbeit der Einfluss von T. gondii auf humane permanente Monozyten der Zelllinie THP-1 untersucht, da sie ähnliche Eigenschaften wie primäre Monozyten aufweisen (Tsuchiya et al. 1980), jedoch in größeren Mengen verfügbar und einfacher zu kultivieren sind. Durchflusszytometrische Versuche demonstrieren hier, vergleichbar mit primären humanen Monozyten, dass T. gondii die konstitutive HLA-A-, -B-, -C-Expression nicht- 
aktivierter THP-1-Monozyten abhängig von der Parasitendosis inhibiert. Während diese Hemmung bei primären humanen Monozyten wenig, aber deutlich erkennbar und bei murinen Zellen äußerst gering ausgeprägt ist (siehe oben, PBMC), kommt es bei THP-1Zellen zu einer z. T. hoch signifikanten Inhibierung. Auf IFN- $\gamma$-Stimulation reagierten permanente Monozyten mit einer deutlich gesteigerten MHC-Klasse-I-Expression, diese war jedoch in gleicher Weise wie in primären, humanen sowie murinen Monozyten abhängig von der Parasitendosis sehr deutlich und zum Teil signifikant durch T. gondii gehemmt (Abb. 3.5) .

Während nicht-stimulierte, primäre Monozyten deutlich HLA-DR, -DP, -DQ auf ihrer Zelloberfläche exprimieren, ist dies bei permanenten THP-1-Monozyten nicht zu beobachten. Vergleichbar mit murinen Makrophagen (Lüder et al. 1998) findet bei THP-1-Zellen nur eine äußerst geringe konstitutive MHC-Klasse-II-Expression statt, welche durch eine Infektion mit Toxoplasmen kaum weiter reduziert wird. Dagegen ist nach Stimulation von THP-1-Zellen mit IFN- $\gamma$ - ähnlich wie bei aktivierten primären Monozyten - die HLA-DR-, -DP-, -DQ-Expression deutlich hochreguliert und mit zunehmender T. gondiiInfektionsrate supprimiert. Diese Beobachtung deckt sich mit korrespondierenden Ergebnissen bei Monozyten murinen Ursprungs.

Der Einfluss der IFN- $\gamma$-Konzentration auf die Parasiten-vermittelte Hemmung von MHC-Molekülen

Versuche dieser Arbeit weisen nicht nur einen inhibitorischen Einfluss von T. gondii auf die HLA-Expression humaner Monozyten nach (3.1), sondern zeigen außerdem, dass dieser hemmende Effekt auch durch hohe Konzentrationen von Interferon- $\gamma$ nicht kompensiert werden kann (3.2). Diese Resultate decken sich mit denen bei murinen Makrophagen, die trotz Steigerung der Interferon- $\gamma$-Konzentration von $25 \mathrm{U} / \mathrm{ml}$ auf $100 \mathrm{U} / \mathrm{ml}$ keinen Anstieg der MHC-Klasse-II-Expression in Gegenwart von T. gondii zeigten (Lüder et al. 1998). MHC-Klasse-I-Moleküle wurden in murinen Monozyten hingegen konstitutiv exprimiert, durch IFN- $\gamma$ leicht hochreguliert und nach einer Infektion mit $T$. gondii signifikant gehemmt. 
Zusammenfassend lässt sich feststellen, dass in der vorliegenden Arbeit der Nachweis gelungen ist, dass T. gondii die MHC-Expression auch in humanen Makrophagen deutlich hemmt. Die Resultate sind dabei in zahlreichen Aspekten mit der schon bekannten inhibitorischen Wirkung auf murine Monozyten vergleichbar. Zusätzlich ergeben sich wenige aber bemerkenswerte Unterschiede zwischen humanen und murinen Monozyten: Zum Einen gibt die Tatsache Anlass für weiterführende Experimente, dass humane Makrophagen in der konstitutiven Expression von MHC-Klasse I klar durch T. gondii supprimiert werden, wohingegen dies bei MHC-Klasse-I (H-2D)-Molekülen der Maus auch nach Infektion mit hohen Parasitendosen nicht der Fall ist (Lüder et al. 1998). Hervorzuheben ist zum Anderen die beachtlich gesteigerte, Interferon- $\gamma$-unabhängige HLA-DR-, -DP, -DQ-Expression bei ex-vivo-isolierten primären Monozyten (PBMC) des Menschen. In Abwesenheit von IFN- $\gamma$ lässt sich solch eine deutliche MHC-Klasse-II-Expression weder bei humanen THP-1-Zellen noch bei murinen Monozyten konstatieren. Da diese Beobachtung mit primären Monozyten sowohl T. gondii-positiver als auch -negativer Spender gemacht wurde, erscheint hier Raum für weitere Vergleiche bzgl. des HLAExpressionsverhaltens und Infektionsstatus (vgl. 4.1).

Insgesamt zeigen die Ergebnisse dieser Arbeit, dass T. gondii sowohl primäre als auch permanente Monozyten des Menschen Infektionsdosis-abhängig in der Expression von MHC-Klasse I und II hemmt. Dies weist darauf hin, dass die Inhibierung der Expression von MHC-Molekülen bei Makrophagen des Menschen - entsprechend denen der Maus (Lüder \& Seeber 2001) - als Evasionsmechanismus von Toxoplasma gondii angesehen werden kann. 


\subsection{Mechanismen der verminderten HLA-Expression nach T. gondii-Infektion}

Zum genaueren Verständnis der Mechanismen, die zu einer Inhibierung der HLAExpression in humanen Monozyten durch $T$. gondii führen, wurden neben durchflusszytometrischen Analysen indirekte Immunfluoreszenztests (IFT) sowie quantitative Real-Time-PCR durchgeführt.

\subsubsection{Die Hemmung der HLA-Expression auf Einzelzellebene}

Zusätzlich zu einer Betrachtung der durch T. gondii veränderten MHC-Oberflächenexpression in FACS-Analysen $(3.1 .1,3.1 .2)$ kann durch indirekte Immunfluoreszenztests (IFT) auch die Verteilung und intrazelluläre Lokalisation von HLA-Molekülen T. gondiiinfizierter, humaner Monozyten untersucht werden. Darüberhinaus ist es mit Hilfe von IFTs möglich, das Expressions-Verhalten der einzelnen Zelle in den Kontext der Gesamtpopulation zu stellen (3.1.3). Analysen mittels Immunfluoreszenztests ergaben, dass T. gondii die Expression von HLA-DR, -DP, -DQ in infizierten humanen Monozyten signifikant hemmt. Es konnte dabei beobachtet werden, dass sowohl die intrazelluläre als auch die Oberflächenexpression der MHC-Moleküle unter dem inhibitorischen Einfluss von Toxoplasmen steht. Interessanterweise zeigte sich außerdem, dass die Suppression der MHC-Klasse-II-Expression nicht nur auf Parasit-positive Zellen beschränkt war, sondern in signifikantem Umfang auch nicht-infizierte Makrophagen einer T. gondii-infizierten Kultur betraf (Abb. 3.8).

Diese Beobachtung erscheint zunächst unerwartet, da in mehreren Studien eine Hemmung der MHC-Expression durch Toxoplasmen vornehmlich bei infizierten Zellen nachgewiesen wurde. Dabei zeigen die Ergebnisse, dass eine Inhibierung durch T. gondii bei humanen Fibroblasten ausschließlich und bei murinen Makrophagen hauptsächlich auf Parasit-positive Zellen beschränkt ist (Lüder et al. 1998; Lang et al. 2006; Kim et al. 2007). Neue Hinweise, dass Toxoplasmen offensichtlich auch Parasit-negative Zellen einer T. gondii-infizierten Umgebung in der Expression von MHC-Molekülen hemmen, werfen die Frage nach dem hier zugrundeliegenden Mechanismus auf. 
Es gibt verschiedene Hinweise für einen löslichen, parasitären Stoff, der einen inhibitorischen Einfluss auf nicht-infizierte sogenannte „Bystander“-Zellen in der Umgebung einer T. gondii-infizierten Zelle ausübt. So sind in der Literatur bereits unterschiedliche sowohl in der akuten als auch chronischen Phase einer Toxoplasmose - von T. gondii sezernierte Stoffe (z.B. ESA, excreted/secreted Antigens) beschrieben, die u.a. für die Zellinvasion und Replikation wichtig sind (Cesbron-Delauw \& Capron 1993; Carruthers 2002; Diana et al. 2005). Die Herkunft, Zusammensetzung sowie Funktion solcher Proteine sind zwar bereits zum Teil bekannt, jedoch noch Gegenstand intensiver Forschung (Dlugonska et al. 2001; Son \& Nam 2001; Costa-Silva et al. 2008; Saadatnia et al. 2011). Ein möglicher Mechanismus der Einflussnahme durch T. gondii könnten sezernierte Proteine darstellen, die unabhängig von intrazellulären Prozessen direkt vom Parasiten an die Umgebung abgegeben werden. Bekannt ist, dass Mikronemen-, Rhoptrien- und GRAProteine während und nach der Wirtszellinvasion sezerniert werden und v.a. für die Invasion und zur Etablierung einer parasitophoren Vakuole (PV) bzw. zur Sicherung des intrazellulären Überlebens in die Zelle ausgestoßen werden (Nam 2009). Die These, dass sezernierte Proteine von T. gondii für den supprimierenden Effekt verantwortlich sind, wird durch aktuelle Veröffentlichungen gestützt. Die Autoren der Studie vermuten, dass der hemmende Einfluss von Toxoplasmen auf die MHC-Expression von murinen Makrophagen möglicherweise sezernierten Mikronemenproteinen von T. gondii zuzuschreiben ist (Stutz et al. 2011). Neben Mikronemenproteinen kämen ebenfalls Rhoptrien- oder Dichte Granula-Proteine als Ursache für diesen Effekt in Frage. Hier würden sich hydrophile Vertreter wie z.B. GRA1 oder GRA5 als mögliche Kandidaten anbieten. Für sezernierte Proteine würde unabhängig vom Proteintyp sprechen, dass Toxoplasmen in Form eines konzentrierten Extrakts bzw. Lysats auch ohne vorherige Wirtszell-Invasion die MHC-Klasse-II-Expression bei Parasit-negativen Makrophagen inhibieren können (Lang et al. 2006; Stutz et al. 2011).

Es ist jedoch auch ein anderer Mechanismus der MHC-Inhibition nicht-infizierter Zellen durch T. gondii möglich. Nicht der Parasit selbst, sondern infizierte Wirtszellen könnten vermehrt lösliche Faktoren sezernieren, die dann über Oberflächenrezeptoren inhibitorisch auf nicht-infizierte Zellen der Umgebung wirken. Dies könnte z.B. durch eine Produktion von Zytokinen wie IL-10 oder TGF- $\beta$ vermittelt sein (Czarniecki et al. 1988; Chan et al. 2010). Die Produktion des anti-inflammatorischen Interleukin-10 wird zwar durch den 
Kontakt mit T. gondii-Lysat (TL) angeregt, scheidet hier jedoch als Faktor aus, da es nachweislich nicht an einer parasitären MHC-Inhibition beteiligt ist (Lang et al. 2006).

Die hier genannten Strategien sowie weitere mögliche Wege der MHC-Inhibition nichtinfizierter Zellen durch T. gondii sind denkbar, bedürften gleichwohl einer genaueren experimentellen Überprüfung.

\subsubsection{Eine Infektion mit T. gondii führt zu einer dosisabhängigen Inhibierung von Transkriptionsfaktoren der HLA-Kaskade}

Analysen der mRNA von Transkriptionsfaktoren und HLA-Molekülen der Interferon- $\gamma$ Signalkaskade mit Hilfe der quantitativen Real-Time-PCR (qRT-PCR) erbrachten eindeutige Ergebnisse: Die für die HLA-Kaskade (1.3.2) essentiellen Transkriptionsfaktoren IRF-1 (interferon-regulatory factor 1) und CIITA (class II transactivator) werden Infektionsdosis-abhängig durch $T$. gondii zum Teil hoch signifikant supprimiert. Die am Ende des Signalweges synthetisierten MHC-Moleküle HLA-DR $\alpha$ und HLA-A unterliegen ebenfalls einer Parasitendosis-abhängigen Inhibition durch Toxoplasmen (3.4.1). Diese Beobachtungen stehen in Einklang mit früheren Versuchen, in denen der Effekt von T. gondii auf die Expression von CIITA und MHC-Molekülen bei Makrophagen der Maus untersucht wurde (Lüder et al. 2001; Lüder et al. 2003b). Bei Betrachtung der Ergebnisse dieser Arbeit scheint sich der hemmende Einfluss von T. gondii auf mehrere Abschnitte der MHC-Klasse-II-Expressions-Kaskade zu erstrecken und die genannten Transkriptionsfaktoren und MHC-Moleküle jeweils einzeln zu supprimieren. Denkbar und sehr wahrscheinlich ist jedoch ein anderer Ansatzpunkt der Inhibierung: Möglicherweise beruht die Hemmung von HLA-Molekülen sowie des Haupttranskriptionsfaktors CIITA auf einem parasitären Eingriff in frühe Abschnitte der Signalkaskade. Die deutliche Hemmung von z.B. IRF-1 könnte so zu einem additiven Effekt führen und die nachfolgende Strecke des Signalwegs auch ohne weiteren Einfluss des Erregers hemmen (Abb. 4.1). Eine wichtige Rolle, ebenfalls weit am Anfang der Kaskade, nimmt zudem STAT1 $\alpha$ (Signal transducer and activator of transcription 1 alpha) ein. In früheren Arbeiten lagen Hinweise vor, dass der Import von STAT1 $\alpha$-Molekülen in den Zellkern durch eine Infektion mit T. gondii reduziert ist und so die IFN- $\gamma$-Kaskade frühzeitig inhibiert wird (Lüder et al. 2001). Zwar bestätigte sich die Vermutung der Import-Blockade nicht (Lang et al. 2006), neueste Untersuchungen kommen jedoch zum Schluss, dass der Parasit an anderer Stelle mit der Bindung von STAT1 $\alpha$ an IFN- $\gamma$-regulierte Promotoren interferiert. Es konnte gezeigt werden, dass Toxoplasmen Prozesse des Chromatinumbaus an IFN- $\gamma$-regulierten Promoto- 
ren inklusive des CIITA-Promotors IV verhindert. So reduziert T. gondii in infizierten Zellen die Aktivität der Chromatin Remodeling Komplexe BRG1 (brahma-related gene 1) und HAT (Histone acetyltransferases) von Histonen an den Promotoren deutlich (Lang et al. 2012). Diese Komplexe haben die Aufgabe, durch eine Acetylierung bzw. Modifizierung von Histonen die Bindungsstellen der korrespondierenden Transkriptionsfaktoren (wie z.B. STAT1 $\alpha$ ) freizugeben und den freien Ablauf der IFN- $\gamma$-Signalkaskade zu ermöglichen. Eine Infektion mit Toxoplasma gondii verhindert dies nachweislich in signifikantem Maße.

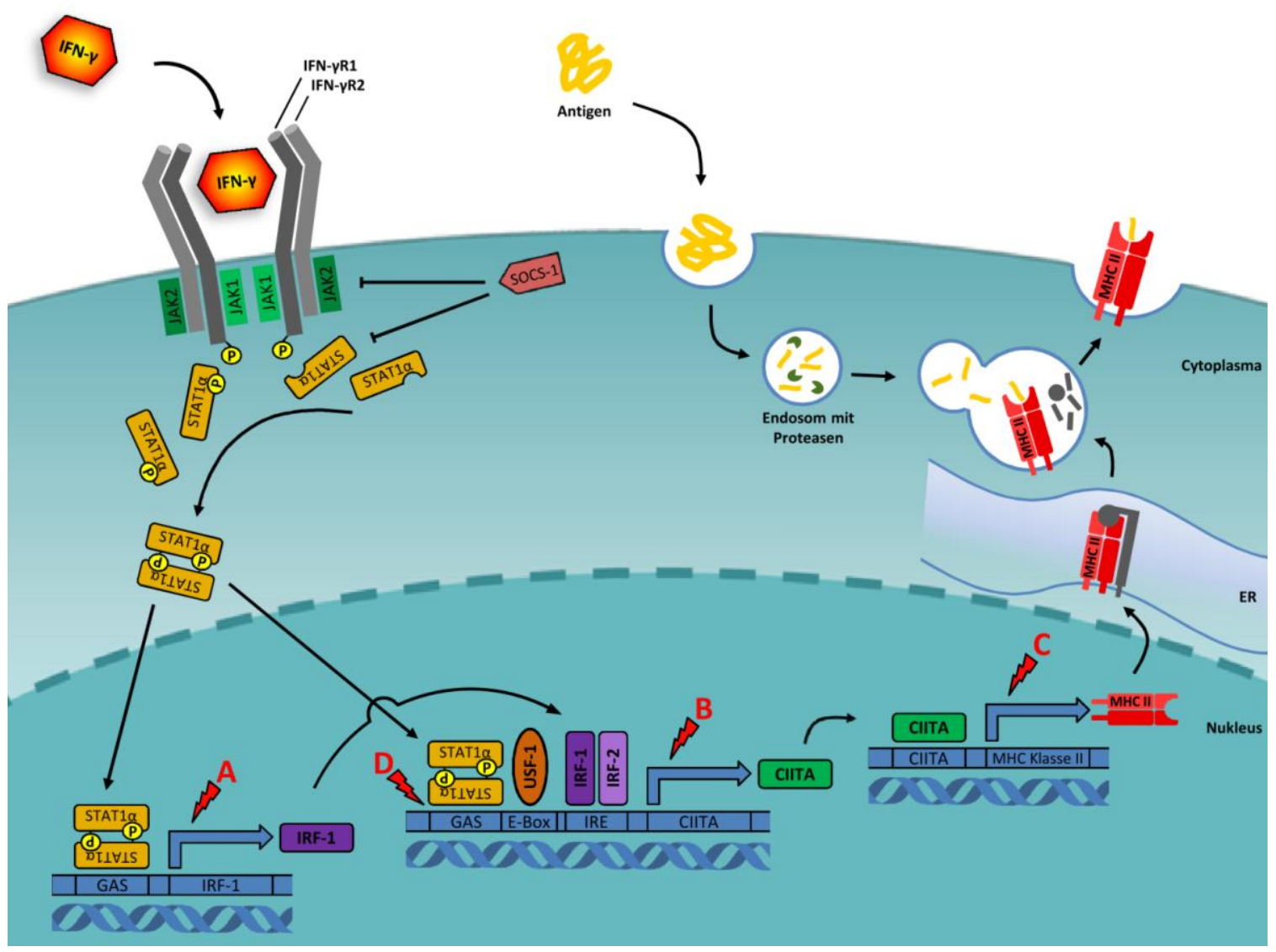

Abb. 4.1 Inhibition der Interferon- - -Signalkaskade durch Toxoplasma gondii

In der Grafik sind beispielhaft Ansatzpunkte einer Inhibition der IFN- $\gamma$-Signalkaskade durch $T$. gondii dargestellt (siehe auch 1.3.2). Analysen dieser Arbeit zeigen, dass die mRNA-Expression der Transkriptionsfaktoren IRF-1 (A) und CIITA (B) in T. gondii-infizierten Zellen signifikant gehemmt wird. Die Genexpression der MHC-Moleküle HLA-DR $\alpha$ und HLA-A unterliegt ebenfalls in signifikantem Maße einer parasitären Inhibierung (C). Außerdem greift T. gondii in das Chromatin-Remodeling von Transkriptionsfaktoren ein (D). Weitere Erläuterungen sind dem Text zu entnehmen.

Der Interaktion von $T$. gondii mit dem Interferon- $\gamma$-Signalweg kommt offenbar eine Schlüsselstellung in der parasitären Einflussnahme auf das Immunsystem seines Wirtes zu. Insbesondere in Makrophagen wirkt sich eine Inhibierung der Signalkaskade offen- 
sichtlich äußerst nachteilig auf die zelluläre Infektabwehr aus. So weisen Mäuse mit IFN- $\gamma$-Rezeptor-defizienten Makrophagen (MIIG, macrophages insensitive to IFN- $\gamma$ ) eine vom Immunsystem kaum zu kontrollierende Parasitenlast sowie eine deutlich erhöhte Sterblichkeit auf (Lykens et al. 2010). Die Autoren der Publikation unterstreichen hierin zudem die essentielle Rolle von Makrophagen in der IFN- $\gamma$-vermittelten Abwehr gegen T. gondii und vergleichen die Folgen des IFN- $\gamma$-Rezeptor-Defekts mit denen bei Mäusen mit dem Phänotyp IFN- $\gamma^{-/}$(Lykens et al. 2010). Patienten, die heterozygot von solch einer Mutation betroffen $\operatorname{sind}^{7}$, scheinen dennoch keine signifikant erhöhte Suszeptibilität gegenüber T. gondii zu haben als gesunde Individuen (Janssen et al. 2002). Die Mutation lässt die meist jungen Patienten jedoch oft an schweren Infekten leiden und teils früh versterben (Sologuren et al. 2011).

Interferon- $\gamma$ ist in der Literatur unbestritten ein essentieller Bestandteil der parasitären Immunabwehr (Yap \& Sher 1999; Carruthers \& Suzuki 2007). Der Wirkungsausfall des Zytokins z.B. durch Interferenz mit der Signalkaskade kann - wie mehrfach bei Mäusen beschrieben - gravierende oder sogar letale Folgen für den Wirt haben. Die Ergebnisse dieser Arbeit mit humanen Monozyten ähneln vielfach denen aus Versuchen mit murinen Zellen. Es spricht vieles dafür, dass die entdeckten Mechanismen auch auf den Menschen zu übertragen sind. Interessant ist an dieser Stelle demnach die Frage, welche Auswirkung eine Inhibition der Interferon- $\gamma$-Kaskade auf den Menschen hat. Wie oben beschrieben kann ein genetischer Defekt des IFN- $\gamma$-Rezeptors durch eine verstärkte Anfälligkeit für Erreger ernste pädiatrische Krankheitsbilder hervorrufen. Es stellt sich die Frage, ob an Toxoplasmose erkrankte Individuen durch einen hierdurch gehemmten Interferon- $\gamma$ Signalweg eine gegen andere Pathogenen ebenfalls supprimierte Immunantwort aufweisen. Im Rahmen einer akuten Toxoplasmose, in der ein größerer Teil der Makrophagen von Parasiten lokal befallen sein können, könnte eine gehemmte MHC-Klasse-IIExpressions-Kaskade durchaus Einfluss auf den Immunstatus des Wirtes gegenüber anderen Antigenen haben. Bei einer chronischen Infektion kommen hingegen in der Regel nur wenige T. gondii-Zysten in Gehirn und Muskulatur vor. Es ist demnach eher unwahrscheinlich, dass die Immunreaktion des Individuums signifikant beeinträchtigt ist, kann aber aufgrund der Ergebnisse dieser Arbeit nicht ausgeschlossen werden (4.1).

\footnotetext{
${ }^{7}$ Rezessive, partielle IFNGR1-Defizienz
} 


\subsection{Resümee und Ausblick}

Es wurde in dieser Arbeit erstmals der Nachweis bei humanen Makrophagen erbracht, dass eine Infektion mit dem Protozoon T. gondii die IFN- $\gamma$-vermittelte MHC-Präsentation in Monozyten, also einer für eine effektive Parasitenabwehr essentiellen Zellpopulation, sehr effektiv supprimiert. Toxoplasmen scheinen Makrophagen darüberhinaus nicht nur in ihrer Antigen-Präsentation deutlich zu hemmen, sondern möglicherweise auch in der Aktivierung sowie der Zusammensetzung der Zellpopulation wesentlich zu modulieren (4.1). Eine genauere Identifizierung von Monozyten-Subpopulationen bei Toxoplasmapositiven und -negativen Individuen würde Ansatzpunkte für weiterführende Experimente bieten. Außerdem ist zu untersuchen, ob die offensichtlich anhaltend erhöhte MHCExpression bei chronisch mit T. gondii infizierten Wirten (3.3) unter Umständen zu einer gesteigerten Immunreaktivität mit anderen Infektionserregern führen kann. Während einer akuten Infektion hingegen überwiegt vermutlich der inhibitorische Effekt von $T$. gondii auf die MHC-Expression von Monozyten. Mögliche Veränderungen in der Immunreaktion auf andere Pathogene bei T. gondii-positiven Personen könnten daher einen bedeutenden Fokus zukünftiger klinischer Untersuchungen darstellen. 


\section{Zusammenfassung}

Toxoplasma gondii ist ein obligat intrazellulär lebender protozoischer Parasit, der ubiquitär vorkommt und sich durch ein breites Wirtsspektrum sowie lebenslang persistierende Infektionen bei Menschen und Tieren auszeichnet. Eine Toxoplasmose verläuft bei immunkompetenten Wirten meist mit geringen Symptomen oder asymptomatisch. Dagegen können die Reaktivierung einer latenten Infektion bei immunsupprimierten Patienten und eine Erstinfektion während der Schwangerschaft mit anschließender konnataler Toxoplasmose des Fetus klinisch sehr schwere Krankheitsbilder bis zum Tod verursachen. T. gondii hat für ein langfristiges Überleben unterschiedliche Mechanismen entwickelt, die ein Gleichgewicht zwischen der Pathogenität des Erregers und der intakten Immunabwehr des Wirtes gewährleisten. In diesem Kontext stellt die Modulation von Signalwegen der Wirtszelle eine wichtige Überlebensstrategie von Toxoplasmen dar. Frühere Arbeiten mit murinen Monozyten haben gezeigt, dass T. gondii die Expression von MHC-Klasse-II-Molekülen auf der Oberfläche infizierter Wirtszellen hemmt und dadurch eine effektive Antigenpräsentation an T-Helfer-Lymphozyten verhindert.

Das Ziel der vorliegenden Arbeit war es herauszufinden, inwieweit Toxoplasma gondii auch die Interferon- $\gamma$-induzierte MHC-Expression von Monozyten des Menschen vermindert. Analysen mittels Durchflusszytometrie und Immunfluoreszenzfärbung zeigten, dass sowohl primäre, aus PBMC des Menschen isolierte Monozyten als auch permanente humane Monozyten (THP-1) durch eine Infektion mit T. gondii in der Expression von HLA-A, -B, -C und HLA-DR, -DP, -DQ signifikant gehemmt werden. Das Ausmaß der Inhibition ist dabei von der Infektionsdosis des Parasiten abhängig und betrifft sowohl die HLA-Expression auf der Zelloberfläche als auch den intrazellulären HLA-Pool. Interessanterweise kann dieser Effekt auch durch hohe Konzentrationen des stimulierenden Zytokins Interferon- $\gamma$ nicht aufgehoben werden. Es zeigt sich außerdem eine signifikant reduzierte Expression von HLA-DR, -DP, -DQ bei Parasit-negativen Zellen einer T. gondii-infizierten Kultur, was möglicherweise durch sezernierte Proteine des Parasiten oder durch die Produktion hemmender Zytokine durch infizierte Wirts-Zellen begründet sein kann.

Die HLA-Expression in in vitro-infizierter und nicht-infizierter primärer Monozyten wurde darüberhinaus hinsichtlich des Infektionsstatus der Spender untersucht. Dazu wurden chronisch mit $T$. gondii infizierte Blutspender wurden serologisch anhand von 
spezifischen IgG-Antikörpern identifiziert. Durchflusszytometrisch zeigte sich, dass Monozyten aus chronisch mit T. gondii infizierten Blut-Spendern signifikant mehr HLA-A, -B, -C und HLA-DR, -DP, -DQ exprimieren als Monozyten aus Toxoplasmanegativen Spendern. Eine Erklärung für diese gesteigerte MHC-Expression könnte eine Dominanz bestimmter Monozyten-Subpopulationen in Abhängigkeit vom Infektionsstatus ihres Spenders sein. Die Expression von HLA-A, -B, -C und HLA-DR, -DP, -DQ wird jedoch sowohl bei Monozyten von T. gondii-positiven als auch Parasit-negativen Individuen durch eine Infektion mit Toxoplasmen in vitro signifikant inhibiert. Analysen mit Hilfe von RT-qPCR zeigten deutlich, dass T. gondii mit der HLA-DR-, -DP-, -DQExpressions-Kaskade interferiert und die Synthese der Transkripte IRF-1 und CIITA dosisabhängig inhibiert. Außerdem sind die Transkripte für HLA-A und HLA-DR $\alpha$ in infizierten Monozyten deutlich reduziert. Dies legt die Annahme nahe, dass T. gondii die Aktivierung von STAT1-abhängigen Promotoren effektiv inhibiert und so die Synthese der sich anschließenden HLA-Expressionskaskade supprimiert.

In der vorliegenden Arbeit wurde erstmalig nachgewiesen, dass T. gondii einen von der Infektionsdosis abhängigen, inhibitorischen Einfluss auf die Expression von HLA-A-, -B-, -C- und HLA-DR-, -DP-, -DQ-Molekülen in Monozyten des Menschen ausübt. Außerdem wurde erstmalig gezeigt, dass Monozyten aus chronisch infizierten Toxoplasmose-Patienten eine höhere HLA-Klasse-I- und -II-Expression aufweisen als Monozyten aus Toxoplasma-negativen Spendern.

Die Ergebnisse dieser Arbeit eröffnen interessante Ansätze für weitere Untersuchungen, insbesondere eine genauere Charakterisierung von Monozyten-Subpopulationen bei T. gondii-positiven Individuen sowie die Erforschung einer möglicherweise gesteigerten Immunreaktivität gegen andere Infektionserreger im Rahmen einer chronischen Toxoplasmose. 


\section{Literaturverzeichnis}

Aliberti J (2005): Host persistence: exploitation of anti-inflammatory pathways by Toxoplasma gondii. Nat Rev Immunol, ㅁ: 162-170

Auffray C, Sieweke MH, Geissmann F (2009): Blood monocytes: development, heterogeneity, and relationship with dendritic cells. Annu Rev Immunol, 27: 669-692

Bahia-Oliveira LM, Jones JL, Azevedo-Silva J, Alves CC, Orefice F, Addiss DG (2003): Highly endemic, waterborne toxoplasmosis in north Rio de Janeiro state, Brazil. Emerg Infect Dis, $\underline{9}(1): 55-62$

Balasundaram MB, Andavar R, Palaniswamy M, Venkatapathy N (2010): Outbreak of acquired ocular toxoplasmosis involving 248 patients. Arch Ophthalmol, 128: 28-32

Berdoy M, Webster JP, Macdonald DW (2000): Fatal attraction in rats infected with Toxoplasma gondii. Proc Biol Sci, 267(1452): 1591-1594

Bobic B, Sibalic D, Djurkovic-Djakovic O (1991): High levels of IgM antibodies specific for Toxoplasma gondii in pregnancy 12 years after primary toxoplasma infection. Case report. Gynecol Obstet Invest, 31(3): 182-184

Boehm U, Klamp T, Groot M, Howard JC (1997): Cellular responses to interferongamma. Annu Rev Immunol, 15: 749-795

Bohne W, Holpert M, Gross U (1999): Stage differentiation of the protozoan parasite Toxoplasma gondii. Immunobiology, 201(2): 248-254

Bonnet F, Lewden C, May T, Heripret L, Jougla E, Bevilacqua S, Costagliola D, Salmon D, Chene G, Morlat P (2005): Opportunistic infections as causes of death in HIVinfected patients in the HAART era in France. Scand J Infect Dis, 37(6-7): $482-487$ 
Bowie WR, King AS, Werker DH, Isaac-Renton JL, Bell A, Eng SB, Marion SA (1997): Outbreak of toxoplasmosis associated with municipal drinking water. The BC Toxoplasma Investigation Team. Lancet, 350: 173-177

Brunda MJ (1994): Interleukin-12. J Leukoc Biol, 55(2): 280-288

Buhl R, Jaffe HA, Holroyd KJ, Borok Z, Roum JH, Mastrangeli A, Wells FB, Kirby M, Saltini C, Crystal RG (1993): Activation of alveolar macrophages in asymptomatic HIV-infected individuals. J Immunol, 150(3): 1019-1028

Burnett AJ, Shortt SG, Isaac-Renton J, King A, Werker D, Bowie WR (1998): Multiple cases of acquired toxoplasmosis retinitis presenting in an outbreak. Ophthalmology, 105: 1032-1037

Butcher BA, Kim L, Johnson PF, Denkers EY (2001): Toxoplasma gondii tachyzoites inhibit proinflammatory cytokine induction in infected macrophages by preventing nuclear translocation of the transcription factor NF-kappa B. J Immunol, 167(4): 2193-2201

Butcher BA, Kim L, Panopoulos AD, Watowich SS, Murray PJ, Denkers EY (2005): IL10-independent STAT3 activation by Toxoplasma gondii mediates suppression of IL-12 and TNF-alpha in host macrophages. J Immunol, 174: 3148-3152

Cao H, Wolff RG, Meltzer MS, Crawford RM (1989): Differential regulation of class II MHC determinants on macrophages by IFN-gamma and IL-4. J Immunol, 143(11): $3524-3531$

Carruthers VB (2002): Host cell invasion by the opportunistic pathogen Toxoplasma gondii. Acta Trop, $\underline{81: 111-122}$

Carruthers VB, Suzuki Y (2007): Effects of Toxoplasma gondii infection on the brain. Schizophr Bull, 33: 745-751 
CDC - Centers for Disease Control and Prevention: Parasites - Toxoplasmosis (Toxoplasma infection). 2002, http://www.dpd.cdc.gov/dpdx/HTML/Toxoplasmosis.htm

Cesbron-Delauw MF, Capron A (1993): Excreted/secreted antigens of Toxoplasma gondii - their origin and role in the host-parasite interaction. Res Immunol, 144(1): 41-44

Chacin-Bonilla L, Sanchez-Chavez Y, Monsalve F, Estevez J (2001): Seroepidemiology of toxoplasmosis in amerindians from western Venezuela. Am J Trop Med Hyg, 65(2): 131-135

Chan LL, Cheung BK, Li JC, Lau AS (2010): A role for STAT3 and cathepsin S in IL-10 down-regulation of IFN-gamma-induced MHC class II molecule on primary human blood macrophages. J Leukoc Biol, 모: 303-311

Chimma P, Roussilhon C, Sratongno P, Ruangveerayuth R, Pattanapanyasat K, Perignon JL, Roberts DJ, Druilhe P (2009): A distinct peripheral blood monocyte phenotype is associated with parasite inhibitory activity in acute uncomplicated Plasmodium falciparum malaria. PLoS Pathog, 5(10): e1000631

Contini C (2008): Clinical and diagnostic management of toxoplasmosis in the immunocompromised patient. Parassitologia, 50(1-2): 45-50

Cook AJ, Gilbert RE, Buffolano W, Zufferey J, Petersen E, Jenum PA, Foulon W, Semprini AE, Dunn DT (2000): Sources of toxoplasma infection in pregnant women: European multicentre case-control study. European Research Network on Conge-

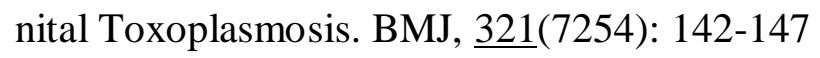

Costa-Silva TA, Meira CS, Ferreira IM, Hiramoto RM, Pereira-Chioccola VL (2008): Evaluation of immunization with tachyzoite excreted-secreted proteins in a novel susceptible mouse model (A/Sn) for Toxoplasma gondii. Exp Parasitol, 120: $227-234$ 
Czarniecki CW, Chiu HH, Wong GH, McCabe SM, Palladino MA (1988): Transforming growth factor-beta 1 modulates the expression of class II histocompatibility antigens on human cells. J Immunol, 140(12): 4217-4223

Debierre-Grockiego F, Molitor N, Schwarz RT, Luder CG (2009): Toxoplasma gondii glycosylphosphatidylinositols up-regulate major histocompatibility complex (MHC) molecule expression on primary murine macrophages. Innate Immun, $\underline{15}(1): 25-32$

Demar M, Ajzenberg D, Maubon D, Djossou F, Panchoe D, Punwasi W, Valery N, Peneau C, Daigre JL, Aznar C, et al. (2007): Fatal outbreak of human toxoplasmosis along the Maroni River: epidemiological, clinical, and parasitological aspects. Clin Infect Dis, 45: e88-95

Denkers EY (2003): From cells to signaling cascades: manipulation of innate immunity by Toxoplasma gondii. FEMS Immunol Med Microbiol, 39(3): 193-203

Derouin F, Pelloux H (2008): Prevention of toxoplasmosis in transplant patients. Clin Microbiol Infect, 14: 1089-1101

Diana J, Vincent C, Peyron F, Picot S, Schmitt D, Persat F (2005): Toxoplasma gondii regulates recruitment and migration of human dendritic cells via different soluble secreted factors. Clin Exp Immunol, 141: 475-484

Dlugonska H, Dytnerska K, Reichmann G, Stachelhaus S, Fischer HG (2001): Towards the Toxoplasma gondii proteome: position of 13 parasite excretory antigens on a standardized map of two-dimensionally separated tachyzoite proteins. Parasitol Res, $\underline{\text { 87(8): 634-637 }}$

Dobrowolski JM, Sibley LD (1996): Toxoplasma invasion of mammalian cells is powered by the actin cytoskeleton of the parasite. Cell, $\underline{84(6): 933-939}$ 
Doesch AO, Ammon K, Konstandin M, Celik S, Kristen A, Frankenstein L, Muller S, Sack FU, Katus HA, Dengler TJ (2010): Negative pretransplant serostatus for Toxoplasma gondii is associated with impaired survival after heart transplantation. Transpl Int, 23: 382-389

Dubey JP (1997): Bradyzoite-induced murine toxoplasmosis: stage conversion, pathogenesis, and tissue cyst formation in mice fed bradyzoites of different strains of Toxoplasma gondii. J Eukaryot Microbiol, 44(6): 592-602

Dubey JP (1998): Advances in the life cycle of Toxoplasma gondii. Int J Parasitol, 28: 1019-1024

Dubey JP (2005): Unexpected oocyst shedding by cats fed Toxoplasma gondii tachyzoites: in vivo stage conversion and strain variation. Vet Parasitol, 133: 289-298

Dubey JP, Beattie CP (1988): Toxoplasmosis of Animals and Man. Parasitology, 100(03): 500-501

Dubey JP, Miller NL, Frenkel JK (1970): The Toxoplasma gondii oocyst from cat feces. J Exp Med, 132(4): 636-662

Dubey JP, Lindsay DS, Speer CA (1998): Structures of Toxoplasma gondii tachyzoites, bradyzoites, and sporozoites and biology and development of tissue cysts. Clin Microbiol Rev, 11(2): 267-299

Dubey JP, Hill DE, Jones JL, Hightower AW, Kirkland E, Roberts JM, Marcet PL, Lehmann T, Vianna MC, Miska K, et al. (2005): Prevalence of viable Toxoplasma gondii in beef, chicken, and pork from retail meat stores in the United States: risk assessment to consumers. J Parasitol, 91(5): 1082-1093

Dunne J, Feighery C, Whelan A (1996): Beta-2-microglobulin, neopterin and monocyte $\mathrm{Fc}$ gamma receptors in opportunistic infections of HIV-positive patients. $\mathrm{Br} \mathrm{J}$ Biomed Sci, 53(4): 263-269 
Ertug S, Okyay P, Turkmen M, Yuksel H (2005): Seroprevalence and risk factors for toxoplasma infection among pregnant women in Aydin province, Turkey. BMC Public Health, $\underline{5}: 66$

Fentress SJ, Behnke MS, Dunay IR, Mashayekhi M, Rommereim LM, Fox BA, Bzik DJ, Taylor GA, Turk BE, Lichti CF, et al. (2010): Phosphorylation of immunityrelated GTPases by a Toxoplasma gondii-secreted kinase promotes macrophage survival and virulence. Cell Host Microbe, $\underline{8}:$ 484-495

Fingerle-Rowson G, Auers J, Kreuzer E, Fraunberger P, Blumenstein M, ZieglerHeitbrock LH (1998): Expansion of CD14+CD16+ monocytes in critically ill cardiac surgery patients. Inflammation, 22(4): 367-379

Flegr J (2007): Effects of toxoplasma on human behavior. Schizophr Bull, 33: 757-760

Flegr J, Havlicek J (1999): Changes in the personality profile of young women with latent toxoplasmosis. Folia Parasitol (Praha), 46(1): 22-28

Foulon W, Naessens A, Derde MP (1994): Evaluation of the possibilities for preventing congenital toxoplasmosis. Am J Perinatol, 11(1): 57-62

Frenkel JK (1988): Pathophysiology of toxoplasmosis. Parasitol Today, $\underline{4}$ : 273-278

Frenkel JK, Ruiz A, Chinchilla M (1975): Soil survival of toxoplasma oocysts in Kansas and Costa Rica. Am J Trop Med Hyg, 24(3): 439-443

Freyre A, Bonino J, Falcon J, Castells D, Correa O, Casaretto A (1999): The incidence and economic significance of ovine toxoplasmosis in Uruguay. Vet Parasitol, $\underline{81}$ : 85-88 
Fukao T, Frucht DM, Yap G, Gadina M, O'Shea JJ, Koyasu S (2001): Inducible expression of Stat4 in dendritic cells and macrophages and its critical role in innate and adaptive immune responses. J Immunol, 166(7): 4446-4455

Fuss IJ, Kanof ME, Smith PD, Zola H (2009): Isolation of whole mononuclear cells from

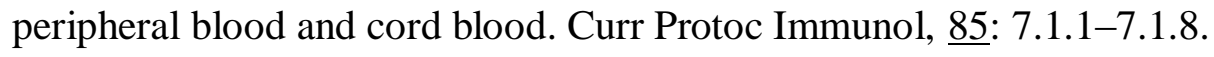

Gazzinelli RT, Hieny S, Wynn TA, Wolf S, Sher A (1993): Interleukin 12 is required for the T-lymphocyte-independent induction of interferon gamma by an intracellular parasite and induces resistance in T-cell-deficient hosts. Proc Natl Acad Sci U S A, 90(13): 6115-6119

Gazzinelli RT, Wysocka M, Hayashi S, Denkers EY, Hieny S, Caspar P, Trinchieri G, Sher A (1994): Parasite-induced IL-12 stimulates early IFN-gamma synthesis and resistance during acute infection with Toxoplasma gondii. J Immunol, 153(6): 2533-2543

Gazzinelli RT, Wysocka M, Hieny S, Scharton-Kersten T, Cheever A, Kuhn R, Muller W, Trinchieri G, Sher A (1996): In the absence of endogenous IL-10, mice acutely infected with Toxoplasma gondii succumb to a lethal immune response dependent on CD4+ T cells and accompanied by overproduction of IL-12, IFN-gamma and TNF-alpha. J Immunol, 157(2): 798-805

Goebel S, Gross U, Luder CG (2001): Inhibition of host cell apoptosis by Toxoplasma gondii is accompanied by reduced activation of the caspase cascade and alterations of poly(ADP-ribose) polymerase expression. J Cell Sci, 114(Pt 19): 3495-3505

Gordon S (2003): Alternative activation of macrophages. Nat Rev Immunol, 3: 23-35

Gordon S, Taylor PR (2005): Monocyte and macrophage heterogeneity. Nat Rev Immunol, $\underline{5}:$ 953-964 
Gross U (2004): [Prevalence and public-health-aspects of toxoplasmosis]. Bundesgesundheitsblatt Gesundheitsforschung Gesundheitsschutz, 477(7): 692-697

Gross U, Muller WA, Knapp S, Heesemann J (1991): Identification of a virulenceassociated antigen of Toxoplasma gondii by use of a mouse monoclonal antibody. Infect Immun, 59(12): 4511-4516

Gross U, Bohne W, Windeck T, Heesemann J (1992): [New views on the pathogenesis and diagnosis of toxoplasmosis]. Immun Infekt, 20(5): 151-155

Hall SM, Pandit A, Golwilkar A, Williams TS (1999): How do Jains get toxoplasma infection? Lancet, $\underline{354:}$ 486-487

Han J, Wang B, Han N, Zhao Y, Song C, Feng X, Mao Y, Zhang F, Zhao H, Zeng H (2009): CD14(high)CD16(+) rather than CD14(low)CD16(+) monocytes correlate with disease progression in chronic HIV-infected patients. J Acquir Immune Defic

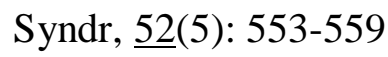

Happe S, Fischer A, Heese C, Reichelt D, Gruneberg U, Freund M, Kloska S, Evers S, Husstedt IW (2002): [HIV-associated cerebral toxoplasmosis -- review and retrospective analysis of 36 patients]. Nervenarzt, $\underline{73}(12): 1174-1178$

Harton JA, Ting JP (2000): Class II transactivator: mastering the art of major histocompatibility complex expression. Mol Cell Biol, 20(17): 6185-6194

Havelaar AH, Kemmeren JM, Kortbeek LM (2007): Disease burden of congenital toxoplasmosis. Clin Infect Dis, 44: 1467-1474

Hermanns B, Brunn A, Schwarz ER, Sachweh JS, Seipelt I, Schroder JM, Vogel U, Schoendube FA, Buettner R (2001): Fulminant toxoplasmosis in a heart transplant recipient. Pathol Res Pract, 197(3): 211-215 
Hill D, Dubey JP (2002): Toxoplasma gondii: transmission, diagnosis and prevention. Clin Microbiol Infect, $\underline{8}:$ 634-640

Hill DE, Chirukandoth S, Dubey JP (2005): Biology and epidemiology of Toxoplasma gondii in man and animals. Anim Health Res Rev, $\underline{6}:$ 41-61

Hippe D, Gais A, Gross U, Luder CG (2009): Modulation of caspase activation by Toxoplasma gondii. Methods Mol Biol, 470: 275-288

Hohlfeld P, Daffos F, Costa JM, Thulliez P, Forestier F, Vidaud M (1994): Prenatal diagnosis of congenital toxoplasmosis with a polymerase-chain-reaction test on amniotic fluid. N Engl J Med, 331(11): 695-699

Horelt A, Belge KU, Steppich B, Prinz J, Ziegler-Heitbrock L (2002): The CD14+CD16+ monocytes in erysipelas are expanded and show reduced cytokine production. Eur J Immunol, 32(5): 1319-1327

Hunter CA, Subauste CS, Van Cleave VH, Remington JS (1994): Production of gamma interferon by natural killer cells from Toxoplasma gondii-infected SCID mice: regulation by interleukin-10, interleukin-12, and tumor necrosis factor alpha. Infect Immun, 62(7): 2818-2824

Innes EA, Vermeulen AN (2006): Vaccination as a control strategy against the coccidial parasites Eimeria, Toxoplasma and Neospora. Parasitology, 133 Suppl: S145-168

Iqbal J, Khalid N (2007): Detection of acute Toxoplasma gondii infection in early pregnancy by IgG avidity and PCR analysis. J Med Microbiol, 56: 1495-1499

Isaac-Renton J, Bowie WR, King A, Irwin GS, Ong CS, Fung CP, Shokeir MO, Dubey JP (1998): Detection of Toxoplasma gondii oocysts in drinking water. Appl Environ Microbiol, 64(6): 2278-2280 
Janssen R, Van Wengen A, Verhard E, De Boer T, Zomerdijk T, Ottenhoff TH, Van Dissel JT (2002): Divergent role for TNF-alpha in IFN-gamma-induced killing of Toxoplasma gondii and Salmonella typhimurium contributes to selective susceptibility of patients with partial IFN-gamma receptor 1 deficiency. J Immunol, 169(7): 3900-3907

Jensen KD, Wang Y, Wojno ED, Shastri AJ, Hu K, Cornel L, Boedec E, Ong YC, Chien YH, Hunter CA, et al. (2011): Toxoplasma polymorphic effectors determine macrophage polarization and intestinal inflammation. Cell Host Microbe, 9: 472-483

Joiner KA, Beckers CJ, Bermudes D, Ossorio PN, Schwab JC, Dubremetz JF (1994): Structure and function of the parasitophorous vacuole membrane surrounding Toxoplasma gondii. Ann N Y Acad Sci, 730: 1-6

Julvez J, Magnaval JF, Meynard D, Perie C, Baixench MT (1996): [Seroepidemiology of toxoplasmosis in Niamey, Niger]. Med Trop (Mars), 56(1): 48-50

Kasper LH (1989): Identification of stage-specific antigens of Toxoplasma gondii. Infect Immun, 57(3): 668-672

Kile BT, Alexander WS (2001): The suppressors of cytokine signalling (SOCS). Cell Mol Life Sci, $\underline{58}(11):$ 1627-1635

Kim K, Weiss LM (2008a): Toxoplasma: the next 100years. Microbes Infect, 10: 978-984

Kim SK, Boothroyd JC (2005b): Stage-specific expression of surface antigens by Toxoplasma gondii as a mechanism to facilitate parasite persistence. J Immunol, 174: 8038-8048

Kim SK, Fouts AE, Boothroyd JC (2007): Toxoplasma gondii dysregulates IFN-gammainducible gene expression in human fibroblasts: insights from a genome-wide transcriptional profiling. J Immunol, 178: 5154-5165 
Klein C, Lisowska-Grospierre B, LeDeist F, Fischer A, Griscelli C (1993): Major histocompatibility complex class II deficiency: clinical manifestations, immunologic features, and outcome. J Pediatr, 123(6): 921-928

Lang C, Algner M, Beinert N, Gross U, Lüder CGK (2006): Diverse mechanisms employed by Toxoplasma gondii to inhibit IFN-gamma-induced major histocompatibility complex class II gene expression. Microbes Infect, $\underline{8}(8)$ : 1994-2005

Lang C, Algner M, Beinert N, Gross U, Luder CG (2006): Diverse mechanisms employed by Toxoplasma gondii to inhibit IFN-gamma-induced major histocompatibility complex class II gene expression. Microbes Infect, $\underline{8}(8)$ : 1994-2005

Lang C, Hildebrandt A, Brand F, Opitz L, Dihazi H, Lüder CGK (2012): Impaired chromatin remodelling at STAT1-regulated promoters leads to global unresponsiveness of Toxoplasma gondii-infected macrophages to IFN- $\gamma$. PLoS Pathog, $\underline{8}(1)$ : e1002483

Leng J, Denkers EY (2009): Toxoplasma gondii inhibits covalent modification of histone $\mathrm{H} 3$ at the IL-10 promoter in infected macrophages. PLoS One, $\underline{4}(10)$ : e7589

Lenzner S, Scholtes U, Peters JH (1998): Focussing human B cell specificity by immunoselection via antigen-presenting cells in vitro. Immunobiology, 198(5): 539-551

Liesenfeld O, Press C, Montoya JG, Gill R, Isaac-Renton JL, Hedman K, Remington JS (1997): False-positive results in immunoglobulin M (IgM) toxoplasma antibody tests and importance of confirmatory testing: the Platelia Toxo IgM test. J Clin Microbiol, 35(1): 174-178

Lindova J, Novotna M, Havlicek J, Jozifkova E, Skallova A, Kolbekova P, Hodny Z, Kodym P, Flegr J (2006): Gender differences in behavioural changes induced by latent toxoplasmosis. Int J Parasitol, 36: 1485-1492 
Lindsay DS, Dubey JP (2009): Long-term survival of Toxoplasma gondii sporulated oocysts in seawater. J Parasitol, 95(4): 1019-1020

Lipman MC, Johnson MA, Bray DH, Poulter LH (1995): Changes to alveolar macrophage phenotype in HIV infected individuals with normal CD4 counts and no respiratory disease. Thorax, 50(7): 777-781

Lopes FM, Goncalves DD, Mitsuka-Bregano R, Freire RL, Navarro IT (2007): Toxoplasma gondii infection in pregnancy. Braz J Infect Dis, 11: 496-506

Lüder CG, Seeber F (2001): Toxoplasma gondii and MHC-restricted antigen presentation:

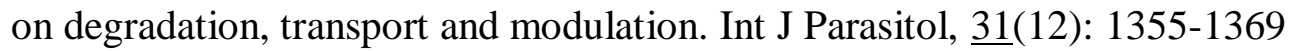

Lüder CG, Gross U (2005): Apoptosis and its modulation during infection with Toxoplasma gondii: molecular mechanisms and role in pathogenesis. Curr Top Microbiol Immunol, 289: 219-237

Lüder CG, Lang T, Beuerle B, Gross U (1998): Down-regulation of MHC class II molecules and inability to up-regulate class I molecules in murine macrophages after infection with Toxoplasma gondii. Clin Exp Immunol, 112(2): 308-316

Lüder CG, Walter W, Beuerle B, Maeurer MJ, Gross U (2001): Toxoplasma gondii downregulates MHC class II gene expression and antigen presentation by murine macrophages via interference with nuclear translocation of STAT1alpha. Eur J Immunol, $\underline{31}(5):$ 1475-1484

Lüder CG, Algner M, Lang C, Bleicher N, Gross U (2003a): Reduced expression of the inducible nitric oxide synthase after infection with Toxoplasma gondii facilitates parasite replication in activated murine macrophages. Int J Parasitol, 33(8): 833-844 
Lüder CG, Lang C, Giraldo-Velasquez M, Algner M, Gerdes J, Gross U (2003b): Toxoplasma gondii inhibits MHC class II expression in neural antigen-presenting cells by down-regulating the class II transactivator CIITA. J Neuroimmunol, 134(1-2): $12-24$

Luft BJ, Remington JS (1992): Toxoplasmic encephalitis in AIDS. Clin Infect Dis, $\underline{15}(2)$ : $211-222$

Lykens JE, Terrell CE, Zoller EE, Divanovic S, Trompette A, Karp CL, Aliberti J, Flick MJ, Jordan MB (2010): Mice with a selective impairment of IFN-gamma signaling in macrophage lineage cells demonstrate the critical role of IFN-gamma-activated macrophages for the control of protozoan parasitic infections in vivo. J Immunol, 184: $877-885$

Mantovani A, Sica A, Locati M (2005): Macrophage polarization comes of age. Immunity, 23: $344-346$

Martinez FO, Sica A, Mantovani A, Locati M (2008): Macrophage activation and polarization. Front Biosci, 13: 453-461

Miller CM, Boulter NR, Ikin RJ, Smith NC (2009): The immunobiology of the innate response to Toxoplasma gondii. Int J Parasitol, 39: 23-39

Mizuno K, Toma T, Tsukiji H, Okamoto H, Yamazaki H, Ohta K, Ohta K, Kasahara Y, Koizumi S, Yachie A (2005): Selective expansion of CD16highCCR2- subpopulation of circulating monocytes with preferential production of haem oxygenase (HO)-1 in response to acute inflammation. Clin Exp Immunol, 142: 461-470

Montoya JG (2002): Laboratory diagnosis of Toxoplasma gondii infection and toxoplasmosis. J Infect Dis, 185 Suppl 1: S73-82

Montoya JG, Liesenfeld O (2004): Toxoplasmosis. Lancet, 363: 1965-1976 
Montoya JG, Remington JS (2008): Management of Toxoplasma gondii infection during pregnancy. Clin Infect Dis, $\underline{47(4): 554-566}$

Montoya JG, Lowe KE, Clayberger C, Moody D, Do D, Remington JS, Talib S, Subauste CS (1996): Human CD4+ and CD8+ T lymphocytes are both cytotoxic to Toxoplasma gondii-infected cells. Infect Immun, $\underline{64(1): 176-181}$

Mosser DM, Edwards JP (2008): Exploring the full spectrum of macrophage activation. Nat Rev Immunol, $\underline{8}:$ 958-969

Muhlethaler-Mottet A, Di Berardino W, Otten LA, Mach B (1998): Activation of the MHC class II transactivator CIITA by interferon-gamma requires cooperative interaction between Stat1 and USF-1. Immunity, $\underline{8}: 157-166$

Murrell KD (1991): Economic losses resulting from food-borne parasitic zoonoses. Southeast Asian J Trop Med Public Health, 22 Suppl: 377-381

Nam HW (2009): GRA proteins of Toxoplasma gondii: maintenance of host-parasite interactions across the parasitophorous vacuolar membrane. Korean J Parasitol, $\underline{47}$ Suppl: S29-37

Nash PB, Purner MB, Leon RP, Clarke P, Duke RC, Curiel TJ (1998): Toxoplasma gondii-infected cells are resistant to multiple inducers of apoptosis. J Immunol, 160(4): 1824-1830

Nicolle C, Manceaux LH (1908): On a leishman body infection (or related organisms) of the gondi. Int J Parasitol, 39(8): 863-864

Nockher WA, Scherberich JE (1998): Expanded CD14+ CD16+ monocyte subpopulation in patients with acute and chronic infections undergoing hemodialysis. Infect Immun, $\underline{66}(6): 2782-2790$ 
Panter MS, Jain A, Leonhardt RM, Ha T, Cresswell P (2012): Dynamics of Major Histocompatibility Complex Class I Association with the Human Peptide-loading Complex. J Biol Chem, 287: 31172-31184

Petersen E, Edvinsson B, Lundgren B, Benfield T, Evengard B (2006): Diagnosis of pulmonary infection with Toxoplasma gondii in immunocompromised HIVpositive patients by real-time PCR. Eur J Clin Microbiol Infect Dis, 25(6): 401-404

Pfaffl MW (2001): A new mathematical model for relative quantification in real-time RTPCR. Nucleic Acids Res, 29(9): e45

Raes G, Beschin A, Ghassabeh GH, De Baetselier P (2007): Alternatively activated macrophages in protozoan infections. Curr Opin Immunol, 19: 454-459

Reis e Sousa C, Hieny S, Scharton-Kersten T, Jankovic D, Charest H, Germain RN, Sher A (1997): In vivo microbial stimulation induces rapid CD40 ligand-independent production of interleukin 12 by dendritic cells and their redistribution to $\mathrm{T}$ cell areas. J Exp Med, 186(11): 1819-1829

Robert-Koch-Institut (2007): Aktuelle Daten und Informationen zu Infektionskrankheiten und Public Heath.Toxoplasmose - neue Fassung des RKI-Ratgeber Infektionskrankheiten - Merkblätter für Ärzte. Epidemiol Bull, 42/2007: 390-394

Rodriguez-Munoz Y, Martin-Vilchez S, Lopez-Rodriguez R, Hernandez-Bartolome A, Trapero-Marugan M, Borque MJ, Moreno-Otero R, Sanz-Cameno P (2011): Peripheral blood monocyte subsets predict antiviral response in chronic hepatitis C. Aliment Pharmacol Ther, 34(8): 960-971

Roghmann MC, Faulkner CT, Lefkowitz A, Patton S, Zimmerman J, Morris JG, Jr. (1999): Decreased seroprevalence for Toxoplasma gondii in Seventh Day Adventists in Maryland. Am J Trop Med Hyg, 60 (5): 790-792 
Saadatnia G, Mohamed Z, Ghaffarifar F, Osman E, Moghadam ZK, Noordin R (2011): Toxoplasma gondii excretory secretory antigenic proteins of diagnostic potential. APMIS, 120(1): 47-55

Sacktor N, Lyles RH, Skolasky R, Kleeberger C, Selnes OA, Miller EN, Becker JT, Cohen B, McArthur JC (2001): HIV-associated neurologic disease incidence changes: Multicenter AIDS Cohort Study, 1990-1998. Neurology, 56(2): 257-260

Saito H, Morita Y, Fujimoto M, Narazaki M, Naka T, Kishimoto T (2000): IFN regulatory factor-1-mediated transcriptional activation of mouse STAT-induced STAT inhibitor-1 gene promoter by IFN-gamma. J Immunol, 164: 5833-5843

Scharton-Kersten TM, Wynn TA, Denkers EY, Bala S, Grunvald E, Hieny S, Gazzinelli RT, Sher A (1996): In the absence of endogenous IFN-gamma, mice develop unimpaired IL-12 responses to Toxoplasma gondii while failing to control acute infection. J Immunol, 157(9): 4045-4054

Schwab JC, Beckers CJ, Joiner KA (1994): The parasitophorous vacuole membrane surrounding intracellular Toxoplasma gondii functions as a molecular sieve. Proc

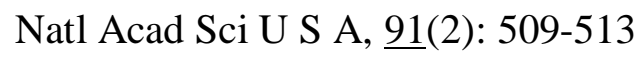

Sette A, Southwood S, Miller J, Appella E (1995): Binding of major histocompatibility complex class II to the invariant chain-derived peptide, CLIP, is regulated by allelic polymorphism in class II. J Exp Med, 181(2): 677-683

Skariah S, McIntyre MK, Mordue DG (2010): Toxoplasma gondii: determinants of tachyzoite to bradyzoite conversion. Parasitol Res, 107(2): 253-260

Slifko TR, Smith HV, Rose JB (2000): Emerging parasite zoonoses associated with water and food. Int J Parasitol, 30: 1379-1393

Sologuren I, Boisson-Dupuis S, Pestano J, Vincent QB, Fernandez-Perez L, Chapgier A, Cardenes M, Feinberg J, Garcia-Laorden MI, Picard C, et al. (2011): Partial reces- 
sive IFN-gammaR1 deficiency: genetic, immunological and clinical features of 14 patients from 11 kindreds. Hum Mol Genet, 20: 1509-1523

Son ES, Nam HW (2001): Detection and characterization of excretory/secretory proteins from Toxoplasma gondii by monoclonal antibodies. Korean J Parasitol, 39(1): 49-56

Stark GR (2007): How cells respond to interferons revisited: from early history to current complexity. Cytokine Growth Factor Rev, 18: 419-423

Steimle V, Siegrist CA, Mottet A, Lisowska-Grospierre B, Mach B (1994): Regulation of MHC class II expression by interferon-gamma mediated by the transactivator gene CIITA. Science, 265(5168): 106-109

Steinfeldt T, Konen-Waisman S, Tong L, Pawlowski N, Lamkemeyer T, Sibley LD, Hunn JP, Howard JC (2010): Phosphorylation of mouse immunity-related GTPase (IRG) resistance proteins is an evasion strategy for virulent Toxoplasma gondii. PLoS Biol, $\underline{8}(12):$ e 1000576

Stepick-Biek P, Thulliez P, Araujo FG, Remington JS (1990): IgA antibodies for diagnosis of acute congenital and acquired toxoplasmosis. J Infect Dis, 162(1): 270-273

Strauss-Ayali D, Conrad SM, Mosser DM (2007): Monocyte subpopulations and their differentiation patterns during infection. J Leukoc Biol, 2: 244-252

Stutz A, Kessler H, Kaschel ME, Meissner M, Dalpke AH (2011): Cell invasion and strain dependent induction of suppressor of cytokine signaling-1 by Toxoplasma gondii. Immunobiology, 217: 28-36

Suzuki Y, Orellana MA, Schreiber RD, Remington JS (1988): Interferon-gamma: the major mediator of resistance against Toxoplasma gondii. Science, 240(4851): $516-518$ 
Tabor A, Alfirevic Z (2009): Update on procedure-related risks for prenatal diagnosis techniques. Fetal Diagn Ther, 27: 1-7

Tenter AM (2009): Toxoplasma gondii in animals used for human consumption. Mem Inst Oswaldo Cruz, 104(2): 364-369

Tenter AM, Heckeroth AR, Weiss LM (2000): Toxoplasma gondii: from animals to humans. Int J Parasitol, $\underline{30}(12-13):$ 1217-1258

Tsuchiya S, Yamabe M, Yamaguchi Y, Kobayashi Y, Konno T, Tada K (1980): Establishment and characterization of a human acute monocytic leukemia cell line (THP-1). Int J Cancer, 26(2): 171-176

Tsuchiya S, Kobayashi Y, Goto Y, Okumura H, Nakae S, Konno T, Tada K (1982): Induction of maturation in cultured human monocytic leukemia cells by a phorbol diester. Cancer Res, $\underline{42(4): ~ 1530-1536 ~}$

Vidovic M, Sparacio SM, Elovitz M, Benveniste EN (1990): Induction and regulation of class II major histocompatibility complex mRNA expression in astrocytes by interferon-gamma and tumor necrosis factor-alpha. J Neuroimmunol, $\underline{30}$ (2-3): 189-200

Wainwright KE, Miller MA, Barr BC, Gardner IA, Melli AC, Essert T, Packham AE, Truong T, Lagunas-Solar M, Conrad PA (2007a): Chemical inactivation of Toxoplasma gondii oocysts in water. J Parasitol, 93(4): 925-931

Wainwright KE, Lagunas-Solar M, Miller MA, Barr BC, Gardner IA, Pina C, Melli AC, Packham AE, Zeng N, Truong T, et al. (2007b): Physical inactivation of Toxoplasma gondii oocysts in water. Appl Environ Microbiol, 73: 5663-5666

Wirth JJ, Kierszenbaum F, Zlotnik A (1989): Effects of IL-4 on macrophage functions: increased uptake and killing of a protozoan parasite (Trypanosoma cruzi). Immunology, $\underline{66}(2):$ 296-301 
Xi H, Blanck G (2003): The IRF-2 DNA binding domain facilitates the activation of the class II transactivator (CIITA) type IV promoter by IRF-1. Mol Immunol, $\underline{39}$ : 677-684

Yap GS, Sher A (1999): Cell-mediated immunity to Toxoplasma gondii: initiation, regulation and effector function. Immunobiology, 201(2): 240-247

Zembala M, Bach S, Szczepanek A, Mancino G, Colizzi V (1997): Phenotypic changes of monocytes induced by HIV-1 gp120 molecule and its fragments. Immunobiology, 197(1): 110-121

Zhang JY, Zou ZS, Huang A, Zhang Z, Fu JL, Xu XS, Chen LM, Li BS, Wang FS (2011): Hyper-activated pro-inflammatory CD16 monocytes correlate with the severity of liver injury and fibrosis in patients with chronic hepatitis B. PLoS One, $\underline{6}(3)$ : e17484

Ziegler-Heitbrock HW, Strobel M, Kieper D, Fingerle G, Schlunck T, Petersmann I, Ellwart J, Blumenstein M, Haas JG (1992): Differential expression of cytokines in human blood monocyte subpopulations. Blood, $\underline{79}(2):$ 503-511 


\section{Anhang}

\begin{tabular}{|c|c|c|c|c|}
\hline \multirow[b]{2}{*}{ Nr. } & \multicolumn{2}{|c|}{ CD14-positiv } & \multicolumn{2}{|c|}{ Isotyp } \\
\hline & Wert & $\%$ & Wert & $\%$ \\
\hline 1 & 78,21 & 80,47 & 11,50 & 5,20 \\
\hline 2 & 68,40 & 66,89 & 17,51 & 19,17 \\
\hline 3 & 11,59 & 97,73 & 15,39 & 0,23 \\
\hline 4 & 86,88 & 85,31 & 11,27 & 7,20 \\
\hline 5 & 243,30 & 61,14 & 79,75 & 27,80 \\
\hline 6 & 199,35 & 89,90 & 28,83 & 6,08 \\
\hline 7 & 511,65 & 85,80 & 62,39 & 8,74 \\
\hline 8 & 519,11 & 82,10 & 71,48 & 8,99 \\
\hline 9 & 179,47 & 54,61 & 69,70 & 10,68 \\
\hline 10 & 888,51 & 81,38 & 245,19 & 11,80 \\
\hline 11 & 182,24 & 27,29 & 193,00 & 16,99 \\
\hline 12 & 604,33 & 81,01 & 116,00 & 16,71 \\
\hline \multirow[t]{2}{*}{$\varnothing$} & \multicolumn{3}{|c|}{78,76} & 11,15 \\
\hline & \multicolumn{3}{|c|}{ $\pm 3,86$} & $\pm 2,30$ \\
\hline
\end{tabular}




\section{Präsentationen}

Teile dieser Arbeit wurden bisher wie folgt präsentiert:

Stalling P., Lüder C.G.K.: Toxoplasma gondii downregulates MHC class I and II expression in primary human macrophages, Statusworkshop 2009 der DGHM Fachgruppe „Eukaryonte Krankheitserreger“, Institut für Medizinische Mikrobiologie und Hygiene, Universitätshautklinik, Tübingen (06.-07.03.2009, Vortrag).

Stalling P., Lüder C.G.K.: Inhibition of HLA antigen expression in primary and permanent human macrophages by infection with Toxoplasma gondii, 16th Japanese-German Cooperative Symposium on Protozoan Diseases, Göttingen (26.09.2008, Poster). 